Florida International University FIU Digital Commons

7-8-2010

\title{
Conformational dynamics associated with calcium binding to calcium transducers
}

Gangadhar Dhulipala

Florida International University

DOI: $10.25148 /$ etd.FI14062264

Follow this and additional works at: https://digitalcommons.fiu.edu/etd

Part of the Chemistry Commons

\section{Recommended Citation}

Dhulipala, Gangadhar, "Conformational dynamics associated with calcium binding to calcium transducers" (2010). FIU Electronic Theses and Dissertations. 2794.

https://digitalcommons.fiu.edu/etd/2794 


\title{
FLORIDA INTERNATIONAL UNIVERSITY
}

\author{
Miami, Florida
}

CONFORMATIONAL DYNAMICS ASSOCIATED WITH CALCIUM BINDING TO CALCIUM TRANSDUCERS

A thesis submitted in partial fulfillment of the

requirements for the degree of

MASTER OF SCIENCE

in

CHEMISTRY

by

Gangadhar Dhulipala 
To: Dean Kenneth Furton

College of Arts and Sciences

This thesis, written by Gangadhar Dhulipala, and entitled Conformational Dynamics Associated with Calcium Binding to Calcium Transducers, having been approved in respect to style and intellectual content, is referred to you for judgment.

We have read this thesis and recommend that it be approved.

Xiaotang Wang

David C. Chatfield

Jaroslava Miksovska, Major Professor

Date of Defense: July 08, 2010

The thesis of Gangadhar Dhulipala is approved.

Dean Kenneth Furton College of Arts and Sciences

Interim Dean Kevin O'Shea University Graduate School

Florida International University, 2010 


\section{DEDICATION}

To all my mentors, friends, and my parents, Subba Rao Dhulipala and Ramasubbulu

Dhulipala 


\section{ACKNOWLEDGMENTS}

I would like to express my sincere gratitude to my major professor, Dr. Jaroslava Miksovska, for giving me the opportunity to work on this exciting project and for her support for the last three years. A special thanks to my committee members Dr. David C. Chatfield and Dr. Xiaotang Wang for their valuable suggestions and comments.

I would like to acknowledge Xiaoduo from Dr. Leng's lab for helping me with the microbiology techniques. Thanks to my father Subba Rao, my mother Ramasubbulu, my brother Muralidhar Dhulipala, and my relatives Venu Babu Gorantla, Sarvani Gorantla, Somaiah Pendurthi, and Uma Devi Pendurthi for their best wishes to fulfill my dreams. I would like to thank my loving sisters Rohini Kolluri, Kalpana and my friends Chotu, Setu, Swathi, Vamsi, Sujatha, Vijay, Sandeep, and Suman for their care and moral support throughout my stay at FIU.

Finally, I would like to thank my labmates Simona, Luisana, Khoa and Mimy for their care and affection. Special thanks to Dr. Yong Cai and all the staff of the Chemistry Department at FIU. Once again, I would like to thank my major professor, Dr. Jaroslava Miksovska, for all her suggestions and guidance in completing my thesis. 


\section{ABSTRACT OF THE THESIS \\ CONFORMATIONAL DYNAMICS ASSOCIATED WITH CALCIUM BINDING TO \\ CALCIUM TRANSDUCERS}

by

Gangadhar Dhulipala

Florida International University, 2010

Miami, Florida

Professor Jaroslava Miksovska, Major Professor

The $\mathrm{Ca}^{2+}$ association to calcium binding proteins ( $\mathrm{CaBPs}$ ) represents an essential step in $\mathrm{Ca}^{2+}$ signal transduction. This study presents a characterization of $\mathrm{Ca}^{2+}$ interactions with two CaBPs, calmodulin and DREAM, using time-resolved photothermal and fluorescence techniques. Calcium binding to the calmodulin C-terminal domain is associated with a volume change of $40 \mathrm{~mL} \mathrm{~mol}^{-1}$ and an enthalpy change of $35 \pm 16 \mathrm{kcal}$ $\mathrm{mol}^{-1}$. These parameters are consistent with the $\mathrm{Ca}^{2+}$ triggered exposure of hydrophobic patches on the calmodulin surface. Also, the rate limiting step for $\mathrm{Ca}^{2+}$ binding to calmodulin is the closed-to-open transition of the C-terminal domain that occurs with a lifetime of $400 \mu \mathrm{s}$. Unlike calmodulin, DREAM exists in a dynamic equilibrium of two conformations and $\mathrm{Ca}^{2+}$ binding shifts the equilibrium towards a more compact conformation. These data clearly demonstrate that conformational dynamics play a crucial role in the transmission of $\mathrm{Ca}^{2+}$ signals. 


\section{TABLE OF CONTENTS}

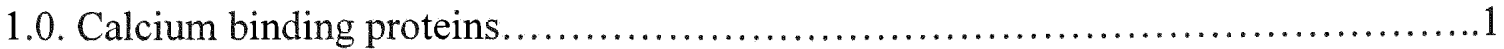

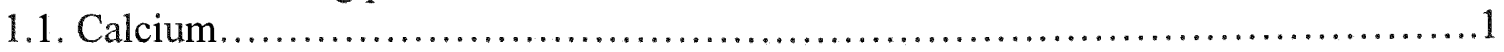

1.2. Calcium as a secondary messenger.............................................. 3

1.3. Calcium binding structural motif............................................. 5

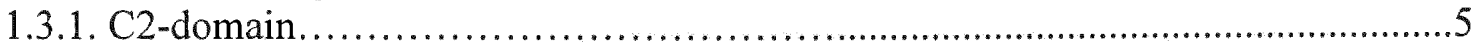

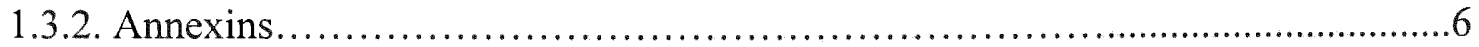

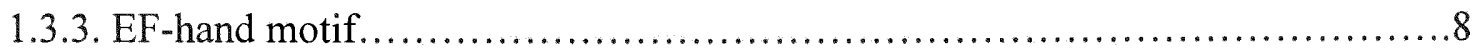

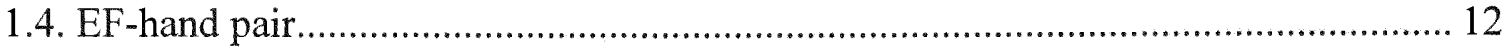

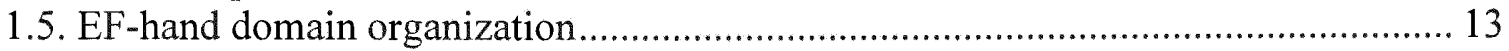

1.6. Affinity and selectivity of EF-hand loop for calcium ........................................... 14

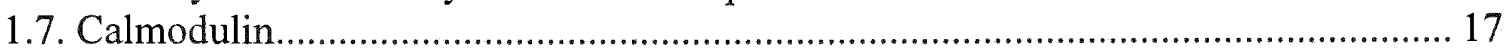

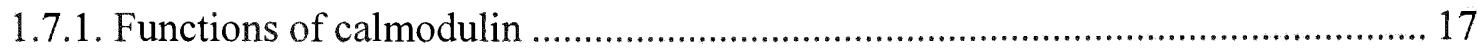

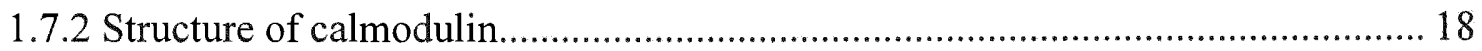

1.7.3. Calcium induced conformational changes in calmodulin ................................. 20

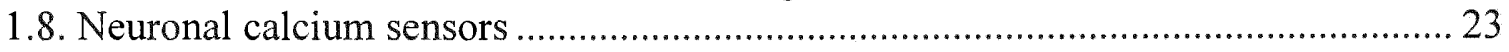

1.9. Recoverin as a prototype neuronal calcium signaling protein ................................. 26

1.10. DREAM (Down Stream Regulatory Element Antagonist Modulator) .................... 28

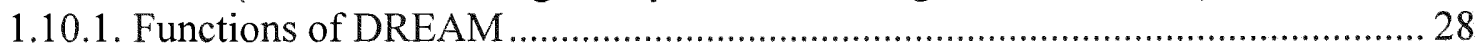

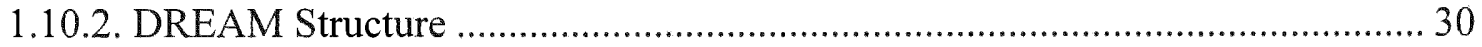

1.10.3. Calcium and magnesium induced conformational changes............................... 35

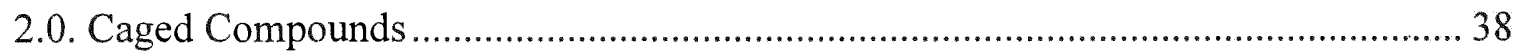

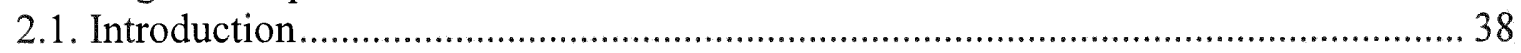

2.2. Mechanism of photo-dissociation of o-nitrobenzyl compounds............................. 40

2.3. Caged calcium compounds ............................................................................. 43

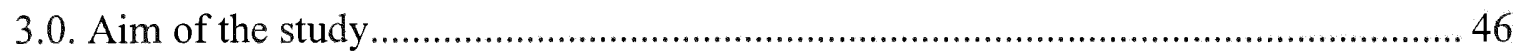

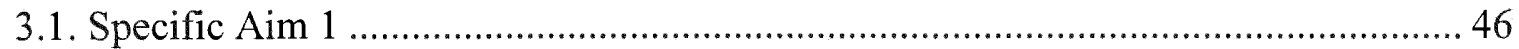

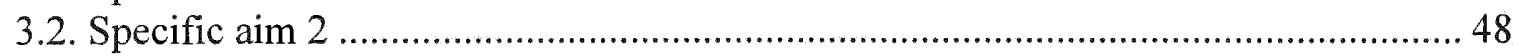

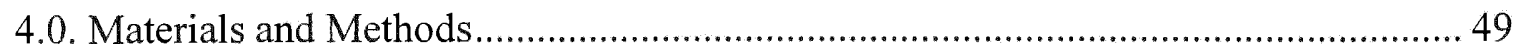

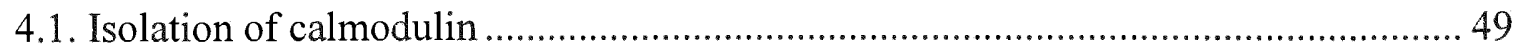

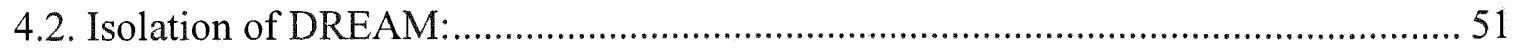

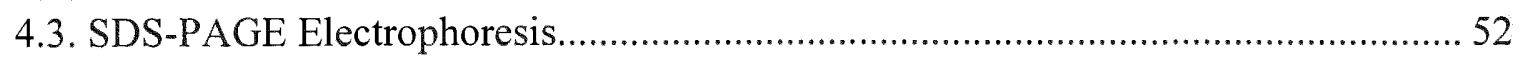

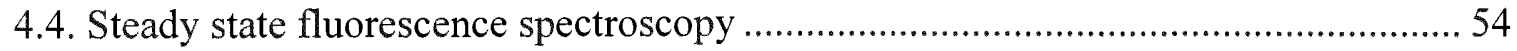

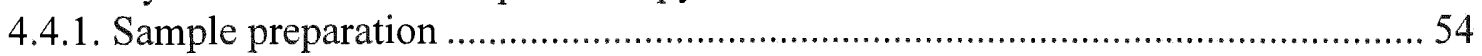

4.5. Frequency domain fluorescence spectroscopy..................................................... 55

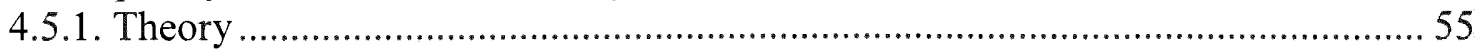

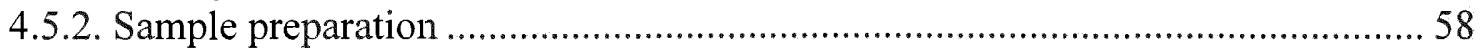

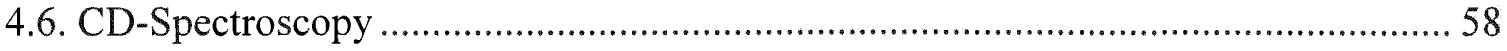

4.7. Photothermal techniques................................................ 59 


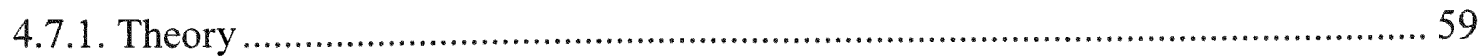

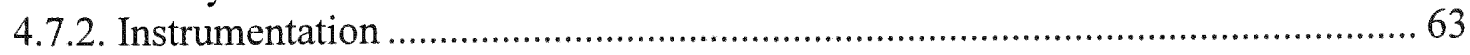

4.7.3. Preparation of the sample for the PBD measurement ...................................... 64

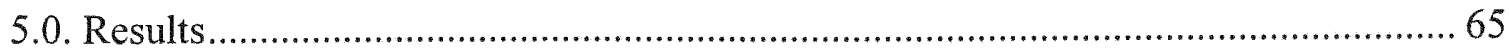

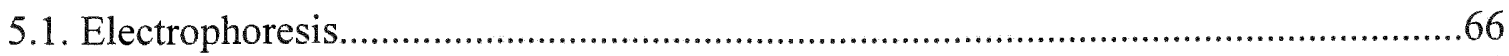

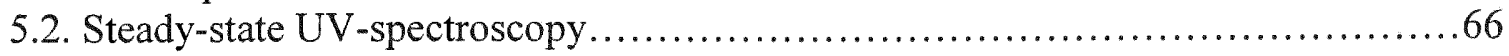

5.3. PBD study of the photodissociation of DM-nitrophen............................................68

5.3.1. Thermodynamic parameters for calcium binding to CaM ................................. 74

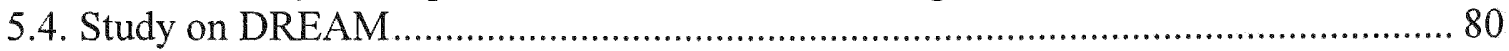

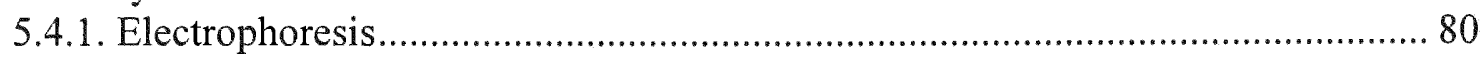

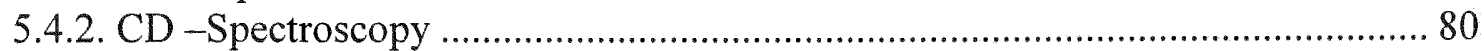

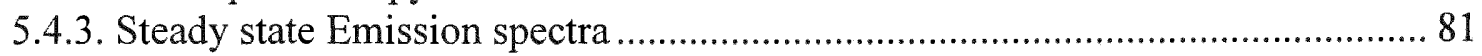

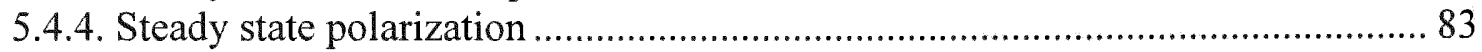

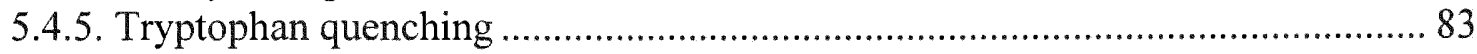

5.4.6. Probing the hydrophobic surfaces using 1,8 ANS, 2,6 -ANS and nile red.......... 85

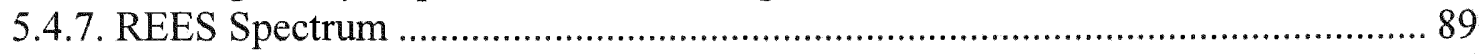

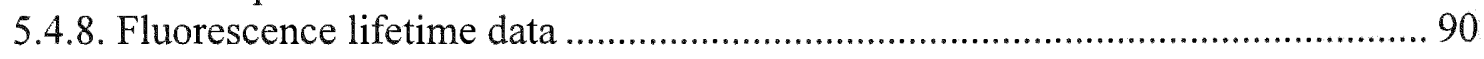

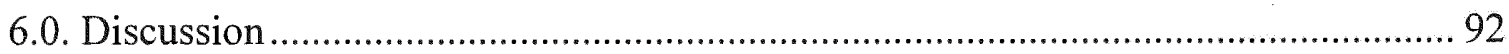

6.1. Photodissociation of DM-nitrophen........................................ 93

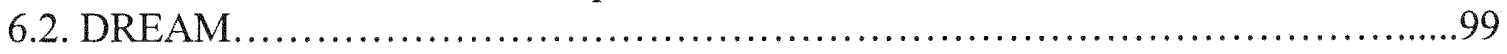

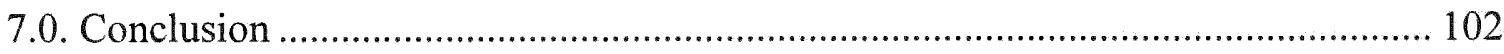

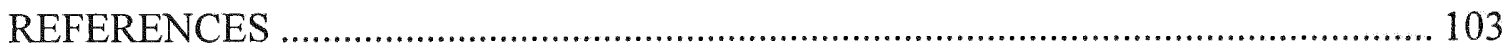




\section{LIST OF TABLES}

TABLE PAGE

Table 1.1. Classification of NCS family of proteins. .24

Table 2.1. Properties of the commonly available caged $\mathrm{Ca}^{2+}$ compounds.... .44

Table 4.1. Composition of LB medium per liter

Table 4.2. Composition of the resolving gel......................................53

Table 4.3. Composition of stacking gel............................................53

Table 5.1. Volume and enthalpy changes determined for photodissociation of DMnitrophen, $\mathrm{Ca}^{2+}$-DM-nitrophen and $\mathrm{Mg}^{2+}$-DM-nitrophen

Table 5.2.Volume and enthalpy changes associated with photodissociation of $\mathrm{Ca}^{2+}$-DM-nitrophen in the presence of CaM.

Table 5.3. Fluorescence polarization data for DREAM in the apo and $\mathrm{Ca}^{2+}$ bound forms

Table $5.4 . \mathrm{K}_{\mathrm{sv}}$ values obtained for Trp quenching by acrylamide and $\mathrm{KI}$

Table 5.5. Fluorescence decay parameters obtained for Trp 169 in apo and $\mathrm{Ca}^{2+}$ bound form of DREAM

Table 6.1. Bond enthalpies for thecovalent bonds involved involved in the photodissociation of DM-nitrophen 


\section{LIST OF FIGURES}

\section{FIGURE}

Figure 1.1. The mechanism of the control of intracellular $\mathrm{Ca}^{2+}$ concentration during $\mathrm{ON}$ and $\mathrm{OFF}$ state 2

Figure 1.2. Various processes regulated by $\mathrm{Ca}^{2+}$ in the body.......................................4

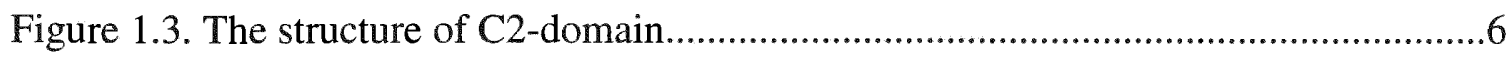

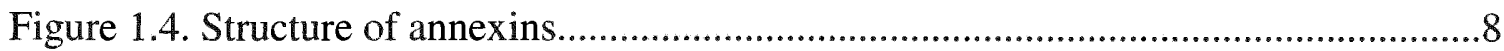

Figure 1.5. Schematic representation of EF-hand showing the name and position of

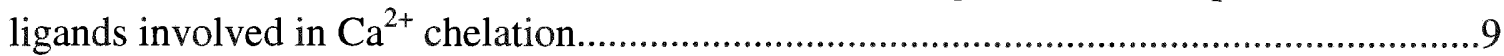

Figure 1.6. Cartoon picture of a single EF-hand...........................................................

Figure 1.7. The organization of two EF-hands as a pair............................................... 12

Figure 1.8. Arrangement of $\mathrm{Ca}^{2+}$ binding domain in CaBPs........................................14

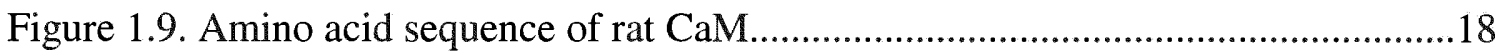

Figure 1.10. The crystal structure of $\mathrm{Ca}^{2+}$ bound calmodulin.......................................19

Figure 1.11. The relative orientation of $\alpha$-helices in the apo form and $\mathrm{Ca}^{2+}$ bound form.

Figure 1.12. Structure of recoverin in apo and $\mathrm{Ca}^{2+}$ bound form $\mathrm{Ca}^{2+}$ ions................... 27

Figure 1.13. Schematic model for the mechanism of DREAM interactions

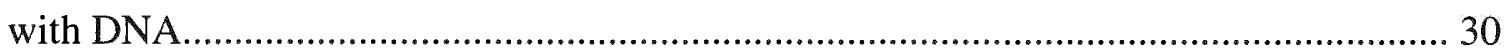

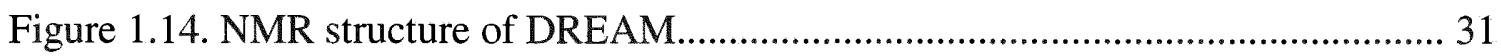

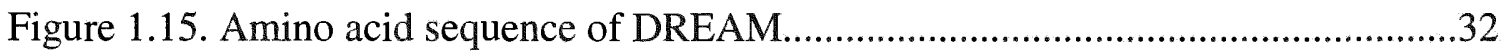

Figure 1.16. Ribbon presentation of the NMR structure of DREAM..............................34

Figure 1.17. Space filling representation of DREAM showing the exposed hydrophobic patch and charged residues in green

Figure 1.18. NMR structure of DREAM showing the interaction between C-terminal helix.

Figure 2.1. Structures of commonly used o-nirobenzyl $\mathrm{Ca}^{2+}$ cages 
Figure 4.1. Solid line represents the excitation light and dotted line represents the emitted light

Figure 4.2. Schematic representation of the PBD setup.................................................64

Figure 5.1. SDS-PAGE electrophoresis for CaM........................................................66

Figure 5.2. Absorption spectra of unphotolysed DM-nitrophen, $\mathrm{Mg}^{2+}-\mathrm{DM}$-nitrophen, $\mathrm{Ca}^{2+}$-DM-nitrophen and photolysed DM-nitrophen, photolysed $\mathrm{Ca}^{2+}-\mathrm{DM}$-nitrophen and photolysed $\mathrm{Mg}^{2+}$-DM-nitrophen

Figure 5.3. PBD signal as a function of laser power for the sample and the reference compound 68

Figure 5.4. PBD signal as a function of number of photons absorbed.

Figure 5.5. Overlay of PBD traces for photodissociation of DM-nitrophen and the reference compound at $20^{\circ} \mathrm{C}$.

Figure 5.6. A) Overlay of PBD traces for photodissociation of $\mathrm{Ca}^{2+}-\mathrm{DM}$-nitrophen

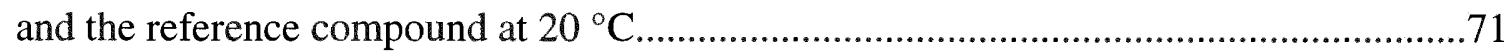

Figure 5.7. Overlay of PBD traces for photodissociation of $\mathrm{Mg}^{2+}-\mathrm{DM}$-nitrophen and the reference compound at $20^{\circ} \mathrm{C}$.

Figure 5.8. Plot of $(S / R) E_{h v}$ versus $C p \rho /(d n / d t) \rho(d n / d \rho)$ for photolysis of DMnitrophen, $\mathrm{Ca}^{2+} \mathrm{DM}$-nitrophen fast phase and slow phase, and $\mathrm{Mg}^{2+}-\mathrm{DM}$-nitrophen..... 73

Figure 5.9. CD spectra of CaM in the presence of $\mathrm{Ca}^{2+}$ saturated DM-nitrophen before illumination, upon irradiation with $355 \mathrm{~nm}$ light for 5 minutes and in the presence of EGTA.

Figure 5.10. Overlay of PBD trace for the reference and the photodissociation of $\mathrm{Ca}^{2+}$ DM-nitrophen in the presence of CaM

Figure 5.11. Overlay of PBD traces for $\mathrm{Ca}^{2+}$ saturated DM-nitrophen, $\mathrm{Ca}^{2+}$ saturated DM-nitrophen in the presence of CaM.

Figure 5.12. Plot of (S/R) $E_{h v}$ versus $C p \rho /(d n / d t) \rho$ for the photolysis of $\mathrm{Ca}^{2+} \mathrm{DM}$-nitrophen in the presence of CaM. .78

Figure 5.13. Kinetics of $\mathrm{Ca}^{2+}$ binding to $\mathrm{CaM}$ as a function of $\mathrm{CaM}$ concentration.........79

Figure 5.14. SDS-PAGE electrophoresis of DREAM .80 
Figure 5.15. CD-spectra of DREAM in the apo and $\mathrm{Ca}^{2+}$ bound form..........................81

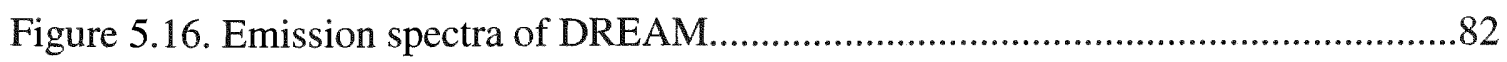

Figure 5.17. Right panel: Stern-Volmer plots for quenching of Trp fluorescence by

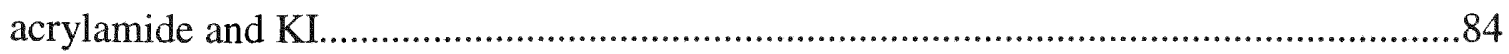

Figure 5.18. Structures of hydrophobic surface probing agents.....................................86

Figure 5.19. Emission spectra of DREAM in the presence and absence of LDAO..........87

Figure 5.20. Emission spectra of hydrophobic surface probing agents in buffer and in

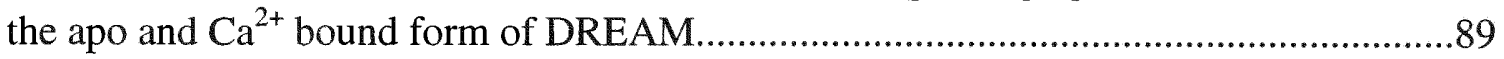

Figure 5.21. REES spectra for DREAM in the apo and $\mathrm{Ca}^{2+}$ bound form......................90

Figure 5.22. Top: Phase delay and modulation ratio in the frequency range of 50 to $250 \mathrm{MHz}$ 


\section{LIST OF ABBREVIATIONS}

1,8-ANS...........1-anilinonapthalene-8-sulfonic acid

2,6-ANS...........2-anilinonapthalene-6-sulfonic acid

CaM.................calmodulin

CaBPs..............calcium binding proteins

CD.......................circular dichroism

DTT...............dithiothreitol

DREAM............down stream regulatory element antagonist modulator

EDTA............. ethylenediaminetetraacetic acid

EGTA..............ethylene glycol tetraacetic acid

HEPES.................(4-(2-hydroxyethyl)-1-piperazineethanesulfonic acid)

KChIPs............potassium channel interacting proteins

LDAO............. laurydimethylsulfoxide

NCS................neuronal calcium sensors

PBD............... photothermal beam deflection

SDS

sodium dodecyl sulfate 


\subsection{Calcium binding proteins}

\subsection{Calcium}

Calcium is an essential bioelement that plays a vital role in the metabolism and physiology of eukaryotes (Clapham et al. 2007, Berridge et al. 2000). Calcium is found in intracellular space, extracellular fluids, and bones and teeth. In bones and teeth, $\mathrm{Ca}^{2+}$ is found in the form of hydroxyapatites (Ganong et al. 2005). A constant $\mathrm{Ca}^{2+}$ concentration of $\sim 2 \mathrm{mM}$ is maintained in the blood (Clapham et al. 2007) and its deviation from the normal level may lead to serious health problems such as hypocalcaemia or hypercalcaemia (Ganong et al. 2005). To maintain $\mathrm{Ca}^{2+}$ homeostasis, there is a frequent exchange of $\mathrm{Ca}^{2+}$ between the blood and other parts of the body such as small intestine, bones, and kidneys as presented in Scheme 1 (Ganong et al. 2005).

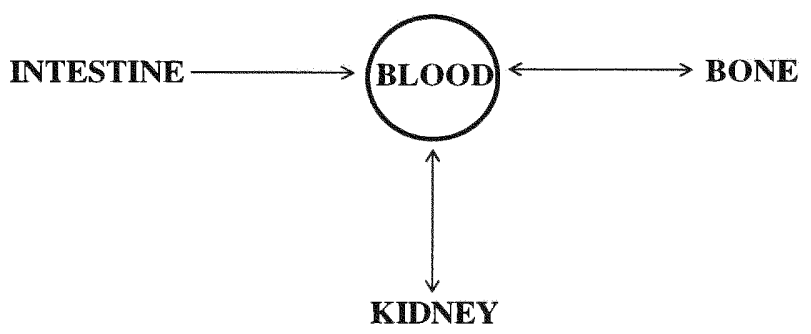

Scheme 1:

Regulation of intracellular $\mathrm{Ca}^{2+}$ concentration is more complex, since this concentration is tightly controlled and oscillates from $\mathrm{nM}$ level in the resting state to $\mathrm{mM}$ level in the activated state (Clapham et al. 1995). Numerous membrane proteins such as pumps, ion channels, and ion exchangers take part in controlling the $\mathrm{Ca}^{2+}$ concentration between the 
resting and the activated state, as shown in Figure 1.1 (Gifford et al. 2007, Berridge et al. 1997, Clapham et al. 2007).

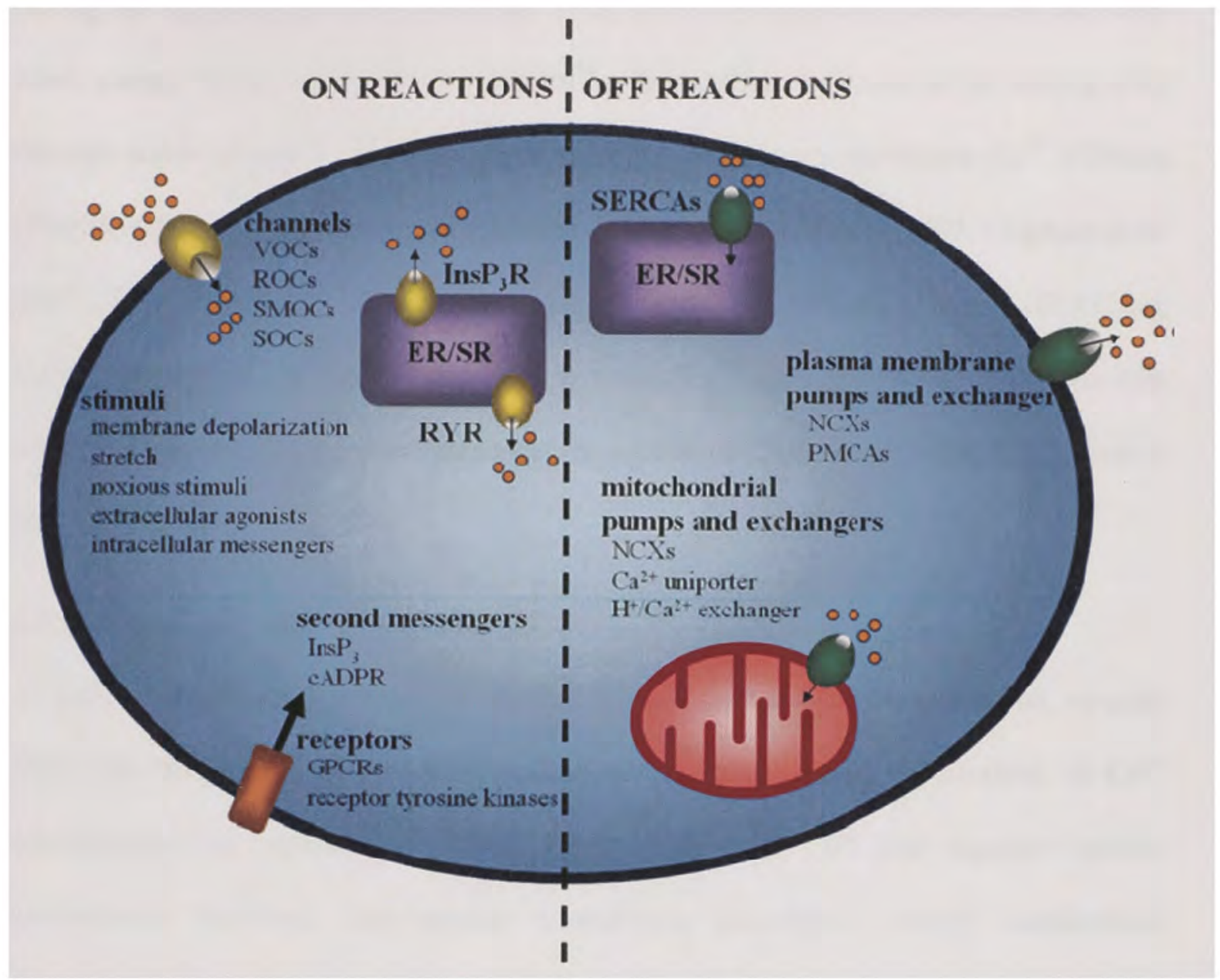

Figure 1.1. The mechanism of the control of intracellular $\mathrm{Ca}^{2+}$ concentration during "ON" and "OFF" state. Figure adopted from Gifford et al. (Gifford et al. 2007).

Membrane protein complexes such as voltage operated ion channels (VOCs), receptor operated ion channels (ROCs), store operated $\mathrm{Ca}^{2+}$ channels (SOCs), and secondary messenger operated $\mathrm{Ca}^{2+}$ channels (SMOCs) allow for influx of $\mathrm{Ca}^{2+}$ into the cytoplasm (Gifford et al. 2007). The release of $\mathrm{Ca}^{2+}$ from internal $\mathrm{Ca}^{2+}$ stores like the endoplasmic and sarcoplasmic reticulum occurs through ryanodine receptors (RYR) and ionositol 
triphoosphate receptors $\left(\operatorname{Ins} \mathrm{P}_{3} \mathrm{R}\right)$, and the process is triggered by secondary messengers like ionositol triphosphate (InsP $\mathrm{P}_{3}$ ) and cyclic ADP-ribose (cADPR) that are generated during the signaling cascades (Berridge et al. 1997, Gifford et al. 2007). On the other hand, during "OFF" reactions, elevated $\mathrm{Ca}^{2+}$ concentration decreases to the resting level through action of sodium $\mathrm{Ca}^{2+}$ exchangers (NCX), and plasma membrane $\mathrm{Ca}^{2+}$ ATPases (PMCAs) that are found within the plasma membrane (Gifford et al. 2007, Clapham et al. 2007). Several other ion channels like sarco-endoplasmic calcium ATPases (SERCAs), $\mathrm{Ca}^{2+}$ uniporters, and $\mathrm{H}^{+} / \mathrm{Ca}^{2+}$ exchangers facilitates $\mathrm{Ca}^{2+}$ entry into the internal stores like mitochondria, endoplasmic and sarcoplasmic reticulum (Gifford et al. 2007, Clapham et al. 2007, Clapham et al. 1995).

\subsection{Calcium as a secondary messenger}

A variety of cellular processes are regulated by change in $\mathrm{Ca}^{2+}$ concentration, ranging from cell division to apoptosis (Clapham et al. 1995). Rapid fluctuations in $\mathrm{Ca}^{2+}$ concentration, so called $\mathrm{Ca}^{2+}$ spikes, occur within the cell and regulate various intracellular functions like muscle contraction, exocytosis, energy metabolism, chemotaxis, activity of gated ion channels, secretion of neurotransmitters, and hormones secretion, gene transcription, and enzymatic activity of kinases and phosphatases as depicted in Figure 1.2 (Ellis-Davis et al. 2009). 


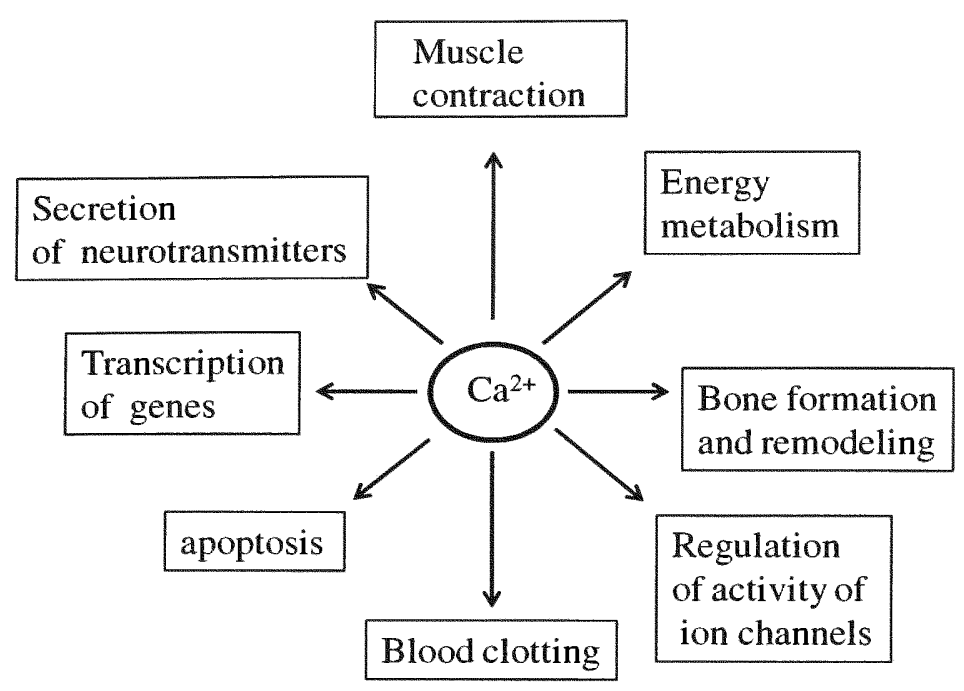

Figure 1.2. Various processes regulated by $\mathrm{Ca}^{2+}$ in the body.

In particular, $\mathrm{Ca}^{2+}$ plays a prominent role in muscle contraction. Binding of $\mathrm{Ca}^{2+}$ to troponin $\mathrm{C}$ triggers muscle contraction by facilitating the interactions between actin and myosin, the main components of the myofilament (Ellis-Davis et al. 2008, Dantzig et al. 1998). Calcium has an important role in neuronal signal transmission since changes in $\mathrm{Ca}^{2+}$ concentration control release of neurotransmitters such as acetylcholine (Zucker et al. 1993, Berridge et al. 1998). In addition, $\mathrm{Ca}^{2+}$ regulates, either directly or through $\mathrm{Ca}^{2+}$ transducers, activity of ion channels, like $\mathrm{Ca}^{2+}$ dependent $\mathrm{K}^{+}$channels that are involved in the contraction of vascular smooth muscle (Ganong et al. 2005). Calcium participates in activation of enzymes like pyruvate dehydrogenase complex involved in energy metabolism (Ganong et al. 2005). Apart from the processes described above, $\mathrm{Ca}^{2+}$ is involved in the regulation of other important physiological processes like blood clotting and bone and teeth formation (Ganong et al. 2005). 


\subsection{Calcium binding structural motif}

$\mathrm{Ca}^{2+}$ participates in regulation of the above mentioned processes by binding to a group of intracellular proteins called $\mathrm{Ca}^{2+}$ binding proteins (CaBPs). All CaBPs contains one of three types of $\mathrm{Ca}^{2+}$ binding structural motifs: the $\mathrm{C} 2$-domain found in synaptogamins, annexins and the EF-hand motif found in more than 2000 proteins (Nalefski et al. 1996, Gereke et al. 2002, Gifford et al. 2007).

\subsubsection{C2-domain}

The C2-domain is a conserved functional domain consisting of 130 residues. Structural studies show that it contains eight $\beta$ strands divided into two pairs that are arranged in anti-parallel fashion like a $\beta$-sandwich (Nalfeski et al. 1996., Essen et al. 1996). These two pairs are connected by three loops at the top and four loops at the bottom of the $\beta$ sandwich as shown in Figure 1.3. The three top loops can bind up to two $\mathrm{Ca}^{2+}$ ions. Each $\mathrm{Ca}^{2+}$ ion in the $\mathrm{C} 2$-domain is coordinated by seven ligands, five of which come from Asp residues and two of which are provided by water molecules (Nalefski et al. 1996). 


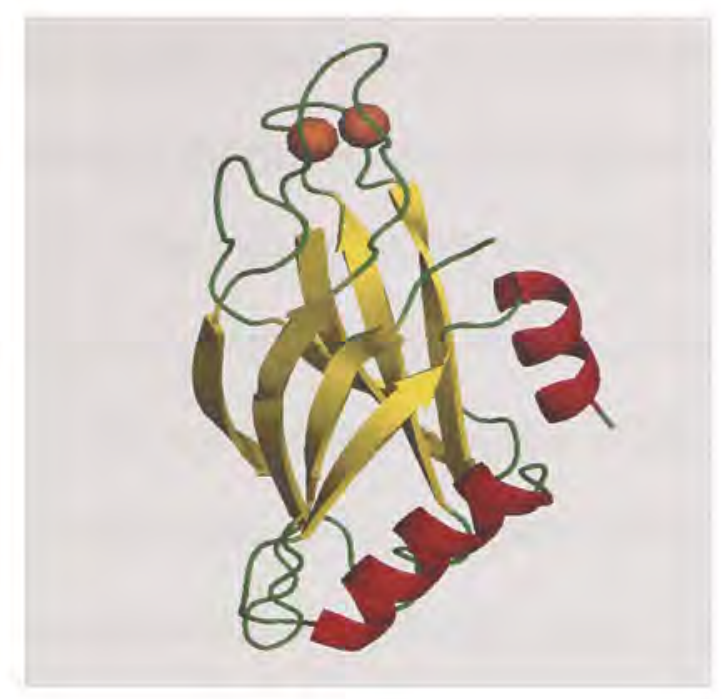

Figure 1.3. The structure of C2-domain. Anti-parallel $\beta$-sheets are shown in yellow, $\mathrm{Ca}^{2+}$ binding loops are shown in green, and $\mathrm{Ca}^{2+}$ ions are shown in orange. PDB code $3 \mathrm{FO} 4$.

$\mathrm{Ca}^{2+}$ binding to $\mathrm{C} 2$-domain triggers protein association to phospholipid membranes and promotes protein-protein interactions. The proposed mechanism for membrane specific binding of $\mathrm{C} 2$-domain proteins is that the $\mathrm{Ca}^{2+}$ binding increases the exposure of hydrophobic residues that ultimately leads to the increased affinity of C2-domain containing proteins for phospholipid membranes and/or other proteins (Scott et al. 1990, Newton et al. 1995). An alternative mechanism involves the exposure of charged residues which can interact with phosphate groups of phospholipid membranes through electrostatic interactions (Newton et al. 1995).

\subsubsection{Annexins}

Annexins represent a group of proteins that contains a characteristic "annexin repeat" formed by a 70 residue long segment. In general, four such annexin repeats are found in annexins. Structurally annexins are composed of two separated domains connected by a 
central core of tightly packed $\alpha$-helices as shown in Figure 1.4 (Weng et al. 1993). As a result of a tight packing of the central core, the overall structure of the protein resembles a disc with a slight curvature forming concave and convex surfaces on the bottom and top of the protein surface, respectively (Weng et al. 1993). Annexins bind to the phospholipid membrane in such a way that the concave surface of the protein points away from the membrane and the convex surface faces towards the membrane (Weng et al. 1993). Annexin association to phosholipid membranes occurs in a $\mathrm{Ca}^{2+}$ dependent manner. The $\mathrm{Ca}^{2+}$ binding sites are located on the convex surface. The $\mathrm{N}$-terminal domain is irregularly structured in the apo-protein and interacts with the central core domain. Upon $\mathrm{Ca}^{2+}$ binding, the $\mathrm{N}$-terminal domain becomes exposed and promotes annexin interactions with other proteins such as S100 proteins (Weng et al. 1993). Annexins have been shown to be involved in various functions like exocytosis, endocytosis, stabilization and organization of phospholipid membranes (Rescher et al. 2004). 


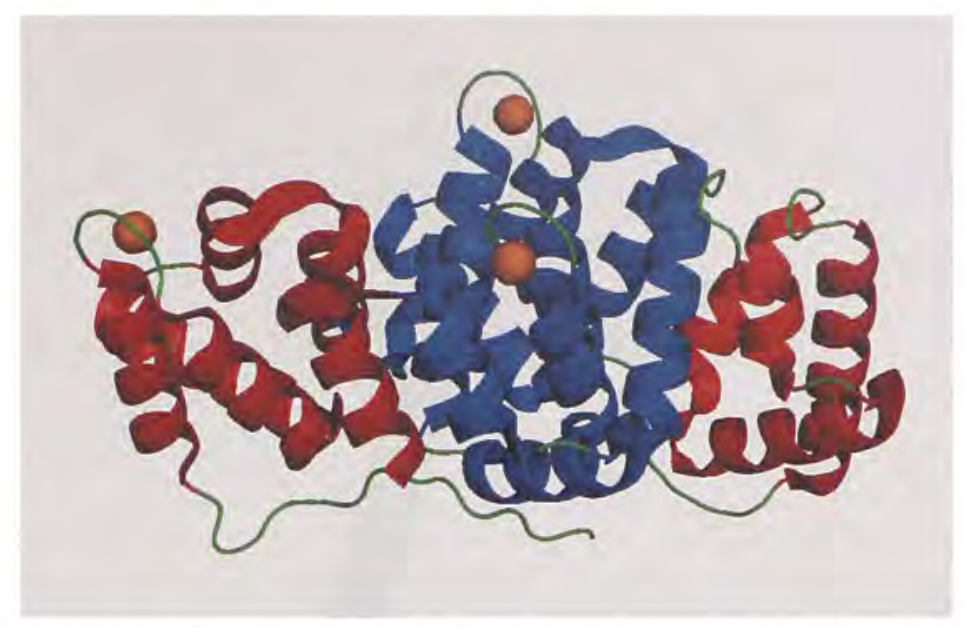

Figure 1.4. Structure of annexins (PDB code: 1YII). Tightly packed central helices are shown in blue and the $\mathrm{N}$ - and $\mathrm{C}$-terminal domains are shown in red.

\subsubsection{EF-hand motif}

Most of the CaBPs contains an EF-hand as the $\mathrm{Ca}^{2+}$ binding structural motif. The name EF-hand was originally proposed by Krestinger when this $\mathrm{Ca}^{2+}$ binding motif was first observed in parvalbumin (Kretsinger et al. 1973). The number of EF-hands usually ranges from four to six and the majority of proteins carry an even number of EF-hands. Each EF-hand consists of an entering $\alpha$-helix and an exiting $\alpha$-helix bridged by a nine residue $\mathrm{Ca}^{2+}$ chelation loop with $\mathrm{Ca}^{2+}$ being coordinated by seven oxygen atoms arranged in pentagonal bi-pyramidal fashion (Gifford et al. 2007). Five oxygen ligands are provided by residues in the chelation loop and the remaining two ligands come from the side chain of the glutamic acid that is located on the exiting helix (Gifford et al. 2007). The residues involved in $\mathrm{Ca}^{2+}$ binding are shown in Figure 1.5. 


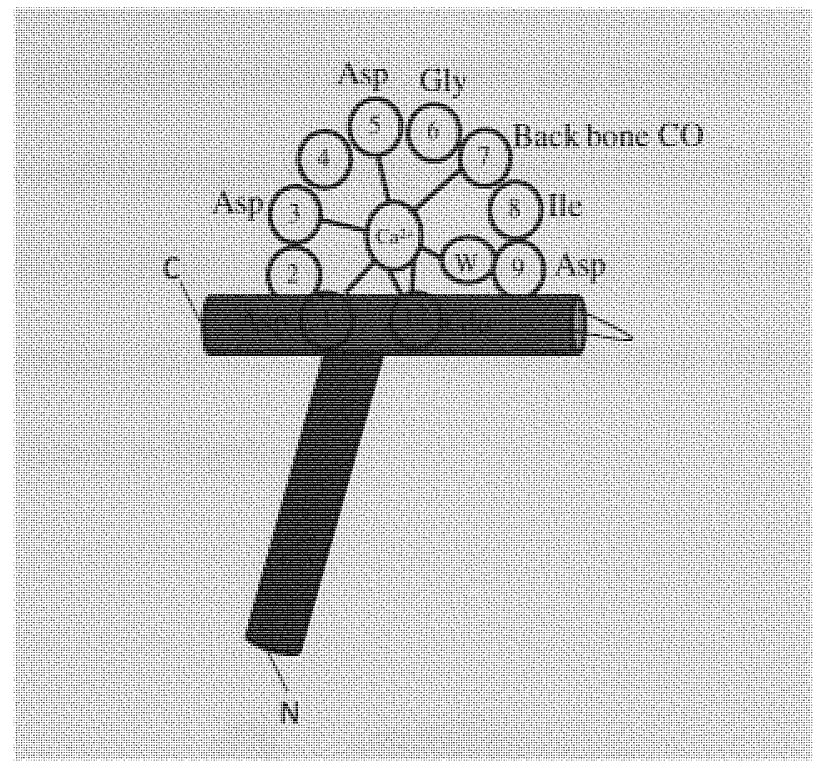

Figure 1.5. Schematic representation of EF-hand showing the name and position of ligands involved in $\mathrm{Ca}^{2+}$ chelation. (Figure modified from Gifford et al. 2007)

Within the chelation loop, $\mathrm{Ca}^{2+}$ is coordinated through the side chains of four Asp residues located in position $1,3,5$ and 8 . The $5^{\text {th }}$ ligand is provided by a carbonyl oxygen from the residue located at $8^{\text {th }}$ position. All residues involved in chelation interact with $\mathrm{Ca}^{2+}$ directly except a residue presented in the ninth position of the loop, which coordinates $\mathrm{Ca}^{2+}$ through a water molecule (Likik et al. 2003, Gifford et al. 2007). Chelating residues also play a prominent role in the stabilization of the loop by forming a network of hydrogen bonds with non-chelating residues. In addition the high conformational flexibility of a glycine residue located in the sixth position allows for a sharp $90^{\circ}$ turn of the loop during $\mathrm{Ca}^{2+}$ binding that facilitates the $\mathrm{Ca}^{2+}$ coordination within the loop (Gifford et al. 2007). The eighth position of the loop is occupied by a conserved hydrophobic residue whose backbone $\mathrm{NH}$ and $\mathrm{CO}$ groups are directed away from $\mathrm{Ca}^{2+}$ 
towards the paired EF-hand (Godzik et al. 1989) and facilitates the formation of the antiparallel $\beta$-sheet through hydrogen bonding with the corresponding $\mathrm{NH}$ and $\mathrm{CO}$ groups of the paired EF-hand. Hydrogen bonding between the paired EF-hand loops facilitates communication between individual EF-hands (Godzik et al. 1989). A cartoon picture of a single EF-hand is shown in Figure 1.6

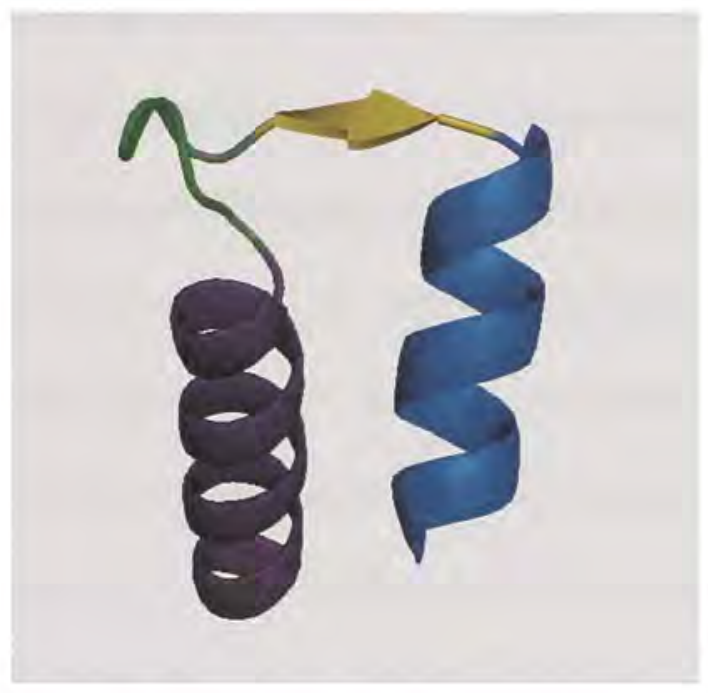

Figure 1.6. Cartoon picture of a single EF-hand. Entering helix is shown in purple, calcium chelation loop is shown in green, exiting helix is shown in blue and the position of the anti-parallel $\beta$-sheet is shown in yellow (PDB code QX5).

Apart from the canonical EF-hand described above, other types of EF-hands, called noncanonical EF-hands, have been reported (Gifford et al. 2007). Non-canonical EF-hands deviate from the regular EF-hands in terms of the number of residues involved in the $\mathrm{Ca}^{2+}$ chelation or in the length of the loop because of the insertion or deletion of residues 
present in the canonical EF-hand (Haiech et al. 2004, Cook et al. 1993, Vijay et al. 1992). These non-canonical EF-hands are categorized into four groups. The first group contains non-canonical EF-hand loops that have a glutamic acid at the $12^{\text {th }}$ position replaced by an aspartic acid. This substitution decreases selectivity for $\mathrm{Ca}^{2+}$, and the loop preferably binds $\mathrm{Mg}^{2+}$ (Cook et al. 1993, Vijay et al. 1992). The second subgroup under noncanonical EF-hand loops is the pseudo EF-hand loop in which the additional residues are inserted between the residues in the $1^{\text {st }}$ and $3^{\text {rd }}$ position. As a result of the residue insertion, backbone carbonyl oxygens of the residues located at $1^{\text {st }}$ and $3^{\text {rd }}$ position act as liganding residues in those pseudo EF-hands, unlike the side chain oxygens as seen in the case of the canonical EF-hands (Nagae et al. 2003, Hohenestter et al. 1996). Insertion of one or two residues into the regular canonical EF-hand loop seems to have a predominantly localized effect, as this type of non-canonical EF-hand shows similar $\mathrm{Ca}^{2+}$ binding properties as canonical EF-hands (Hohenester et al. 1996). The third type of noncanonical EF-hand differs from the regular EF-hand in terms of length of the loop. The EF-hand in this group contains an eleven residue loop that binds $\mathrm{Ca}^{2+}$ preferably through backbone carbonyl oxygens and a water molecule (Bianchard et al. 1997). The fourth type of non-canonical EF-hand contains an insertion of two additional residues in the Cterminal end of the loop that makes the residue in $12^{\text {th }}$ position move far away from the liganding position. Because of such displacement of the bidentate ligand, residues located in the N-terminal part of the loop coordinate $\mathrm{Ca}^{2+}$ in an octahedral geometry, and this type of chelation leads to lower affinity for $\mathrm{Ca}^{2+}$ (Jia et al. 2001). 


\subsection{EF-hand pair}

In the majority of EF-hand proteins, EF-hands always occur in pairs even if one of the EF-hand is nonfunctional as in the case of Neries diversicolor sarcoplasmic reticulum $\mathrm{Ca}^{2+}$ binding proteins (Vijay et al. 1992). There are some proteins that contain an odd number of EF-hands, for example a voltage gated $\mathrm{Ca}^{2+}$ channel has a single functional EF-hand (Bunet et al. 2005). Parvalbumin contains three EF-hands but the unpaired EFhand is not functional (Babini et al. 2005). The EF-hands, apart from acting as $\mathrm{Ca}^{2+}$ binding sites, are also involved in promoting protein dimerization as seen in case of five EF-hand containing proteins like calpain, in which the fifth EF-hand gets paired up with a corresponding single EF-hand presented on the second monomer (Blanchard et al. 1997, Jia et al. 2001, Ilari et al. 2002, Jia et al. 2000, Reid et al. 1990, Shaw et al. 1990, Shaw et al. 1992). An example of the organization of an EF-hand pair is shown in Figure 1.7.

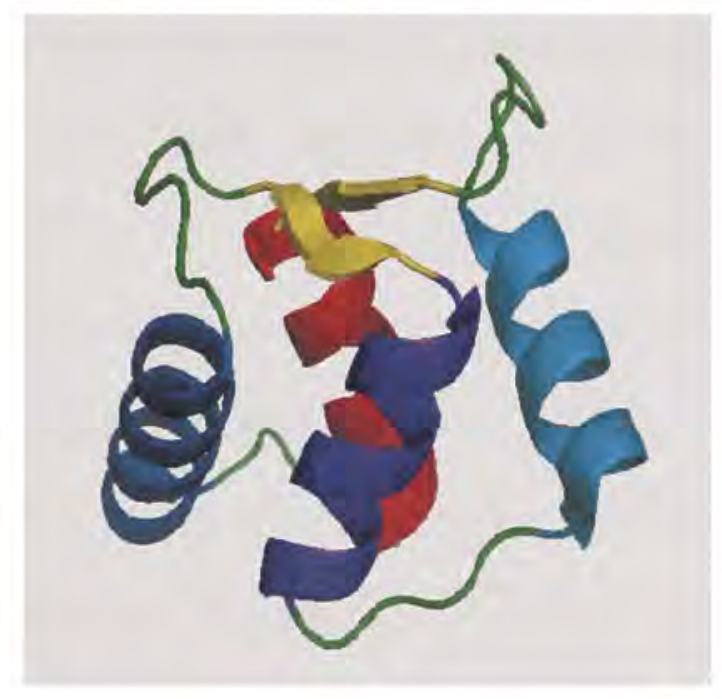

Figure 1.7. The organization of two EF-hands as a pair (PDB code: 1QX5). The two $\mathrm{Ca}^{2+}$ binding loops (in green) interact through anti-parallel $\beta$-sheets. 
The two EF-hands found in each pair are thought to communicate through an anti-parallel $\beta$-sheet formed by the hydrophobic residues at the eighth position of the loop (Gifford et al. 2007). Some proteins have EF-hands that do not form the anti-parallel $\beta$-sheet but still occur in pairs. However, such EF-hands have significantly lower affinity for $\mathrm{Ca}^{2+}$ (Cook et al. 1993). The strong tendency of the EF-hands to exist as a pair is further supported by several studies on isolated EF-hands of calmodulin $(\mathrm{CaM})$ and troponin $\mathrm{C}$ (Reid et al. 1990, Shaw et al. 1990, Shaw et al. 1992). In solution, the isolated EF-hands tend to form homodimers in a $\mathrm{Ca}^{2+}$ dependent manner. On the other hand, EF-hand homodimers readily dissociate and form heterodimers in the presence of a complementary EF-hand, indicating a strong affinity for heterodimers (Raid et al. 1981, Shaw et al. 1991).

\subsection{EF-hand domain organization}

In general, most of the EF-hand containing proteins contain four EF-hands arranged in two pairs with one pair in the $\mathrm{N}$-terminal domain and another pair in the $\mathrm{C}$-terminal domain (Gofford et al. 2007). Although there is certain similarity in structural organization of CaBP's, the ability to perform different functions comes from the diversity in the organization of the domains. On the basis of the structural arrangement of the individual domains, EF-hand proteins are broadly classified into three groups (Gofford et al. 2007). The proteins that belong to the first type have their $\mathrm{N}$ and $\mathrm{C}$ terminal domains connected by a flexible linker allowing the two domains to orient in different positions with respect to each other as seen in CaM and troponin C (Gifford et al. 2007, Babu et al. 1985). The second type of proteins are the neuronal calcium sensors where the two domains are connected by a "U" shaped linker forming a compact globule- 
like-structure with the two domains facing each other as shown in Figure 1.8 (Ames et al. 2000, Ames et al. 1999). This type of the domain arrangement restricts the movement of the individual domains. The third type of domain arrangement exhibits a compact globular structure similar to the neuronal calcium sensor family (NCS) except that the two domains are arranged opposite each other as seen in inverterbrate sarcoplasmic reticulum CaBPs (Cook et al. 1993, Vijay et al. 1992). Other proteins like calbindin have six EF-hands arranged in three pairs and the two domains are arranged in a more compact fashion in a way similar to that of NCS (Kojetin et al. 2006).

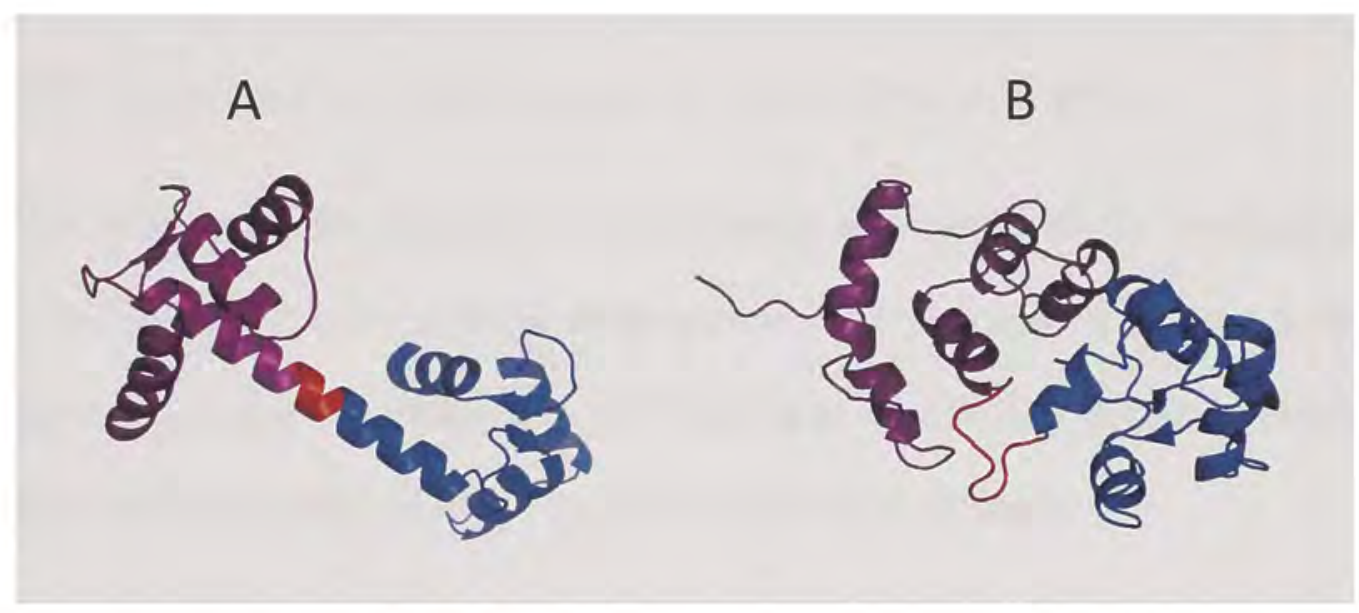

Figure 1.8. Arrangement of $\mathrm{Ca}^{2+}$ binding domain in CaBPs. A) CaM with a flexible linker (PDB code: 1EXR). B) Recoverin with a "U" shaped linker (PDB code: 1JSA). In both proteins, $\mathrm{N}$ - and $\mathrm{C}$-terminal domains are shown in violet and blue, respectively, and the linker is shown in red. 


\subsection{Affinity and selectivity of EF-hand loop for calcium}

$\mathrm{Ca}^{2+}$ binding affinity of EF-hand loops ranges from the $\mathrm{nM}$ to the $\mathrm{mM}$ level (Gifford et al. 2007). It is quite surprising considering that EF-hand binding sites have very similar structures and coordinate $\mathrm{Ca}^{2+}$ in similar fashions. The differences in $\mathrm{Ca}^{2+}$ affinity may arise from the differences in their intrinsic binding affinity and/or from the selectivity of the particular EF-hand to bind $\mathrm{Ca}^{2+}$ over similar cations like $\mathrm{Mg}^{2+}$ (Gifford et al 2007). In addition, the cooperativity between the EF-hands may be a key factor in tuning the $\mathrm{Ca}^{2+}$ binding properties. The affinity of the EF-hand to bind $\mathrm{Ca}^{2+}$ may also be altered by CaBPs interaction with target proteins (Johnson et al. 1996, Olwin et al. 1984, Olwin et al. 1985, Persechini et al. 1996, Yazawa et al. 1992, Gifford et al. 2007).

Intrinsic binding affinity depends on the free energy associated with $\mathrm{Ca}^{2+}$ binding as well as on the difference in the stability of the protein in the apo and $\mathrm{Ca}^{2+}$ bound form. The change in free energy associated with $\mathrm{Ca}^{2+}$ binding to the EF-hand includes enthalpic and entropic contributions according to Equation 1 (Gifford et al. 2007)

$$
\Delta \mathrm{G}=\Delta \mathrm{H}-\mathrm{T} \Delta \mathrm{S}
$$

where $\Delta G$ is change in the free energy, $\Delta H$ represents the change in enthalpy, $T$ is the temperature, and $\Delta \mathrm{S}$ stands for change in the entropy. Previous studies proposed that water molecules exist in a "frozen state" in the $\mathrm{Ca}^{2+}$ binding loop and play an important role in determining the entropic contribution to the affinity of the EF-hand (Gifford et al. 2007). The magnitude of the entropy increase depends on the number of water molecules exchanged between the loop and the surrounding solvent upon $\mathrm{Ca}^{2+}$ binding (Gifford et al. 2007, Drake et al. 1996, Lee et al. 2004). On the other hand, enthalpy changes 
associated with $\mathrm{Ca}^{2+}$ ions binding to the loop are generally endothermic because of the high dehydration energies of the $\mathrm{Ca}^{2+}$. However depending on the position and arrangement of the chelating residues, the overall enthalpy change for $\mathrm{Ca}^{2+}$ can be exothermic as a result of constructive electrostatic interactions between the negatively charged chelating residues and the $\mathrm{Ca}^{2+}$ ion (Gifford et al. 2007). A favorable enthalpy change is usually observed if the repulsion between the liganding residues is minimal in the $\mathrm{Ca}^{2+}$ bound form (Gifford et al. 2007, Reid et al. 1980).

Another important aspect of $\mathrm{Ca}^{2+}$ binding to CaBPs is the selectivity of the EF-hand for the $\mathrm{Ca}^{2+}$ ion compared to $\mathrm{Na}^{+}, \mathrm{K}^{+}$, and $\mathrm{Mg}^{2+}$ (Falke et al. 1991). The EF-hands have a very low affinity for $\mathrm{Na}^{+}$and $\mathrm{K}^{+}$ions because these cations are not able to completely shield the negative charge on the EF-hand loop (Falke et al. 1991). More importantly, the $\mathrm{Mg}^{2+}$ ion concentration in the resting cell is $10^{2}$ to $10^{4}$ fold higher than the $\mathrm{Ca}^{2+}$ concentration (Gifford et al. 2007) and all the canonical EF-hands bind $\mathrm{Ca}^{2+}$ with much higher affinity compared to $\mathrm{Mg}^{2+}$. There are two factors that contribute to this selectivity for $\mathrm{Ca}^{2+}$ over $\left.\mathrm{Mg}^{2+}: 1\right) \mathrm{Mg}^{2+}$ ion is smaller and thus the energy required to dehydrate the smaller ion is larger than the energy for $\mathrm{Ca}^{2+}$ ion dehydration. 2) arrangement of the chelating residues in pentagonal bi- pyramidal fashion in an EF-hand loop is not the preferred geometry for $\mathrm{Mg}^{2+}$ ion chelation (Martin, et al. 1990). However, in case of noncanonical EF-hands with high affinity for $\mathrm{Mg}^{2+}$, the $\mathrm{Mg}^{2+}$ ion is coordinated by six ligands in octahedral geometry because of the rotation of $\mathrm{C}_{\alpha}-\mathrm{C}_{\beta}$ bond of aspartate residue at the $12^{\text {th }}$ position of the EF-hand loop (Houdusse et al. 1996, Blumenschein et al. 2000). 
Because of this rotation, Asp can act as a monodentate ligand and it reduces the total number of liganding residues to six (Anderson et al. 1997).

Entropy also contributes to the high selectivity of the $\mathrm{Ca}^{2+}$ specific EF-hand, since coordination of $\mathrm{Mg}^{2+}$ by canonical EF-hands includes an additional water molecule (Potter et al. 1975). Other important factor is the cooperativity between the EF-hand loops forming an EF-hand pair. Positive cooperativity between the EF-hands contributes to the increase in EF-hand affinity for $\mathrm{Ca}^{2+}$, but cooperative binding was not observed incase of $\mathrm{Mg}^{2+}$ binding (Linse et al. 1991, Gifford et al. 2007).

\subsection{Calmodulin}

\subsubsection{Functions of calmodulin}

Calmodulin is an important intracellular protein that regulates a variety of physiological processes including smooth muscle contraction, activation of kinases and phosphatases, energy metabolism and cyclic nucleotide metabolism (Clapham et al. 2007). For example, regulation of smooth muscle contraction occurs through a reversible phosphorylation of regulatory light chain myosin by CaM activated myosin light chain kinase (Meador et al. 1992). CaM is involved in the regulation of activity of various ion channels like plasma membrane $\mathrm{Ca}^{2+}$ ATPases (PMCAs) (Siegel et al. 1999). Apart from this, $\mathrm{CaM}$ is also participates in the regulation of energy metabolism by controlling the activity of certain enzymes such as phosphorylase kinase that is a key enzyme in glycogen metabolism (Cox et al. 1982). Interestingly, CaM is nearly uniformly distributed throughout the cytoplasm whereas other CaBPs are found to be localized within the cell, indicating the wide range of CaM functions (Babu et al. 1985). 


\subsubsection{Structure of calmodulin}

Calmodulin is a $17 \mathrm{kDa}$ protein containing 148 residues with a high degree of $\alpha$-helical structure. It has four EF-hands and each domain contains one EF-hand pair (Babu et al. 1985). All four EF-hands are capable of $\mathrm{Ca}^{2+}$ binding. The amino acid sequence of the protein along with the residues involved in the formation of EF-hand loops is shown in

Figure 1.9 (Shea et al. 1996).

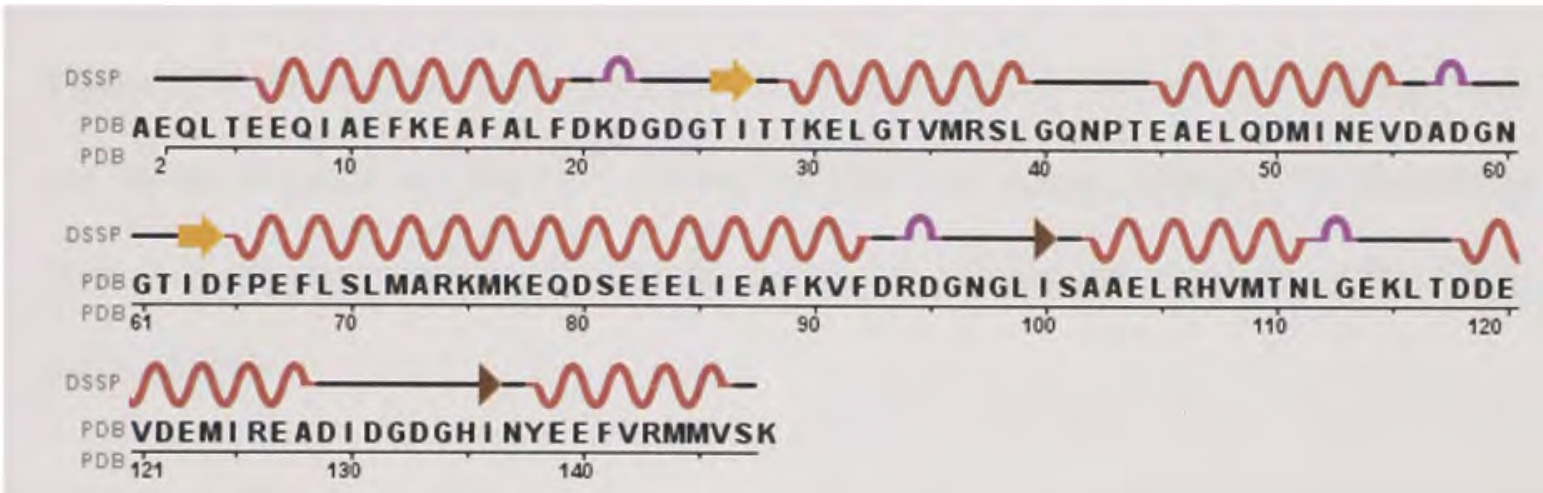

Figure 1.9. Amino acid sequence of rat $\mathrm{CaM}$. The amino acid residues involved in the formation of $\alpha$-helices are shown in orange, $\beta$-sheets in yellow, and EF-hands in purple. PDB code: 1 EXR 


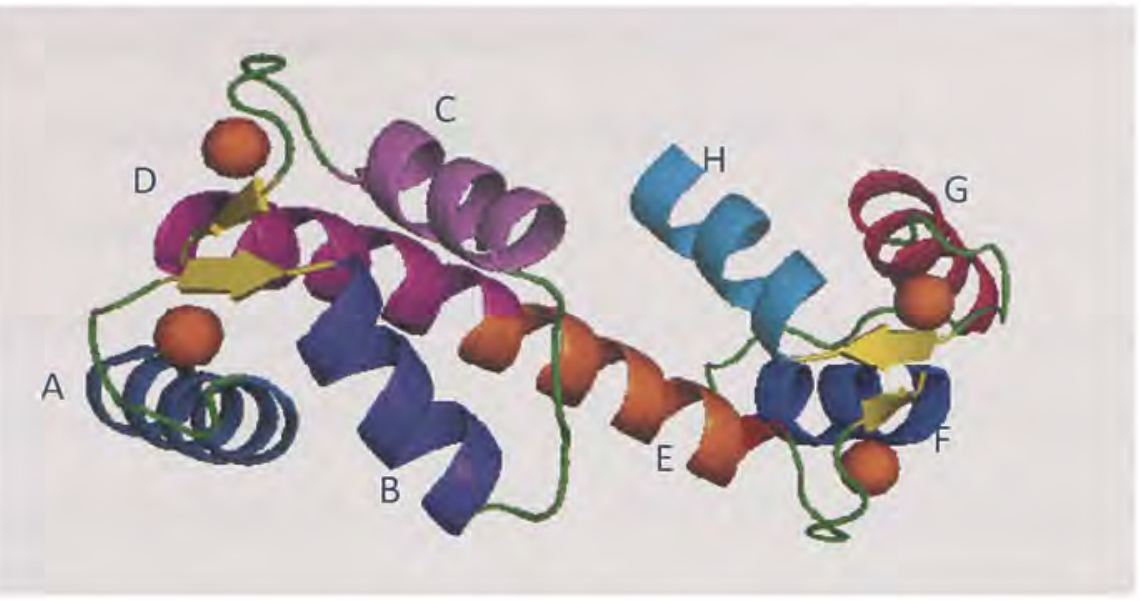

Figure 1.10. The crystal structure of $\mathrm{Ca}^{2+}$ bound calmodulin. All four $\mathrm{Ca}^{2+}$ binding loops are shown in green and the $\mathrm{Ca}^{2+}$ cations are shown as orange spheres. All the helices from $\mathrm{A}-\mathrm{H}$ are represented with different colors, the $\beta$-sheets are shown in yellow (PDB code: 1EXR).

The CaM crystal structure shows eight $\alpha$-helices labelled A-D and E-H that are found in the $\mathrm{N}$ and $\mathrm{C}$-terminal domain respectively, as shown in Figure 1.10. Helices $\mathrm{A} / \mathrm{B}, \mathrm{C} / \mathrm{D}$, $\mathrm{E} / \mathrm{F}$, and $\mathrm{G} / \mathrm{H}$ form pairs connected by nine residue $\mathrm{Ca}^{2+}$ binding loops forming EF-hands 1, 2, 3, and 4 respectively (Kubinova et al. 1985, Shea et al. 1996). The exiting helix D of EF-hand loop 2 continues as entering helix E of EF-hand loop 3 found in the C-terminal domain. The helices D and E together acts as a linker between the two domains and is often called the "central helix" (Zhang et al. 1995). Such interdomain arrangement gives the protein a dumbbell structure (Babu et al. 1985). Previous NMR studies on CaM proposed that the central helix is very flexible and plays a prominent role in the binding of CaM to the target proteins (Ikura et al. 1992, Meador et al. 1993, Meador et al. 1992). However, it is still under debate whether the central helix has more $\alpha$-helical content in 
the apo form or the $\mathrm{Ca}^{2+}$ bound form (Kubinova et al. 1985). The X-ray structure of CaM indicated that the central helix has more $\alpha$-helical content than NMR data does in case of $\mathrm{Ca}^{2+}$ saturated CaM (Babu et al. 1985, Zhang et al. 1995). The difference probably arised from the experimental conditions used in X-ray studies that may promote formation of $\alpha$ helices. The two pairs of helices found in each domain form a compact globular structure through extensive hydrophobic interactions. However, helix $\mathrm{C}$ from the $\mathrm{N}$-terminal domain and helix $\mathrm{G}$ from the $\mathrm{C}$-terminal domain have few hydrophobic contacts compared to other helices in their respective domains (Zhang et al. 1995).

\subsubsection{Calcium induced conformational changes in calmodulin}

The entering and exiting helices of EF-hands are almost anti-parallel to each other in the $\mathrm{Ca}^{2+}$ free form of $\mathrm{CaM}$. The inter-helical angles in the $\mathrm{C}$-domain are slightly higher than in the $\mathrm{N}$-domain in the apo form of $\mathrm{CaM}$ indicating a smaller degree of hydrophobic interactions involved in the packing of C-domain (Zhang et al. 1995). It was also shown that helix A from the $\mathrm{N}$-terminal domain interacts with the residues presented in the central helix and stabilizes the N-terminal domain in the apo form (Chen et al. 2008). Differences in the arrangement of the helices in the two domains likely contribute to the higher $\mathrm{Ca}^{2+}$ binding affinity of the C-terminal domain (Kubinova et al. 1995, Babu et al. 1985, Zhang et al. 1995). Indeed, the affinity of the EF-hand pair at the C-terminal domain is about 10 times higher $\left(\mathrm{K}_{\mathrm{d}}=1 \mu \mathrm{M}\right)$ than the affinity of the EF-hand pair in the N-terminal domain $\left(\mathrm{K}_{\mathrm{d}}=10 \mu \mathrm{M}\right)$, which is more stable in apo form (Kubinova et al. 1995, Babu et al. 1985, Zhang et al. 1995). 
Binding of $\mathrm{Ca}^{2+}$ to EF-hands leads to the repositioning of the exiting helix to be perpendicular with respect to the entering helix as shown in Figure 1.11 (Gifford et al. 2007, Zhang et al. 1995). This helical movement brings the bidentate ligand at the $12^{\text {th }}$ position close to the $\mathrm{Ca}^{2+}$ in the liganding position.
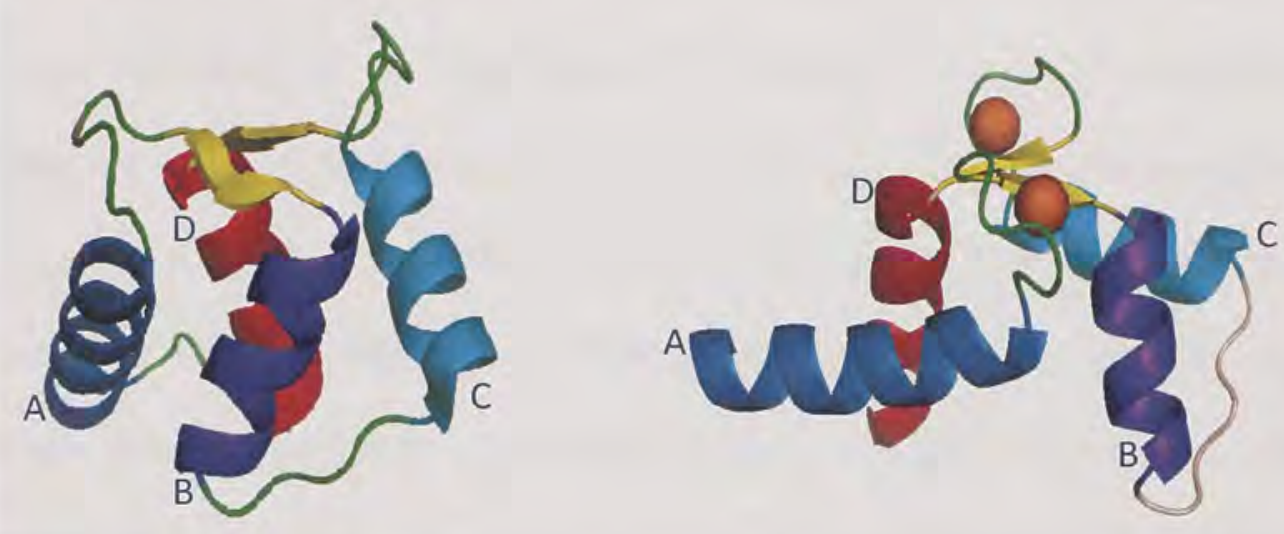

Figure 1.11. The relative orientation of $\alpha$-helices in the apo form (left) and $\mathrm{Ca}^{2+}$ bound form (right) of $\mathrm{CaM}$. In the apo form, the entering and exiting helices are nearly antiparallel to each other whereas in the $\mathrm{Ca}^{2+}$ bound form they are perpendicular to each other (PDB code: 1QX5, 1EXR)

Calcium induced repositioning of $\alpha$-helices leads to increase of the distance and the angle between the EF-hand helices, causes loss of interhelical hydrophobic contacts and promotes an opening of both domains which is termed "close-to-open domain transition". Similar changes in the helical angles were observed in troponin $\mathrm{C}$ and in neuronal $\mathrm{Ca}^{2+}$ sensor recoverin indicating that the change in helical angles is a common conformational change that occurs in majority of the $\mathrm{Ca}^{2+}$ regulatory proteins (Herzberg et al. 1988, 
Zhang et al. 1995). When CaM is in the apo form, the repulsion between the negative charges of the liganding residues makes the EF-hand loops more flexible compared to $\mathrm{Ca}^{2+}$ bound form which might be one of the reasons why the crystal structure of apo CaM has not yet been determined (Zhang et al. 1995, Babu et al. 1985).

Exposure of the hydrophobic patches on $\mathrm{N}$ - and $\mathrm{C}$-terminal domain of $\mathrm{CaM}$ is the other major change that occurs in the $\mathrm{CaM}$ upon $\mathrm{Ca}^{2+}$ binding. The exposed hydrophobic patches contain a central hydrophobic groove surrounded by negatively charged residues (Meador et al. 1993, Meador et al. 1992). Exposure of hydrophobic patches is likely to be important step of $\mathrm{CaM}$ activation since, $\mathrm{CaM}$ interactions with target proteins occur predominantly through hydrophobic interactions (Ikura et al. 1986, Meador et al. 1993, Meador et al. 1992). However, the mechanism of CaM activation of target proteins is more complex. In some cases, CaM binds to target proteins even in the absence of $\mathrm{Ca}^{2+}$ as seen in the case of neuromodulin (Apel et al. 1992). CaM ability to activate target proteins in apo form was attributed to the fact that hydrophobic residues are partially surface exposed in the apo form of CaM (Apel et al. 1992). Structural studies have shown that several methionine residues are located in hydrophobic patches. Four out of the nine methionine residues found in $\mathrm{CaM}$ are presented in the $\mathrm{N}$ - and $\mathrm{C}$-terminal domain and one methionine is located in the central helix (Babu et al. 1988). Shielding of methionine residues from the solvent in the apo $\mathrm{CaM}$ and their exposure upon $\mathrm{Ca}^{2+}$ binding suggests that methionine residues play an important role in the interaction of $\mathrm{CaM}$ with target proteins (Zhang et al. 1995, O’ Niel et al. 1988). 
The detailed sequence of conformational changes that occur upon $\mathrm{Ca}^{2+}$ binding to $\mathrm{CaM}$ was proposed recently by $\mathrm{Chen}$ et al. (2008). As a result of $\mathrm{Ca}^{2+}$ binding to the $\mathrm{C}$-terminal domain, rearrangement of helices occurs and facilitates the formation of a hydrogen bond between Tyr 138 found in the EF-hand 4 and Glu 82 that is situated in the central helix (Chen et al. 2008). In the apo form, helix A stabilizes the N-terminal binding site by forming extensive contacts with the central helix (Faga et al. 2003). However, formation of the hydrogen bond between the Tyr 138 and Glu 82 and the reorganization of the helices in the C-terminal domain, promotes the formation of more organized helical structure in the helix A. As a result, helix A is detached from the central $\alpha$-helix leading to the destabilization of the $\mathrm{N}$-terminal domain. The instability promotes $\mathrm{Ca}^{2+}$ binding to the N-terminal EF-hands, and subsequent reaarangement of the $\alpha$-helices in N-terminal domain. All these sequential changes that occur upon $\mathrm{Ca}^{2+}$ binding subsequently leads to the exposure of hydrophobic patch through which calmodulin interacts with a wide variety of targets (Chen et al. 2008).

\subsection{Neuronal calcium sensors}

Neuronal calcium sensors (NCS) represent a new family of $\mathrm{Ca}^{2+}$ binding proteins that were first described by Nef et al. (Nef et al. 1996). The expression of the NCS family of proteins is primarily limited to neuronal cells (Chin et al. 2000, Burgoyne et al. 2001, Burgoyne et al. 2007). Such localization to a specific type of cells indicates that NCS proteins participate in the regulation of specific functions. In the human genome, NCS family of proteins are encoded by 14 genes and show a large diversity in their functions as a result of the existence of the splice variants (Burgoyne et al. 2004). Current studies show that NCS are involved in numerous functions like nucleotide metabolism, gene 
expression, modulation of activity of ion channels, regulation of gene expression, etc. (Braunwell et al. 1999). Neuronal calcium sensors are broadly divided into five sub classes (A-E) based on their sequence similarity, expression pattern and functions as shown in Table 1.1. (Burgoyne et al. 2001).

Table 1.1. Classification of NCS family of proteins

\begin{tabular}{ccc}
\hline Class & Name of the subfamily & First appearance \\
\hline A & Frequenins (NCS-1) & Yeast \\
B & VILIPS & Nematodes \\
C & Recoverins & Amphibians \\
D & GCAPs & Amphibians \\
E & KChIPs & Mammals \\
\hline
\end{tabular}

Vision like proteins (VILIPS) subfamily includes VILIP-1, VILIP-2, VILIP-3, neurocalcins and hippocalcin (Nef et al. 1996, Braunewell et al. 1999). The GCAPs (GCAP 1-8) are the guanylate cyclase activating proteins and KChIPs (KChIPs 1-5) are the potassium channel interacting proteins. Frequenins, also called NCS-1, are the first NCS members to be identified as neuronal $\mathrm{Ca}^{2+}$ sensors. NCS-1 was initially found in yeast (Saccharomyces cerevisiae) and its sequence shares about $59 \%$ identity with its human analog frequenin (Burgoyne et al. 2001). Frequenins are primarily expressed in neuronal and kidney cells and are involved in a wide variety of processes such as neurotransmission, regulation of activity of calcium and potassium channels and most importantly in controlling short term synaptic plasticity (Slippy et al. 2003, Guo et al. 2002, Nakamura et al. 2001). 
VILIPS are primarily expressed in brain cells of mammals, and are involved in the activation of guanylyl cyclase and regulation of the activity of P/Q type $\mathrm{Ca}^{2+}$ channels (Lautermilch et al. 2005). Guanylate cyclase activating proteins and recoverin belong to the class $\mathrm{C}$ and $\mathrm{D}$, respectively, and modulate the activity of retinal guanylyl cyclase found in retinal cells (Makino et al. 2004, Sampath et al. 2005, Pennesi et al. 2003). The last subfamily of the NCS are the potassium channel interacting proteins which are widely expressed in the brain and also in heart tissues. Recent studies confirmed that KChIP's interact with potassium channels in the absence of $\mathrm{Ca}^{2+}$ and modulate the channel activity in a $\mathrm{Ca}^{2+}$ dependent manner (Braunwell et al. 1999). Potassium channel interacting proteins were also associated with assisting of potassium channels trafficking from Golgi complex to the plasma membranes (Burgoyne et al. 2001, Pioletti et al. 2006).

Neuronal calcium sensors belong to the EF-hand super family and contain four EF-hands, with the first EF-hand, being non-functional due to the insertion of two extra residues, cysteine, and proline, in the $\mathrm{Ca}^{2+}$ binding loop (Schaad et al. 1996). Proteins that belong to the recoverin sub family have non functional EF-hand 4 in addition to EF-hand 1 (Schaad et al. 1996, Burgoyne et al. 2001, Ames et al. 1997).

The sequence similarity between the CaM and NCS members is less than 25\% (Burgoyne et al. 2007). Structural studies have shown that NCS members have a compact globular structure, unlike CaM which has a dumbbell shaped structure (Burgoyne et al. 2007). All members of NCS family are N-terminally acylated, very often with myristoyl group. except the E class members (An et al. 2000, Burgoyne et al. 2007). According to the initially proposed mechanism of $\mathrm{Ca}^{2+}$ signaling by NCS, the myristoyl group is buried in 
the hydrophobic pocket and the apo protein is localized in cytosol. As a result of $\mathrm{Ca}^{2+}$ induced conformational changes, the myristoyl group becomes solvent exposed thereby allowing the NCS members to associate to membranes (Burgoyne et al. 2007). However, such $\mathrm{Ca}^{2+}$ induced repositioning of the myristoyl group does not represent a general mechanism of $\mathrm{Ca}^{2+}$ transduction in NCS proteins, since the members of the NCS-1 family were shown to associated to the plasma membrane and Golgi complex in the absence of $\mathrm{Ca}^{2+}$ (Burgoyne et al. 2001). In case of GCAP 2, myristoyl group is a solvent exposed in the apo state and was found to be buried inside a hydrophobic pocket upon $\mathrm{Ca}^{2+}$ binding indicating that $\mathrm{Ca}^{2+}$ association to this protein triggers GCAP dissociation from phospholipid membranes (Burgoyne et al. 2001)

\subsection{Recoverin as a prototype neuronal calcium signaling protein}

Recoverin is the first member of the NCS family to be crystallized and its structure is known in the apo and $\mathrm{Ca}^{2+}$ bound form (Schaad et al 1996). In neuronal cells at high $\mathrm{Ca}^{2+}$ concentrations, recoverin prevents the deactivation of rhodopsin by interacting with rhdopsin kinase thereby increasing the lifetime of the photoexcited rhodopsin (Sanada et al. 1996, Braunwell et al. 1999).

The crystal structure of recoverin in apo and $\mathrm{Ca}^{2+}$ bound forms are shown in Figure 1.12. The $\mathrm{N}$ and C-terminal domains are linked by a " $U$ " shaped linker. Only EF-hand 2 and EF-hand 3 bind $\mathrm{Ca}^{2+}$ with a high affinity $\left(\mathrm{K}_{\mathrm{d}}=1 \mu \mathrm{M}\right)$. Recoverin as other NCS, undergoes $\mathrm{N}$-terminal acetylation by myristic acid and this modification is essential for its $\mathrm{Ca}^{2+}$ dependent association to the phospholipid membranes (Burgoyne et al. 2007). In the apo form, the myristoyl group is packed in a hydrophobic cavity formed by residues 
from EF-hand 2, 3 and 4 (Burgoyne et al. 2001). Structural studies show that upon $\mathrm{Ca}^{2+}$ binding a conformational switch leads to the exposure of the myristoyl group and exposure of hydrophobic surface through the the rotation of $\mathrm{N}$-terminal domain by about $45^{\circ}$ with respect to C-terminal domain (Ames et al. 1997, Burgoyne et al. 2001).. The repositioning of the myristoyl group upon $\mathrm{Ca}^{2+}$ binding to recoverin is facilitated by the glycine residues presented at the $42^{\text {nd }}$ and $96^{\text {th }}$ position (Ames et al. 1997). Exposure of the myristoyl group to the solvent facilitates association of recoverin to the phospholipid membranes (Ames et al. 1997).

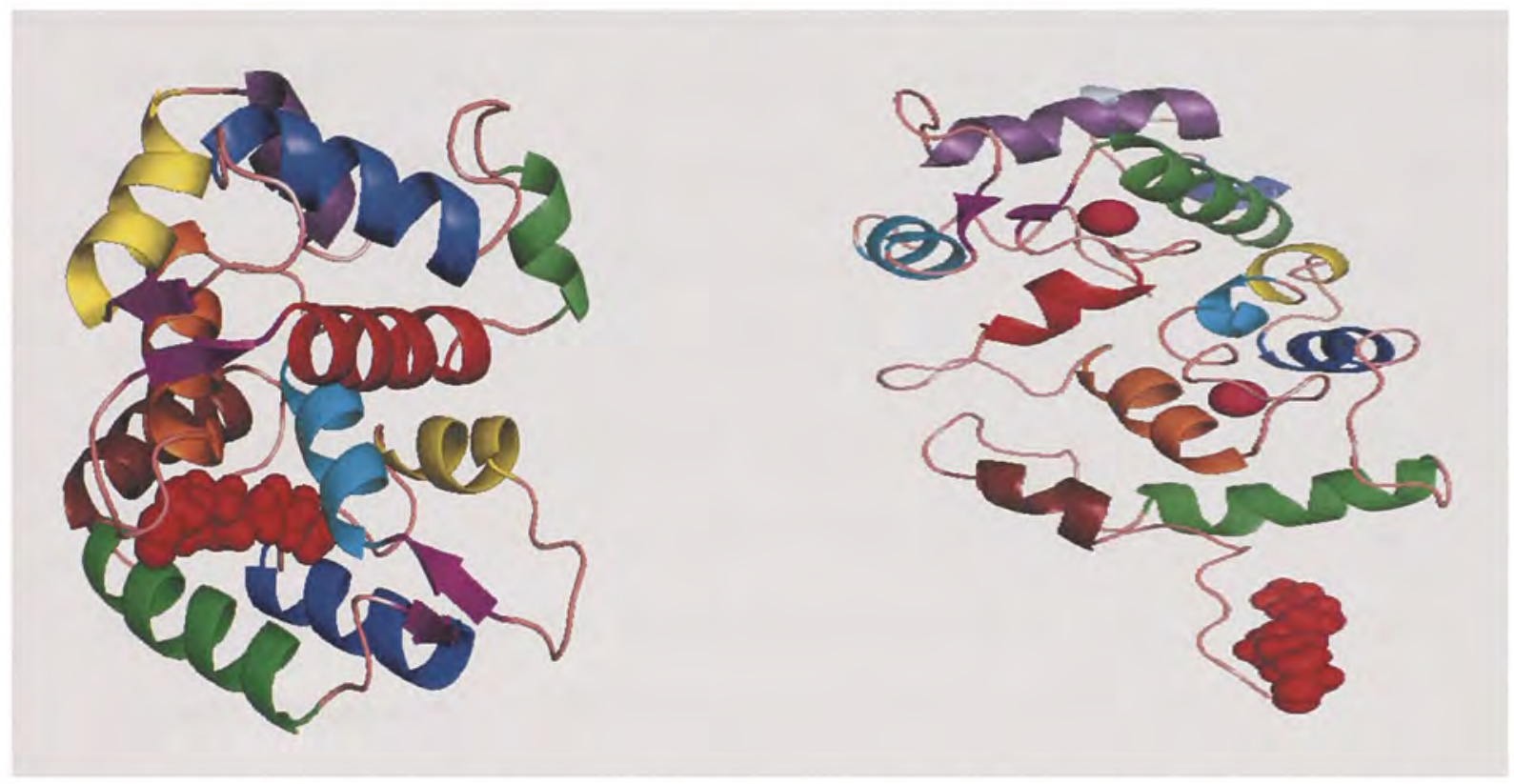

Figure 1.12. Structure of recoverin in apo (left) and $\mathrm{Ca}^{2+}$ bound form (right). $\mathrm{Ca}^{2+}$ ions are shown as pink spheres. In apo form the myristoyl group (shown as red spheres) is sequestered in a hydrophobic cavity whereas upon $\mathrm{Ca}^{2+}$ binding the myristoyl group is exposed to the solvent (PDB code: 1IKU, 1JSA). 


\subsection{DREAM (Down Stream Regulatory Element Antagonist Modulator)}

\subsubsection{Functions of DREAM}

The NCS family member DREAM, also known as calsenilin or KChIP 3 is a $29 \mathrm{kDa}$ protein that is involved in the regulation of cellular processes ranging from regulation of transcription of genes to modulation of activity of $\mathrm{Kv}_{4}$ ion channels (Craig et al. 2002). In the nucleus, DREAM binds to DRE elements on the DNA and regulates the transcription of prodynorphin and $c$-fos genes (Carrion et al. 2001). Upon $\mathrm{Ca}^{2+}$ binding DREAM dissociates from DNA as a result of induced conformational changes. A schematic representation of DREAM interaction with DNA is shown in the Figure 1.13 (Mellstrom et al. 2001). The importance of the DREAM as a transcriptional regulator was confirmed by the studies on DREAM knockout mice which exhibited ongoing analgesia because of the over expression of prodynorphin (Cheng et al. 2002). Calsenilin was also found to be involved in the transcriptional regulation of the apoptotic gene hrk by binding to the DRE sequence present in its 3' untranslated region in a $\mathrm{Ca}^{2+}$ dependent manner (Sanz et al. 2001). In addition to binding to DRE elements, DREAM is found to interact with hormone receptor elements and regulate the transcription of vitamin D and retinoic acid receptors (Scsucova et al. 2005). Calsenilin acts as transcriptional activator in a $\mathrm{Ca}^{2+}$ dependent manner by interacting with transcription factors like CREB and CREM (Ledo et al. 2002, Ledo et al. 2000).

In cytoplasm of eukaryotic cells DREAM interacts with the C-terminal residues of presinilin 1 and presenilin 2 in the vicinity of endoplasmic reticulum and Golgi apparatus. Presenilins are a part of gamma secretase that are involved in the production of $A \beta$ proteins that were associated with Alzheimer's disease (Craig et al. 2000, Coughlan et al. 
2000). Down stream Regulatory Antagonist Modulator (DREAM) was also found to induce apoptosis by altering the $\mathrm{Ca}^{2+}$ homeostasis within the cell in the presence of apoptotic triggers like thapsigargin (Lilliehook et al. 2002).

Down stream Regulatory Antagonist Modulator (DREAM) forms an intrinsic subunit of the $\mathrm{Kv}_{4}$ potassium channels located in the heart and brain cells and modulates their activity (Burgoyne et al. 2007, Carrion et al. 1999, Mellstrom et al. 2001).The binding of the DREAM to the $\mathrm{Kv}_{4}$ potassium channels was shown to be $\mathrm{Ca}^{2+}$ independent. However, the modulation of the channel activity is $\mathrm{Ca}^{2+}$ dependent (Burgoyne et al. 2001). KChIP 3 is also involved in the trafficking of $\mathrm{Kv}_{4}$ potassium channels to the plasma membrane (Burgoyne et al. 2004). Previous studies have shown that in the absence of KChIP 3, $\mathrm{Kv}_{4}$ potassium channels are retained on the Golgi complex and are unable to diffuse to the plasma membrane (O'Callaghan et al. 2003). However, deletion of 40 residues at the $\mathrm{N}$ terminal domain allows $\mathrm{Kv}_{4}$ association to the plasma membrane. On the basis of these studies it was proposed that, $\mathrm{Kv}_{4}$ channel trafficking to the membranes involves masking of the N-terminal residues of the potassium channels (O'Callaghan et al. 2003, Burgoyne et al. 2004). 


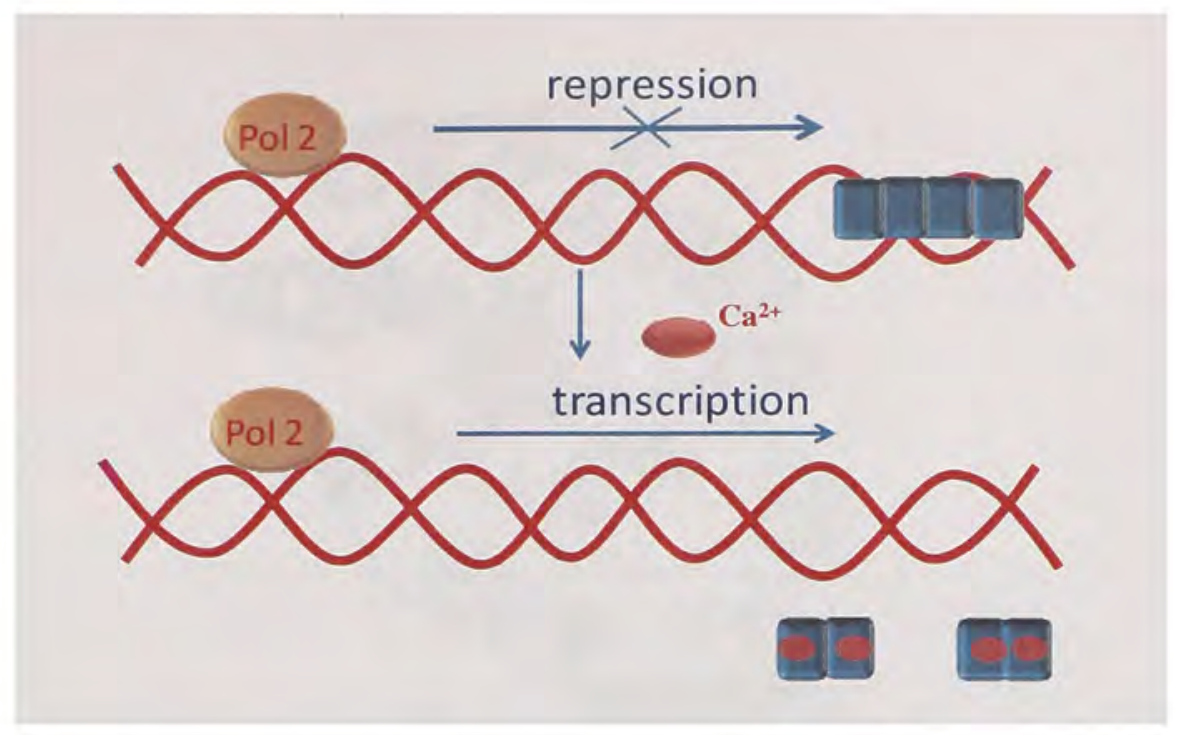

Figure 1.13. Schematic model for the mechanism of DREAM interactions with DNA. In the apo form DREAM binds to DNA as a tetramer and upon $\mathrm{Ca}^{2+}$ binding DREAM dissociates from DNA and undergoes dimerization.

\subsubsection{DREAM Structure}

Down stream Regulatory Antagonist Modulator (DREAM) is a 256 amino acid residue protein with predominantly $\alpha$-helical structure as shown in Figure 1.14 (Lustin et al. 2008). The NMR structure of DREAM-C shows a compact globular structure similar to recoverin and other KChIP's with ten $\alpha$-helices and four $\beta$ sheets (Lusin et al. 2008). The $\mathrm{N}$ and C-terminal domain face each other and are connected by a " $\mathrm{U}$ " shaped linker (Lusin et al. 2008). DREAM-C is a deletion mutant of full length DREAM lacking the first 64 residues (Osawa et al. 2001, Osawa et al. 2005). 


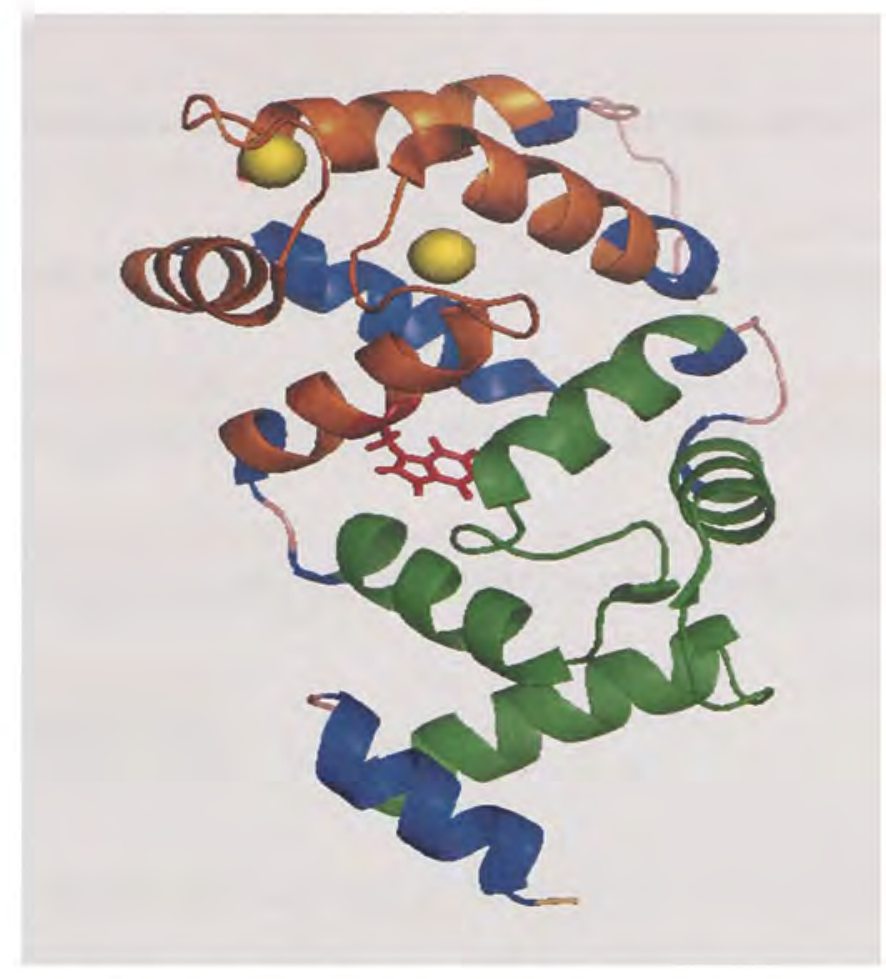

Figure 1.14. NMR structure of DREAM. N-terminal helices of $\mathrm{Ca}^{2+}$ binding loops are shown in green and the $\mathrm{C}$-terminal helices are shown in brown. $\mathrm{Ca}^{2+}$ ions are shown as yellow spheres (PDB code 2JUL).

Down stream Regulatory Antagonist Modulator (DREAM) has four EF-hands arranged as a pair in each domain. Only three EF-hands bind $\mathrm{Ca}^{2+}$ with a high affinity. The EFhand 1 is non functional because of the presence of a cysteine-proline insertion in the $\mathrm{Ca}^{2+}$ binding loop (Osawa et al. 2005). The presence of proline produces a kink in the $\mathrm{Ca}^{2+}$ binding loop thereby causing the liganding residues to deviate from their chelating positions (Burgoyne et al. 2001, Lusin et al. 2008). The amino acid sequence and the residues involved in forming the EF-hand are shown in Figure 1.15. 


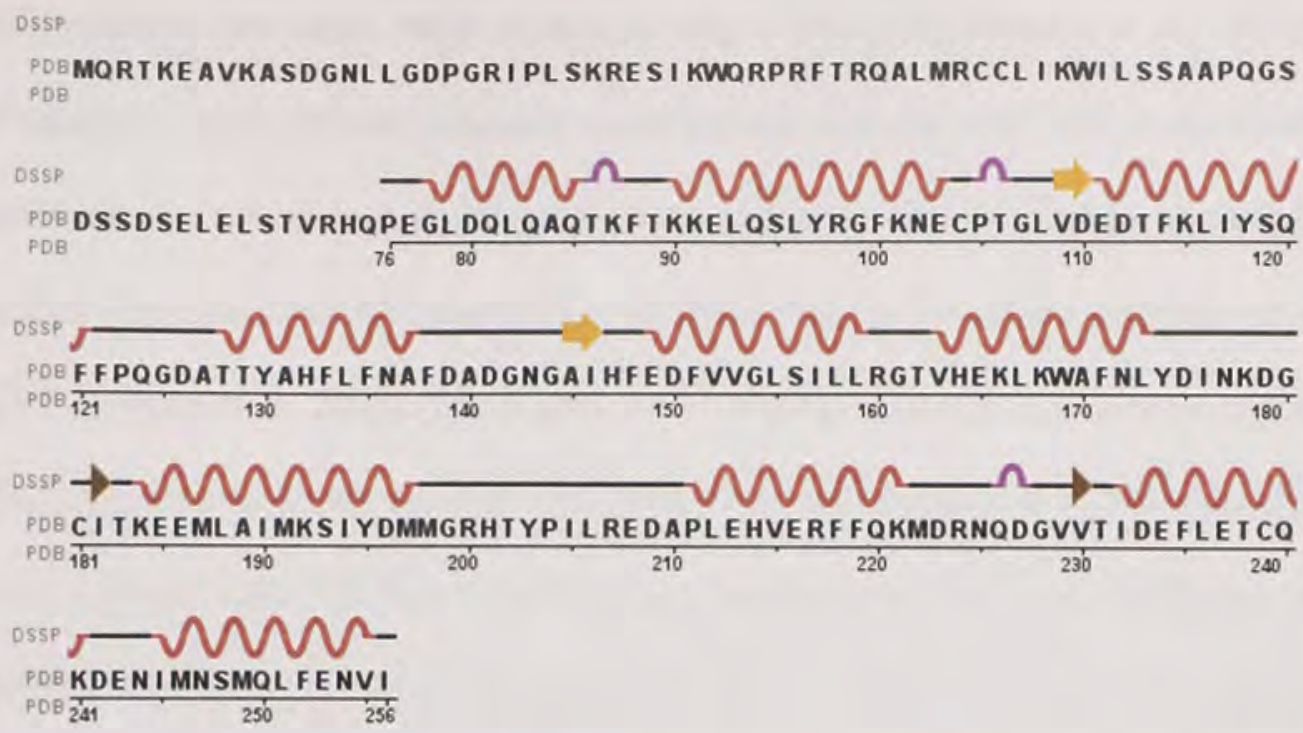

Figure 1.15. Amino acid sequence of DREAM. The amino acid residues involved in the formation of $\alpha$-helices are shown in orange, $\beta$-sheets in yellow, and EF-hands in purple (PDB code 2JUL).

The EF-hand 2 has a higher affinity for $\mathrm{Mg}^{2+}\left(\mathrm{K}_{\mathrm{d}}=13 \mu \mathrm{M}\right)$ than for $\mathrm{Ca}^{2+}$ because of the presence of Asp in the $12^{\text {th }}$ position of the loop and EF-hands 3 and 4 have a high affinity for $\mathrm{Ca}^{2+}$ and their $\mathrm{K}_{\mathrm{d}}$ is about $1 \mu \mathrm{M}$ (Osawa et al. 2001). Apo-DREAM exists as a tetramer and binds to DNA (Osawa et al. 2005). The role of $\mathrm{Mg}^{2+}$ binding to EF-hand 2 remains unclear. However, $\mathrm{Mg}^{2+}$ binding to EF-hand 2 was proposed to be necessary for its sequence specific binding to DRE elements on DNA (Osawa et al. 2001). On the other hand, in the absence of DNA, binding of $\mathrm{Mg}^{2+}$ to DREAM is likely to stabilize the protein in monomeric form as proposed by Osawa et al. (Osawa et al. 2005). Previous studies have also found that four DRE molecules bind to the DREAM tetramer. Among the four DRE molecules, one molecule binds with a higher affinity $\left(K_{d}=75 \mathrm{nM}\right)$ 
compared to the other three molecules $\left(K_{d}=740 \mathrm{nM}\right)$ (Osawa et al. 2001). Calcium binding to apo DREAM induces conformational changes that lead to the dissociation of tetramer into two dimers in the concentrations below $150 \mu \mathrm{M}$. In the concentrations range above $200 \mu \mathrm{M}$, DREAM exists as a tetramer irrespective of the presence or absence of $\mathrm{Ca}^{2+}$ (Osawa et al. 2005). The $\mathrm{K}_{\mathrm{d}}$ for the change in oligomerization state of the DREAM from tetramer to dimer was reported to be $\sim 500 \mathrm{nM}$ (Lusin et al. 2008). Metal ions $\left(\mathrm{Ca}^{2+}\right.$, $\mathrm{Mg}^{2+}$ ) bound DREAM has more organized and compact structure compared to the apoDREAM (Craig et al. 2002). The interactions between the $\mathrm{N}$ - and $\mathrm{C}$ - terminal domain are facilitated by the hydrophobic residues exposed on the surface of the EF-hand 2 and EFhand 3. The residues that contribute to these domain-domain interactions are Y130, F133, L134 and A137 from EF-hand 2 and L173, I190, M197 from EF-hand 3 (Lusin et al. 2008).

Other hydrophobic residues L155, L158, L159, and L251 are well conserved among the members of the NCS family (Lustin et al. 2008). The exposed N-terminal hydrophobic residues $\mathrm{L} 155, \mathrm{~L} 158$ and $\mathrm{L} 159$ are thought to be involved in the dimer formation by interactions with L251 at the C-terminal domain in a head to tail orientation (Lustin et al. 2008) as shown in Figure 1.16. Similar LxxLL motif was found to be involved in a target binding as seen in case of transcriptional cofactor proteins that binds to hormone activated nuclear receptor (Heery et al. 1997, Nolte et al. 1998, Shiau et al. 1998). Apart from the conserved residues, there is a solvent exposed hydrophobic patch found on the DREAM surface consisting of residues F100, F114, I117, Y118, F121, F122, Y151 (Lustin et al. 2008) as shown in Figure 1.17 (Left panel). On the opposite surface of the 
exposed hydrophobic patch there are a number of charged residues (K87, K90, K91, K98, K101, R160 and K166) that are not found among other members of this family like recoverin and may be important for DNA-DREAM interactions (Lustin et al. 2008) as shown in Figure 1.17 (Right panel).

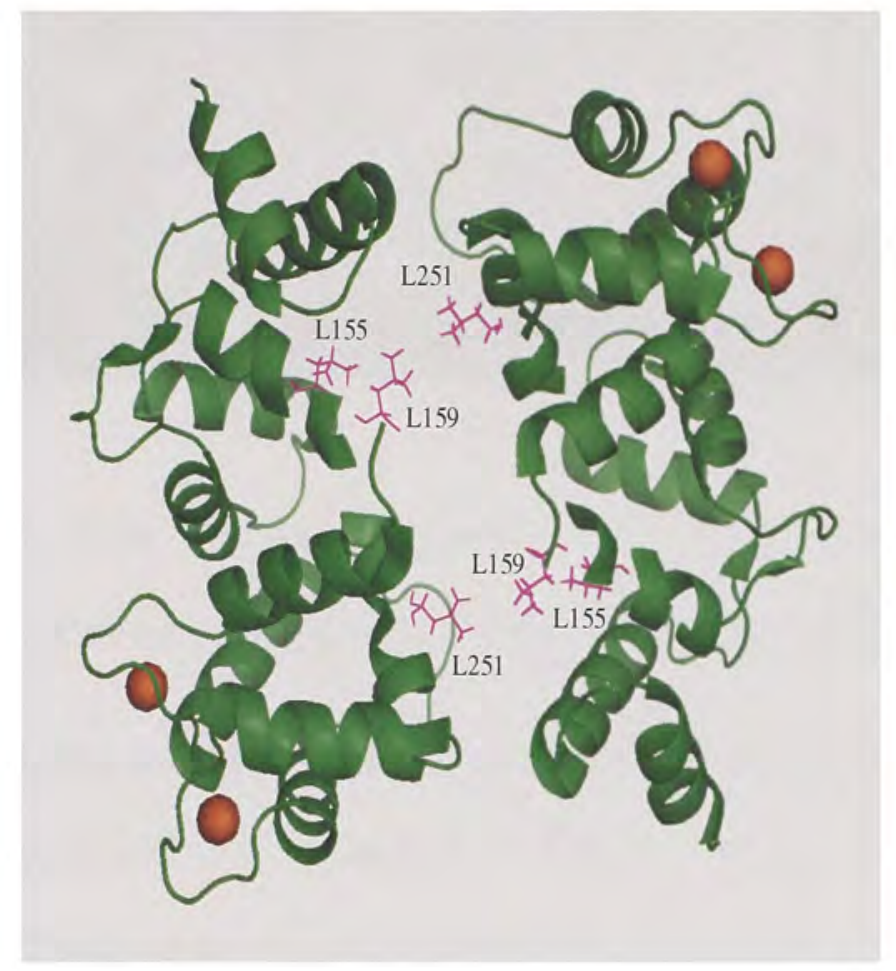

Figure 1.16. Ribbon presentation of the NMR structure of DREAM. Residues proposed to be involved in dimer formation are shown in magenta, $\mathrm{Ca}^{2+}$ ions are shown as orange spheres (PDB code 2JUL). 


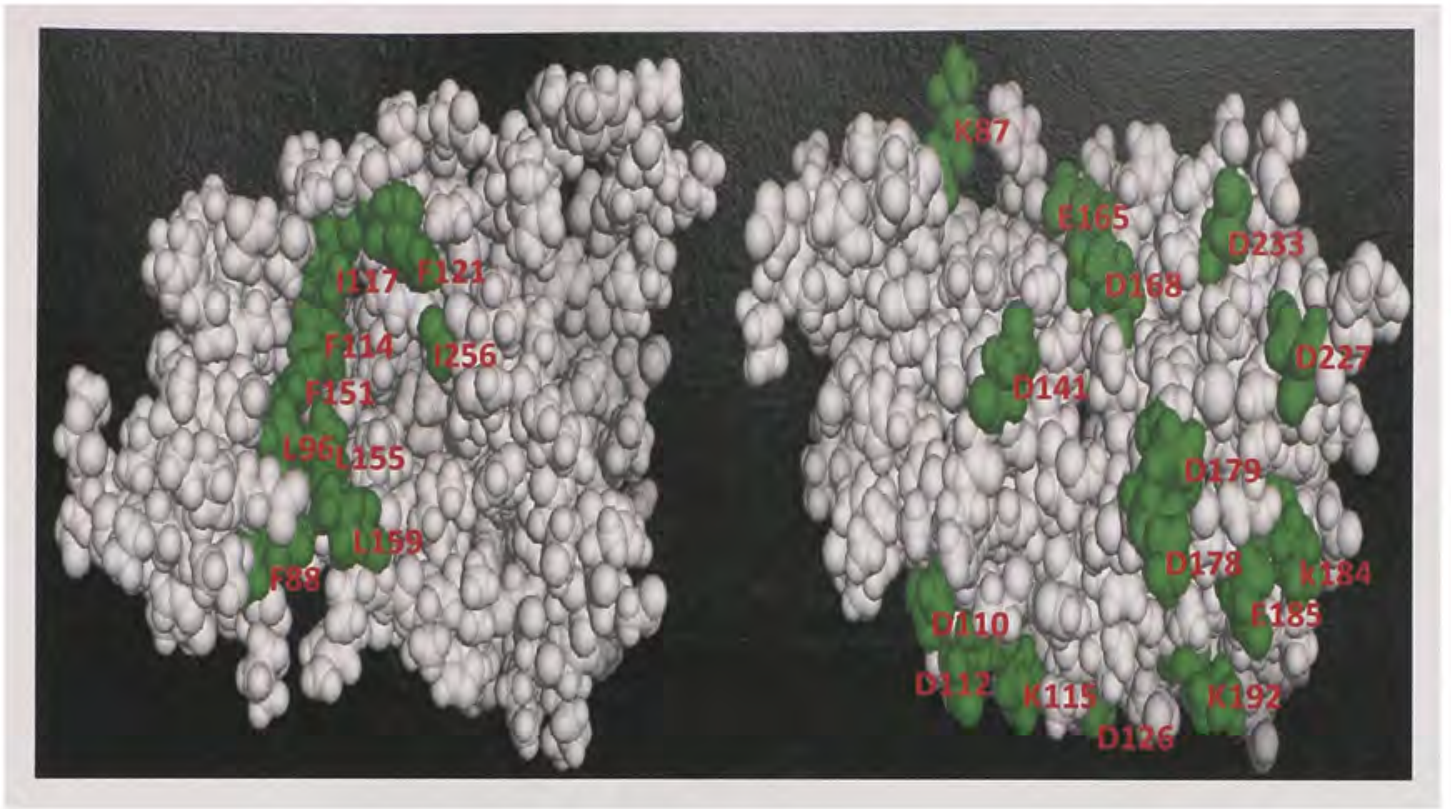

Figure 1.17. Space filling representation of DREAM showing the exposed hydrophobic patch (left panel) and charged residues (right panel) in green (PDB code 2JUL).

\subsubsection{Calcium and magnesium induced conformational changes}

The conformational changes that occur upon $\mathrm{Ca}^{2+}$ binding to DREAM are in terms of change in oligomerization state of DREAM (Osawa et al. 2001). Binding of $\mathrm{Mg}^{2+}$ and $\mathrm{Ca}^{2+}$ decreases the DREAM structural flexibility as seen in NMR and mass spectroscopic studies (Craig et al. 2002, Lusin et al. 2008). DREAM association to DNA may be facilitated through interactions between charged residues situated on the protein surface (Figure 1.17) or by forming a coordinate bond between $\mathrm{Mg}^{2+}$ and phosphoryl oxygens from DNA as seen in case of many other DNA binding proteins (Osawa et al. 2003). Based on the NMR structure of the $\mathrm{Ca}^{2+}$ bound form of DREAM it was proposed that $\mathrm{Ca}^{2+}$ binding may lead to exposure of the hydrophobic residues L155, L158, L159 from the $\mathrm{N}$-terminal domain and L251 from the C-terminal domain that are believed to 
participate in the dimer formation. The exposed hydrophobic residues at the dimer interface might block the charged residues (K87, K90, K91, K98, K101, R160 and K166), that are thought to be involved in DNA binding. (Lusin et al. 2008, Osawa et al. 2003)

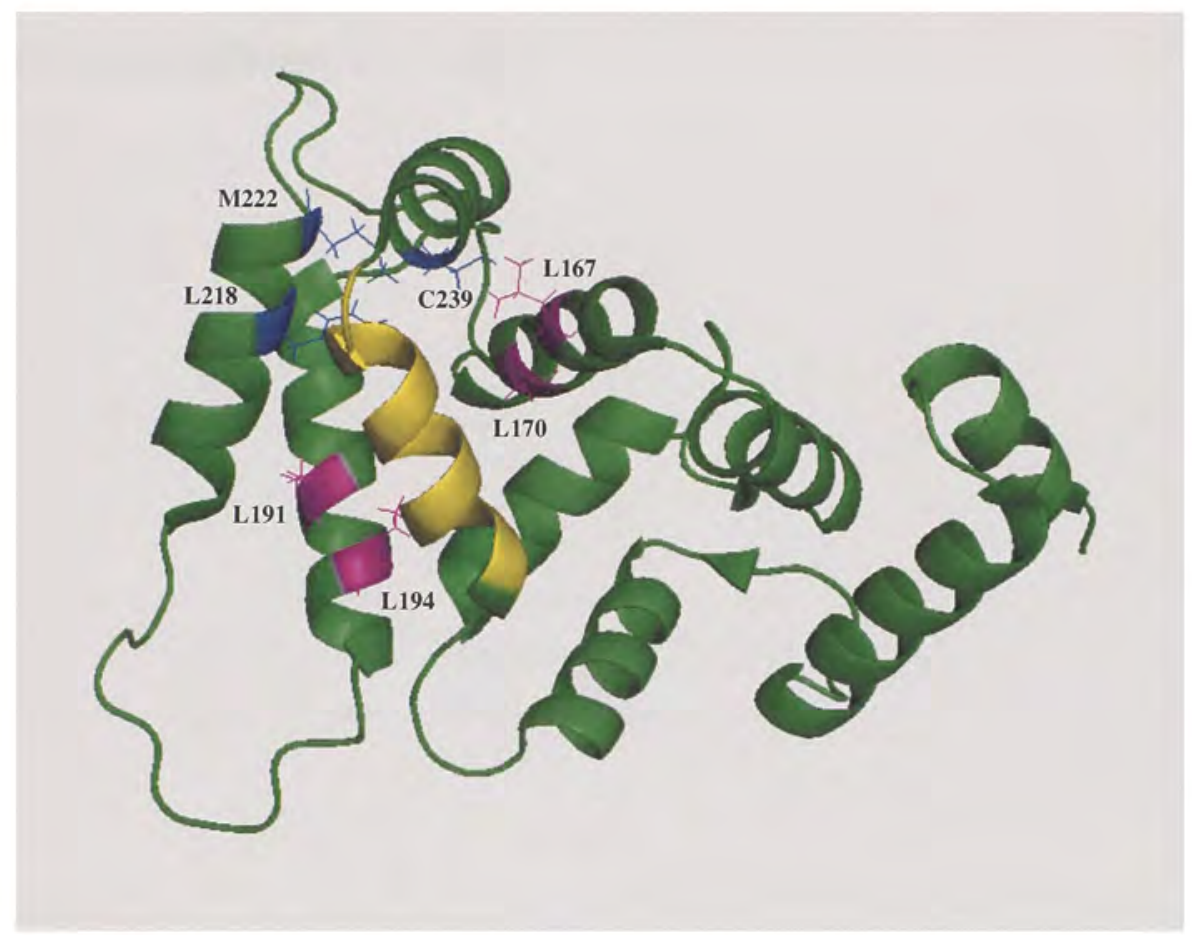

Figure 1.18. NMR structure of DREAM showing the interaction between C-terminal helix and the residues from EF-hand 3 and EF-hand 4. C-terminal helix is shown in yellow, residues from EF-hand 3 are shown in magenta and residues from EF-hand 4 are shown in blue (PDB code 2JUL).

According to an alternative mechanism, the C-terminal helix (243-254) forms hydrophobic contacts with the residues presented in EF-hand 3 (L167, A170, M191 and 
L194) and EF-hand 4 (F218, M222 and C239) as shown in Figure 1.18 (Lusin et al. 2008). Upon $\mathrm{Ca}^{2+}$ binding, the $\mathrm{C}$-terminal helix (residues $243-254$ ) that may interact with EF-hand 3 and 4 in the apo form is likely to be displaced and form hydrophobic contacts with EF-hand 2. The interactions between EF-hand 2 and the C-terminal helix may disrupt the $\mathrm{Mg}^{2+}$ interaction with DNA and thereby promote the DREAM dissociation from DRE sequence (Osawa et al. 2003). 


\subsection{Caged Compounds}

\subsection{Introduction}

Caged compounds are photolabile derivatives of the bioactive molecules of interest that allow for a spatial and temporal control of the bioactive molecule concentration. In a caged compound a bioactive molecule is trapped in an inactive form until the caged compound is irradiated (McCray et al. 1989). The bioactive molecule is then released from the cage what leads to an increase of its solution concentration. A photorelease of caged molecule offers several advantages in terms of targeted release of caged bioactive molecule to initiate the biochemical processes. For example, in kinetic studies of ligand receptor interactions using traditional techniques, delays because of ligand diffusion has been a major problem (Mayer et al. 2006). Using caged compounds the molecule of interest can be caged and photocleaved close to the receptor, limiting the delay as a result of diffusion (Mayer et al. 2006). Caging of molecule of interest may also increase its membrane permeability as seen in case of adenosine $3^{\prime}, 5^{\prime}$-cyclic monophosphate (Giovannardi et al. 1998). Caged compounds also offer an effective way to protect bioactive molecules from metabolic transformation as reported for caged ionositol triphosphate (Nerbonne et al. 2000). As a result, several compounds ranging from protons to small peptides and proteins have been caged including $\mathrm{Ca}^{2+}$, DNA, mRNA, nucleotides, ATP, $\mathbb{P}_{3}$, enzymes, fluorescent compound like fluorescein, neurotransmitters like glutamine, GABA, glycine, aspartic acid, serotonin, and dopamine have been caged (Mayer et al. 2006, Pelliccioli et al. 2002) 
Several conditions have to be fulfilled for successful application of caged compounds. The caged compound as well as its photoproducts should be soluble in aqueous solutions. Photoproducts must have very low affinity for the released bioactive molecule and should be biologically inert. Caged compounds should have a high absorptivity above $300 \mathrm{~nm}$ to prevent the concomitant excitation of other biological species (Givens et al. 2003). The release rate of the caged bioactive molecule should be faster than the kinetics to be studied. The photochemical quantum yield should be reasonably high i.e., at least larger than 0.1 for efficient release of the caged molecule. Finally the synthetic procedure of a caged compound should be relatively simple with a high yield (Pelliccioli et al. 2002).

Caged compounds have been successfully used in several studies. For example, caged $\mathrm{Ca}^{2+}$ compounds like DM-nitrophen and NP-EGTA are widely used to regulate various processes controlled by the change in $\mathrm{Ca}^{2+}$ concentration (Adams et al. 1988). An important application is the study of the impact of membrane depolarization on neurotransmitter release. $\mathrm{Ca}^{2+}$ release from ion channels was blocked using pharmacological agents and the Calcium concentration was raised by uncaging the caged $\mathrm{Ca}^{2+}$ compound thereby causing membrane depolarization. These results showed that membrane potential has no direct role in the neurotransmitter release (Zucker et al, 1988). An alternative pathway for the study of processes activated by $\mathrm{Ca}^{2+}$ is by using caged secondary messengers like inositol triphosphate to trigger the intracellular release of the $\mathrm{Ca}^{2+}$ (Pelliccioli et al. 2002). For example 4, 5-dimethoxy-2-nitrobenzyl ether have been successfully used as ionositol triphosphate cage for the release of $\mathrm{Ca}^{2+}$ in the gene expression studies ( $\mathrm{Li}$ et al. 1998). The other major area of caged compounds application 
is to study fast protein folding reactions since these reactions occur on ns to $\mu$ s time scale and was successfully used in case of a small peptide villin headpiece showing that coilhelix transition occurs on the $400 \mathrm{~ns}$ time scale (Eaton et al. 2000, Hansen et al. 2000). Several caged peptides have been synthesized and used to inhibit activity of target proteins. For example, caged peptides have been used to study the role of $\mathrm{Ca}^{2+}$ bound CaM complex with myosin in the movement of leukocytes using RS-20 cage, a target peptide for CaM binding (Walker et al. 1998, Tatsu et al. 1996).

Fluorescent probes such as fluorescein, resofurin, and rhodamines have been also caged in such a way that caged fluorophores become fluorescent upon irradiation (Jasuja et al. 1999). Caged fluorophores have been applied for visualization and tracking of cellular components (Speccht et al. 2009). Other applications include quantification of the photoreleased substrates. For example caged 8-hydroxypyrene-1, 3, 6-trisulfonic acid was used to quantify the amount of aspartate released from a caged L-aspartate (Jasuja et al. 1999). Other promising area is an application of caged compounds or caged proteins to photo-trigger biological events is the time resolved X-ray studies (Srajer et al. 1996, Specht et al. 2001). Caged DNA can also be used to control the gene expression by the plasmid photo-protection. This approach was found to be successful in the suppression of luciferase expression in rat skin cells (Monroe et al. 1999).

\subsection{Mechanism of photo-dissociation of o-nitrobenzyl compounds}

There are several types of protecting groups available, such as o-nitrobenzyl (2nitrobenzyl), o-alkylated aryl ketones, benzoin group, p-hydroxyphenacyl group, osubstituted methyl phenols, and coumarinyl group (Pelliccioli et al. 2002). Among them 
2-nitrobenzyl group based cages are often used because of their ability to be covalently attached to a wide variety of functional moieties like amines, phosphates, carboxylic acids, alcohols, and nucleotides (McCray et al. 1989). Apart from their ability to carry a variety of substrates, o-nitrobenzyl cages provide several advantages in term of high quantum yield and relatively fast photorelease of caged compound (Nerbonne et al. 1986, Gurney et al. 1987, Kaplan et al. 1993).

The reaction mechanism for the photorelease of the protected moiety from 2-nitrobenzyl compounds have been previously studied using determined IR, time-resolved absorption spectroscopy and computational methods (Cheng et al. 2002, Gaplovsky et al. 2005, Corrie et al. 2003, Schworer et al. 2001, Ill'ichev et al. 2004). The mechanism is shown in Scheme 2.<smiles>CCCc1ccccc1[N+](=O)[O-]</smiles>

a<smiles>[Y][CH+][C@H](C)[C@@H](C)C([R])=O</smiles>

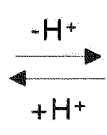

b<smiles>[X]C([2H])(O)c1ccccc1[N+](=O)[O-]</smiles><smiles>[X]C([R])=C1C=CC=CC1=[N+]([CH])[O-]</smiles><smiles></smiles><smiles>[R]C([X])=C1C=CC=CC1=[N+]([O-])O</smiles><smiles>[X]C1([2H])ON(O)c2ccccc21</smiles>

Scheme 2:

The initial step in the reaction mechanism is the rapid transfer of a proton from benzylic

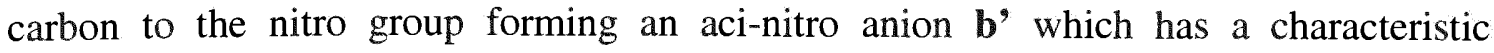


absorption spectrum between $400-440 \mathrm{~nm}$. The aci-nitro anion is found to be in the equilibrium with its protonated form $\mathbf{b}$ and decays to form a cyclic benzisoxazolidine $\mathbf{c}$. The benzisoxazolidine than decays into a hemiacetal intermediate $\mathbf{d}$ that subsequently undergoes a hydrolysis to form a 2-nitroso benzaldehyde product $\mathbf{e}$ by releasing the caged species $\mathbf{X}$. The decay of the aci-nitro anion can be easily monitored by time resolved absorption spectroscopy by following the absorption change in the range between 400 $440 \mathrm{~nm}$ (Wieboldt et al. 2002). Previous studies indicated that the decay of aci-nitro intermediate depends on the type of cage and as well as the nature of leaving group (Corrie et al. 2005, Schwore et al. 2001, Il'Ichev et al. 2004). For example, the release of the proton from nitrobenzaldehyde occurs on a nanosecond time scale whereas the release of alcohol group from caged alcohols happens on the millisecond time scales (Abbruzzetti et al. 2003, George et al. 1980, Morrison et al. 1965). It was shown that the rate constant for each step in the reaction mechanism depends on the $\mathrm{pH}$, solvent, and the nature of the leaving group (Corrie et al. 2003, Schworer et al. 2001, Ill'ichev et al. 2004). For example, in case of caged ATP, the aci-nitro intermediates decays with the rate constant of $86 \mathrm{~s}^{-1}$ with concomitant release of ATP. On the other hand, methanol release from 2-nitrobenzyl methyl ethers occurs with the rate of $2.5 \times 10^{-2} \mathrm{~s}^{-1}$ that is significantly slower than the decay of aci-nitro intermediates (Ill'ichev et al. 2004). In case of DM-nitrophen the decay of aci-nitro intermediates is found to be biphasic with a rate constant of $8.0 \times 10^{3} \mathrm{~s}^{-1}$ and $11 \times 10^{3} \mathrm{~s}^{-1}$ (Ayer et al. 1999). 


\subsection{Caged calcium compounds}

Among the caged compounds, $\mathrm{Ca}^{2+}$ cages are widely used in various physiological studies. A number of $\mathrm{Ca}^{2+}$ cages have been developed with either EDTA or EGTA as their parent chelators. Among them, DM-nitrophen, nitr-5, NP-EGTA are important cages whose affinity for $\mathrm{Ca}^{2+}$ changes more than 1000 times upon photolysis (Ellis-Davis et al. 2008). Nitro-phenyl-EGTA has a higher selectivity for $\mathrm{Ca}^{2+}$ than for $\mathrm{Mg}^{2+}$. However, it is not widely used as its affinity for $\mathrm{Ca}^{2+}$ is highly $\mathrm{pH}$ dependent (Adams et al. 1988). The other disadvantage of using NP-EGTA is its relatively high $\mathrm{K}_{\mathrm{d}}$ compared to DM-nitrophen which is about $80 \mathrm{nM}$ (Nerbonne et al. 1996). The $\mathrm{K}_{\mathrm{d}}$ value of NPEGTA indicates that only $50 \%$ of the chelator is saturated at the physiological $\mathrm{Ca}^{2+}$ concentrations $(100 \mathrm{nM})$ and hence a fraction of $\mathrm{Ca}^{2+}$ released upon photolysis rebinds to the free unphotolysed chelator, instead of binding to the target proteins. On the other hand, DM-nitrophen has a very low $K_{d}$ of about $4 \mathrm{nM}$ and thus DM-nitrophen is completely saturated at the physiological $\mathrm{Ca}^{2+}$ concentrations. The main disadvantage of using DM-nitrophen is that it is not highly selective for $\mathrm{Ca}^{2+}$ (Nerbonne et al. 1996). Apart from NP-EGTA and DM-nitrophen, which are widely used and commercially available, other $\mathrm{Ca}^{2+}$ cages were synthesized and characterized including nitr-5, nitr-7, DMNPE-4, nitr-2, NDBF-EGTA (Ellis-Davies et al. 2008). The usage of nitr-5, nitr-7, and nitr-2 is limited because of their high $\mathrm{K}_{\mathrm{d}}$ which is in the range of $100 \mathrm{nM}$ and the affinity of photoproducts for $\mathrm{Ca}^{2+}$ is only about 40 times lower compared to the unphotolysed cage (Hassoni et al. 1994, Van-Koeveringe et al. 1994). General properties of commonly used $\mathrm{Ca}^{2+}$ cages are summarized in the Table 2.1 (Ellis-Davis et al. 2008) and the structure of DM-nitrophen, NP-EGTA and nitr-2 is shown in Figure 2.1. Unlike 
other caged compounds, affinity of diazo- 2 for $\mathrm{Ca}^{2+}$ increases about 30-40 times upon photolysis i.e. it has a $\mathrm{K}_{\mathrm{d}}$ about $2.2 \mu \mathrm{M}$ before illumination whereas photoproducts formed has a significantly lower $\mathrm{K}_{\mathrm{d}} \sim 80 \mathrm{nM}$ (Adams et al. 1993). This compound has been successfully used in studies of muscle relaxation (Ashley et al. 1991).

Table 2.1. Properties of the commonly available caged $\mathrm{Ca}^{2+}$ compounds.

\begin{tabular}{|c|c|c|c|c|c|c|c|c|}
\hline & 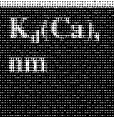 & 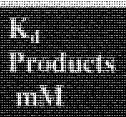 & 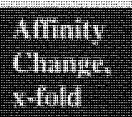 & 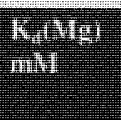 & 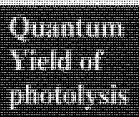 & 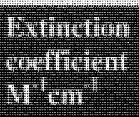 & 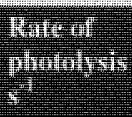 & 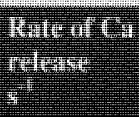 \\
\hline DM-Nitrophen & 5 & 3 & from (n) & 0,0025 & 11.18 & 4,300 & $8 \times 10^{3}$ & $33 \times 10^{4}$ \\
\hline NP-ECTIA & 80 & 1 & 12,500 & 9 & 023 & 975 & $5 \times 10^{3}$ & $6.3 \times 1 n^{b}$ \\
\hline DMWHE & 48 & 2 & 41,700 & 10 & now & 5,120 & $3.3 \times 10^{4}$ & $45 \times 10^{4}$ \\
\hline NDBH-EGTA & 100 & 2 & 20,000 & 15 & 0.7 & 18.400 & $26 \times 10$ & $20 \times 10^{\circ}$ \\
\hline BAYTA & 110 & & 17 & & & & & \\
\hline Nitis & 145 & 000os & 54 & 8.5 & 0.012 & 5,500 & $25 \times 10^{3}$ & \\
\hline Nitt 7 & 54 & 0.12 & 42 & 5.4 & b.jn! 1 & 5,50 & $2.5 \times 10^{3}$ & \\
\hline
\end{tabular}


<smiles>COc1cc(C(CN(C)C)N(C)C)c([N+](=O)[O-])cc1OC</smiles>

DM-nitrophen

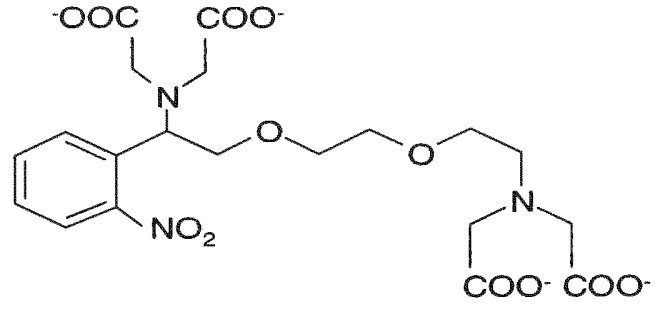

NP-EGTA<smiles>COC(c1ccc(C(CC(=O)[O-])CC(=O)O)c(OCCOc2cc(C)ccc2C(CC(=O)O)CC(=O)O)c1)c1cc2c(cc1[N+](=O)[O-])OCO2</smiles>

Figure 2.1. Structures of commonly used o-nirobenzyl $\mathrm{Ca}^{2+}$ cages. 


\subsection{Aim of the study}

\subsection{Specific Aim 1}

To construct the thermodynamic profile associated with photorelease of $\mathrm{Ca} 2+$ from $\mathrm{DM}$ nitrophen and its binding to $\mathrm{CaM}$.

Previous studies on $\mathrm{Ca}^{2+}$ binding to $\mathrm{CaM}$ have showed that upon $\mathrm{Ca}^{2+}$ binding a hydrophobic patch is exposed on the protein surface as a result of $\mathrm{Ca}^{2+}$ induced conformational changes, thereby enabling the protein to activate target proteins. To date, the majority of the biochemical and biophysical studies have been focused on understanding the equilibrium properties of the apo and $\mathrm{Ca}^{2+}$ bound forms of $\mathrm{CaM}$, including $\mathrm{Ca}^{2+}$ and $\mathrm{Mg}^{2+}$ affinity constants, the structure of the apo and $\mathrm{Ca}^{2+}$ bound $\mathrm{CaM}$ and $\mathrm{Ca}^{2+}$ induced conformational changes. It was also proposed that $\mathrm{Ca}^{2+}$ binding to $\mathrm{CaM}$ is a two step reaction which includes $\mathrm{Ca}^{2+}$ binding to the $\mathrm{C}$-terminal domain followed by binding to the $\mathrm{N}$-terminal domain (Gifford et al. 2007). Significantly less is known about the kinetics of $\mathrm{Ca}^{2+}$ binding and time-resolved energetics of conformational changes associated with $\mathrm{Ca}^{2+}$ binding to calmodulin. Recent studies by Parker et al. (2008) and Tjandra et al. (1995) showed that the kinetics of conformational changes induced by $\mathrm{Ca}^{2+}$ binding to the $\mathrm{C}$-terminal domain occur with a $\tau \sim 490 \mu$ s whereas to the $\mathrm{N}$-terminal domain is slower with $\tau \sim 20 \mathrm{~ms}$. Since CaM possesses a single internal fluorophore, tyrosine, the number of spectroscopic techniques that can be used to monitor the time profiles of $\mathrm{Ca}^{2+}$ induced conformational changes in this protein is limited. More importantly, mixing techniques like stopped-flow, probe kinetics occurr on a longer time scale ( $>1 \mathrm{~ms}$ ) and thus do not provide information about structural changes occurring on sub-millisecond time scales. Hence, I took advantage of caged $\mathrm{Ca}^{2+}$ compound DM- 
nitrophen in combination with photothermal beam deflection to determine the volume and enthalpy changes associated with $\mathrm{Ca}^{2+}$ binding to $\mathrm{CaM}$. Since the overall volume and enthalpy changes are determined in photothermal measurements this approach allows one to evaluate conformational changes in the absence of intrinsic or extrinsic fluorophore. The proposed model for $\mathrm{Ca}^{2+}$ binding to CaM is shown in Scheme 3 .

$$
\mathrm{Ca}^{2+}-\mathrm{DM} \text {-nitrophen }+ \text { apo-CaM } \stackrel{\mathrm{h} v}{\longrightarrow}\left(\mathrm{Ca}^{2+}\right)_{2}-\mathrm{CaM}+(\mathrm{DM}-\text { nitrophen })_{\mathrm{pp}} \longrightarrow\left(\mathrm{Ca}^{2+}\right)_{4}-\mathrm{CaM}
$$

\section{Scheme 3:}

According to this model, photolysis of $\mathrm{Ca}^{2+}-\mathrm{DM}$-nitrophen leads to $\mathrm{Ca}^{2+}$ released into the solution and then $\mathrm{Ca}^{2+}$ preferentially binds to $\mathrm{CaM}$, as the affinity of the DMnitrophen photoproducts (DM-nitrophen ${ }_{\mathrm{pp}}$ ) for $\mathrm{Ca}^{2+}$ is smaller than that of $\mathrm{CaM}$. Initially, the released $\mathrm{Ca}^{2+}$ binds to the $\mathrm{C}$-terminal domain forming $\left(\mathrm{Ca}^{2+}\right)_{2}-\mathrm{CaM}$, and reaction is completed upon $\mathrm{Ca}^{2+}$ binding to the $\mathrm{N}$-terminal domain forming $\left(\mathrm{Ca}^{2+}\right)_{4}-\mathrm{CaM}$. Though measurements of the volume changes in proteins are relatively unusual they provide valuable information in terms of quantification of ligand induced conformational changes, since the volume change represents the overall change in the molecular structure. As DM-nitrophen forms part of our sample along with the protein, as shown in Scheme 3, the thermodynamic parameters for the photodissociation of DM-nitrophen, DM-nitrophen saturated with $\mathrm{Ca}^{2+}$ and $\mathrm{DM}$-nitrophen saturated with $\mathrm{Mg}^{2+}$ were also determined. The data obtained from specific aim 1 provide information about the kinetics as well as the energetics associated with $\mathrm{Ca}^{2+}$ induced conformational changes in $\mathrm{CaM}$. 


\subsection{Specific Aim 2}

To probe the conformational dynamics coupled with $\mathrm{Ca}^{2+} / \mathrm{Mg}^{2+}$ binding to DREAM.

Down stream Regulatory Antagonist Modulator (DREAM) is a member of a newly discovered NCS family that is found predominantly in neuronal cells. The fact that DREAM directly regulates expression of numerous genes in $\mathrm{Ca}^{2+}$ dependent manner, makes it a unique model for understanding the mechanism of EF-hand proteins interaction with DNA. However, little is known about $\mathrm{Ca}^{2+} / \mathrm{Mg}^{2+}$ interaction with DREAM mainly because of the absence of the 3D structure of apo and DNA bound protein. Also, the kinetic data on $\mathrm{Ca}^{2+}$ interactions with DREAM are scarce. With this in mind, I isolated and purified DREAM-C and investigated structural changes associated with $\mathrm{Ca}^{2+} / \mathrm{Mg}^{2+}$ binding to DREAM using steady-state and time-resolved fluorescence spectroscopic techniques. I hypothesize that the ligand induced alteration in the DREAM equilibrium dynamics leads to the change in the affinity between individual DREAM monomers. The present study will take advantage of a single tryptophan residue 169 , found in the sequence of DREAM. Tryptophan 169 is a part of the conserved hydrophobic surface located between the EF-hands 2 and 3. Thus, monitoring the fluorescence properties of Trp residue will allow one to probe conformational changes within the interface of the $\mathrm{C}$ and $\mathrm{N}$-terminal domain of DREAM. Moreover $\mathrm{Ca}^{2+}$ induced changes in the hydrophobic surface of DREAM will be probed using fluorophores 2,6ANS, 1,8-ANS and nile red that selectively bind to hydrophobic surfaces on protein. 


\subsection{Materials and Methods}

\subsection{Isolation of calmodulin}

Calmodulin was isolated and purified according to the procedure described previously by Hayashi et al. 1998. E. coli (BL21) containing CaM plasmid (donated by Dr. J. P. Davis, Ohio State University) was grown on LB agar medium (15 g of agar per one litre of LB medium) with $100 \mu \mathrm{g} \mathrm{mL}-1$ of ampicillin for $12-14$ hours at $37^{\circ} \mathrm{C}$. The composition of LB medium is shown in Table 4.1. Single colonies were isolated and used to inoculate one litre of LB medium containing $100 \mu \mathrm{g} \mathrm{mL}^{-1}$ of ampicillin.

Table 4.1. Composition of LB medium per liter

\begin{tabular}{|l|c|}
\hline \multicolumn{1}{|c|}{ Component } & Amount $(\mathrm{g}) / \mathrm{L}$ \\
\hline Tryptone & 10 \\
Yeast extract & 5 \\
$\mathrm{NaCl}$ & 10 \\
$\mathrm{pH}=7.0$ & \\
\hline
\end{tabular}

Upon inoculation, cells were grown at $37^{\circ} \mathrm{C}$ and $250 \mathrm{rpm}\left(\mathrm{Max}^{\mathrm{Q}} 4000\right.$, Barnstead International) until the absorbance reached an O.D. between $0.6-0.8$ at $600 \mathrm{~nm}$. Subsequently, CaM expression was induced by adding $0.4 \mathrm{mM}$ isopropyl $\beta-\mathrm{D}-1$ galactothiopyranoside (IPTG), and the cells were grown for an additional 3-4 hours. Cells were then harvested by centrifugation for 15 minutes at $8000 \mathrm{rpm}$ at $10^{\circ} \mathrm{C}$ (Allegra ${ }^{\mathrm{TM}}$ 64R centrifuge, Beckman Coulter). Collected cells were resusupended in $35 \mathrm{~mL}$ of 
resuspension buffer per one litre of the LB medium used. The composition of the resusupension buffer was $50 \mathrm{mM}$ Tris, $\mathrm{pH}=7.5,1 \mathrm{mM}$ DTT, $1 \mathrm{mM}$ PMSF, $2 \mathrm{mM}$ EDTA. Resusupended cells were placed on ice and sonicated using a sonic dismembrator (Fischer Scientific, Model 100) for $30 \times 30$ seconds with a maximum output of 10 . The solution was centrifuged at $11000 \mathrm{rpm}$ for 30 minutes (Allegra ${ }^{\mathrm{TM}} 64 \mathrm{R}$ centrifuge, Beckman Coulter) and the resulting supernatant was collected. 27 grams of ammonium persulfate was slowly added to the supernatant upon continuous stirring at $4{ }^{\circ} \mathrm{C}$ to obtain $45 \%$ saturation. The resulting solution was centrifuged for 30 minutes at $11500 \mathrm{rpm}$ and $4{ }^{\circ} \mathrm{C}$ (Allegra ${ }^{\mathrm{TM}}$ 64R centrifuge, Beckman Coulter) and the supernatant was collected. Susequently, $5 \mathrm{mM} \mathrm{CaCl}_{2}$ was added to the supernatant and the supernatant was loaded on a phenylsepharose CL-4B column ( $15 \mathrm{~mL}$ of resin per one litre of $\mathrm{LB}$ medium, GE Healthcare) which was pre-equilibrated with a wash buffer A (50 mM Tris, $\mathrm{pH} 7.5,500$ $\mu \mathrm{M} \mathrm{CaCl}_{2}$ and $1 \mathrm{mM}$ DTT). The column was then washed with wash buffer A until the absorbance at $280 \mathrm{~nm}$ decreased to below 0.03 . Subsequently, the column was washed with wash buffer B (50 mM Tris, pH 7.5, $500 \mu \mathrm{M} \mathrm{CaCl}_{2}, 1 \mathrm{mM}$ DTT, $0.5 \mathrm{M} \mathrm{NaCl}$ ) until the absorbance of the eluent at $280 \mathrm{~nm}$ was less than 0.01 . Finally, the protein was eluted using elution buffer (50 mM Tris, $\mathrm{pH} 7.5,5 \mathrm{mM}$ EDTA, $0.15 \mathrm{M} \mathrm{NaCl}$ and $1 \mathrm{mM}$ DTT) and $2 \mathrm{~mL}$ fractions of elute were collected. The concentration of $\mathrm{CaM}$ in the collected fractions was determined using an extinction coefficient of $3300 \mathrm{M}^{-1} \mathrm{~cm}^{-1}$ at $280 \mathrm{~nm}$ (Hayashi et al. 1998) and the protein purity was checked using 15\% SDS-PAGE electrophoresis, as described below. 


\subsection{Isolation of DREAM}

Down stream Regulatory Antagonist Modulator (DREAM) was isolated according to the procedure described previously by Lusin et al. (Lusin et al. 2008). The plasmid containing the gene for DREAM (Omics Link expression clone, T7 promoter) with Cterminal His-tag (6 histidine residues) was purchased from Genecoepia and transformed into E. coli strain BL21 DE3 (Stratagene) through electroporation (Bio-Rad, MicroPulser $\left.{ }^{\mathrm{TM}}\right)$. For electroporation, $1 \mu \mathrm{L}$ of DNA was added to $40 \mu \mathrm{L}$ of competent cells and subjected to an electric pulse of $1.8 \mathrm{kV}$ for $5 \mathrm{~ms}$. Transformed cells were grown on LB agar medium with $100 \mu \mathrm{g} \mathrm{mL} \mathrm{m}^{-1}$ of ampicillin for $12-14$ hours at $37{ }^{\circ} \mathrm{C}$. Single colonies were isolated and used to inoculate one litre of $\mathrm{LB}$ medium ( $\mathrm{pH}=7.0$ ) containing $100 \mu \mathrm{g} \mathrm{mL}^{-1}$ of ampicillin. Cells were grown at $37{ }^{\circ} \mathrm{C}$ and $250 \mathrm{rpm}$ on a shaker $\left(\operatorname{Max}^{\mathrm{Q}} 4000\right.$, Barnstead International) until the absorbance at $600 \mathrm{~nm}$ reaches an O.D. between 0.6-0.8. Protein expression was induced by the addition of $0.7 \mathrm{mM}$ IPTG and cells were grown for an additional 3-4 hours. Cells were then collected by centrifugation at $8000 \mathrm{rpm}$ at $4{ }^{\circ} \mathrm{C}$ for 15 minutes (Allegra ${ }^{\mathrm{TM}} 64 \mathrm{R}$ centrifuge, Beckman Coulter) and then resuspended in a lysis buffer $(20 \mathrm{mM}$ Tris- $\mathrm{HCl}, \mathrm{pH} 8.0,0.3 \mathrm{M} \mathrm{NaCl}, 1$ $\mathrm{mM} \beta$-mercaptoethanol and $20 \%$ glycerol, $1 \mathrm{mM}$ PMSF, $0.2 \%$ Tween 20 and $1 \mathrm{mM}$ $\mathrm{MgCl}_{2}$ ). Suspended cells were placed on ice and disrupted using a sonic dismembrator (Fischer Scientific, Model 100) for $30 \times 30$ seconds and the resulting solution was centrifuged for 30 minutes at $10000 \mathrm{rpm}$ and $4{ }^{\circ} \mathrm{C}$ (Allegra ${ }^{\mathrm{TM}} 64 \mathrm{R}$ centrifuge, Beckman Coulter). The resulting supernatant was loaded onto a Ni-NTA agarose column (5 PRIME GmbH) which was equilibrated with wash buffer A (20 mM Tris-HCl, pH 8.0, $0.3 \mathrm{M} \mathrm{NaCl}, 1 \mathrm{mM} \beta$-mercaptoethanol and $20 \%$ glycerol). The column was washed with 
a buffer A containing $10 \mathrm{mM}$ imidazole until the absorbance of the eluent decreased below 0.03 at $280 \mathrm{~nm}$ and then was washed with buffer A containing $25 \mathrm{mM}$ imidazole until the absorbance of the eluent was below 0.01 at $280 \mathrm{~nm}$.

The protein was finally eluted with wash buffer A containing $150 \mathrm{mM}$ imidazole and 2 $\mathrm{mL}$ fractions of the eluent were collected and dialyzed against dialysing buffer $(10 \mathrm{mM}$ Tris-HCl, pH 7.4, 1 mM EDTA, 1 mM DTT, 10 mM laurydimethylsulfoxide (LDAO)) for 24 hours to remove the excess of imidazole. DREAM concentration was determined using an extinction coefficient of $25 \times 10^{3} \mathrm{M}^{-1} \mathrm{~cm}^{-1}$ at $280 \mathrm{~nm}$ (Lusin et al. 2008) and the protein purity was probed using $15 \%$ SDS gel electrophoresis.

\subsection{SDS-PAGE Electrophoresis}

Electrophoresis was performed according to the procedure described by Laemmli et al. (1970). Resolving gel and stacking gel containing $15 \%$ and 5\% acrylamide, respectively, were prepared by adding the required amount of acrylamide from a stock solution containing $30 \%$ acrylamide and $0.8 \% \mathrm{~N}, \mathrm{~N}$ '-bis-methylene acrylamide by weight. The composition of the resolving gel and stacking gel are shown Table 4.2 and 4.3. 
Table 4.2. Composition of the resolving gel

\begin{tabular}{|l|c|}
\hline Components & Amount \\
\hline Acrylamide & $15 \%$ \\
\hline Tris- $\mathrm{HCl}(\mathrm{pH}=8.80)$ & $1.5 \mathrm{M}$ \\
\hline $\mathrm{SDS}$ & $10 \%$ \\
\hline Ammonium persulfate & $10 \%$ \\
\hline Tetramethylethylenediamine & $0.04 \%$ \\
\hline
\end{tabular}

Table 4.3. Composition of stacking gel

\begin{tabular}{|l|c|}
\hline Components & Amount \\
\hline Acrylamide & $5 \%$ \\
\hline Tris- $\mathrm{HCl}(\mathrm{pH}=6.80)$ & $0.5 \mathrm{M}$ \\
\hline SDS & $10 \%$ \\
\hline Ammonium persulfate & $10 \%$ \\
\hline Tetramethylethylenediamine & $0.04 \%$ \\
\hline
\end{tabular}

Gel polymerization was initiated by addition of freshly prepared $10 \%$ ammonium persulfate and $0.04 \%$ tetramethylethylenediamine by volume. Gels were prepared on 10 $\mathrm{cm}$ glass plates using a SE 600 vertical slab unit (GE Healthcare). The running buffer used contained $0.025 \mathrm{M}$ Tris, $\mathrm{pH} 8.3,0.192 \mathrm{M}$ glycine and 0.1\% SDS. Protein samples of desired concentrations were prepared in a sample buffer $(0.125 \mathrm{M}$ Tris- $\mathrm{HCl}, \mathrm{pH} 6.8,4$ $\%$ SDS, $20 \%$ glycerol, $0.02 \%$ bromophenol blue and $0.2 \mathrm{M} \mathrm{DTT})$. Before loading on the 
gel, samples were heated in boiling water for $3 \mathrm{~min}$. Electrophoresis was carried out at a constant voltage of $120 \mathrm{~V}$ with varying current using a power supply (Model FB300, Fischer Scientific) until the protein samples reached the bottom of the gel. Gels were then removed from the glass plates and stained overnight using a staining solution $(0.1 \%$ comassie blue R-350, $10 \%$ acetic acid and $20 \%$ methanol). Finally, the gels were then destained using a destaining solution (10\% acetic acid and $50 \%$ methanol in water).

\subsection{Steady state fluorescence spectroscopy}

\subsubsection{Sample preparation}

Steady state fluorescence emission spectra and polarization data were recorded using a PC1 fluorimeter (ISS, Illinois) by using an excitation wavelength of $295 \mathrm{~nm}$. For REES (Red Edge Excitation Shift) measurements the excitation wavelength was varied from 280 to $300 \mathrm{~nm}$. The apo and $\mathrm{Ca}^{2+}$ bound DREAM samples were prepared by dissolving DREAM stock solution in $20 \mathrm{mM}$ Tris buffer, $\mathrm{pH} 7.4,10 \mathrm{mM}$ LDAO, $1 \mathrm{mM}$ DTT and adding $1 \mathrm{mM}$ EDTA to the apo and $1 \mathrm{mM} \mathrm{CaCl}_{2}$ to the $\mathrm{Ca}^{2+}$ bound sample respectively. To prepare $\mathrm{Mg}^{2+}$-DREAM, $3 \mathrm{mM} \mathrm{MgCl} 2$ was added to DREAM in the presence of $1 \mathrm{mM}$ EGTA. In the measurements which used hydrophobic surface probing agents, $10 \mu \mathrm{M}$ DREAM was placed in $20 \mathrm{mM}$ Tris- $\mathrm{HCl}$ buffer, $\mathrm{pH} 7.4,1 \mathrm{mM}$ DTT, $1 \mathrm{mM}$ EDTA or 1 $\mathrm{mM} \mathrm{CaCl}_{2}$ and was incubated with $1 \mu \mathrm{M}$ probe (1,8- ANS, 2,6-ANS, or nile red) for 30 minutes at room temperature before the emission spectra were performed. The wavelengths used for the excitation of 1,8-ANS, 2,6-ANS and nile red were 350,385 and $552 \mathrm{~nm}$ respectively. 


\subsection{Frequency domain fluorescence spectroscopy}

\subsubsection{Theory}

The fluorescence lifetime measurements provide information about structural fluctuations and conformational heterogeneity in the proteins, since changes in the fluorescence lifetimes reflect structural perturbation in the vicinity of the intrinsic or extrinsic fluorophore (Ross et al. 2008). Fluorescence decay lifetimes are usually in the range of picoseconds to a few nanoseconds and can be measured using either a time-domain or frequency-domain fluorimeter. In time-domain measurements, the fluorescent molecule is excited with a picosecond pulse and the resulting emission intensity is measured as a function of time (Berezin et al. 2010). On the other hand, in frequency domain measurements the fluorescent probe is excited with a sinusoidally modulated high frequency $(\omega)$ light. As a result, the emitted light is phase shifted $(\Phi)$ with respect to the excitation light and its amplitude is modulated as shown in Figure 4.1. (Ross et al. 2008) 


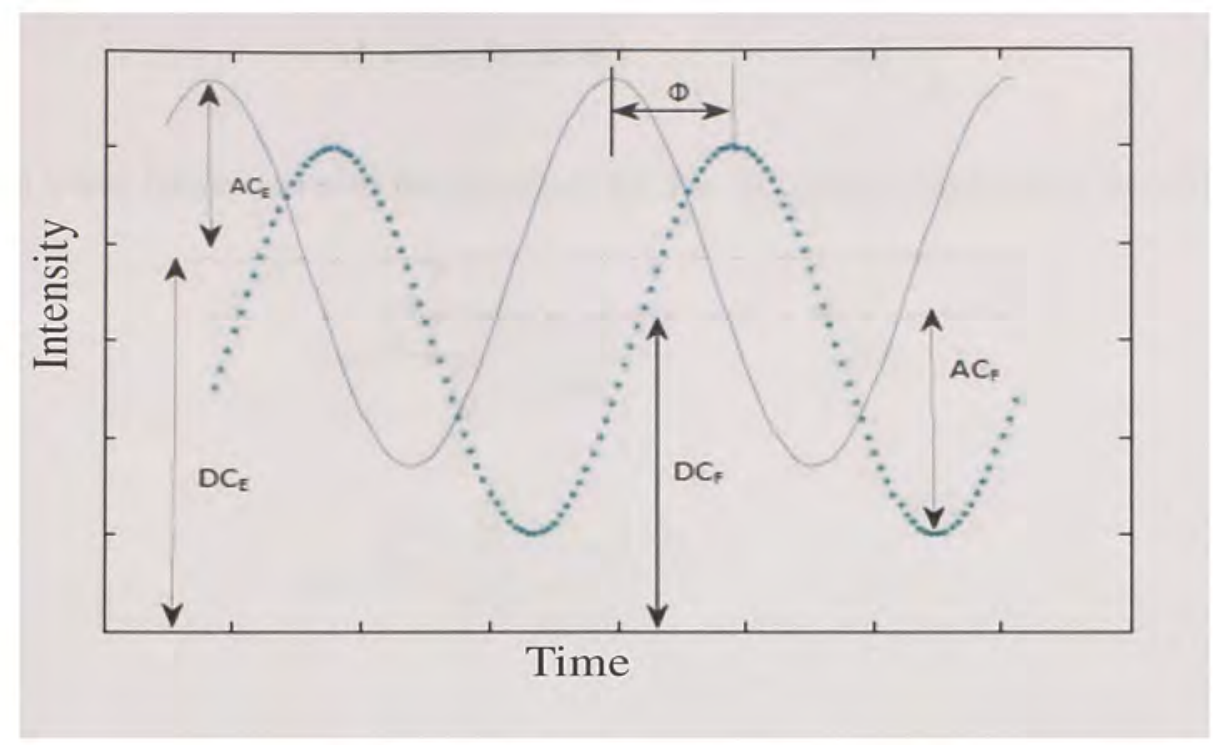

Figure 4.1. Solid line represents the excitation light. Dotted line represents the emitted light with a phase shift and modulation amplitude. AC and DC denotes the amplitudes of the sine wave, where as the subscripts $\mathrm{E}$ and $\mathrm{F}$ represents excited and emitted light respectively. Modified from Ross et al. 2008

For a fluorophore with a single lifetime, the lifetime can be determined directly from a phase shift (Ф) according to Equation 2 (Ross et al. 2002)

$$
\tau=\tan (\Phi / \omega)
$$

The lifetime can also be obtained from the relative modulation values (M) of the excitation and emission light by using the Equations 3-6.

$$
\begin{aligned}
& \mathrm{M}_{\mathrm{E}}=\left(\mathrm{AC}_{\mathrm{E}}\right) /\left(\mathrm{DC}_{\mathrm{E}}\right) \\
& \mathrm{M}_{\mathrm{F}}=\left(\mathrm{AC}_{\mathrm{F}}\right) /\left(\mathrm{DC}_{\mathrm{F}}\right) \\
& \mathrm{M}=\mathrm{M}_{\mathrm{F}} / \mathrm{M}_{\mathrm{E}}
\end{aligned}
$$




$$
\mathrm{M}=1 /\left(1+\omega^{2} \tau^{2}\right)
$$

The wave forms can also be described by the following Equations 7 and 8

$$
\begin{aligned}
& \mathrm{S}=\frac{\int_{0}^{\infty} I(t) \sin \omega t d t}{\int_{0}^{\infty} I(t) d t} \\
& \mathrm{G}=\frac{\int_{0}^{\infty} I(t) \cos \omega t d t}{\int_{0}^{\infty} I(t) d t}
\end{aligned}
$$

where $\mathrm{I}(\mathrm{t})$ is the impulse response function at any time $t . S$ and $\mathrm{G}$ are the sin and cosine transforms of the impulse response function respectively and $\omega$ is the frequency.

In order to characterize the process with multi-exponential decay, the excited light was modulated over a wide range of frequencies and the corresponding phase shift and modulation ratios were measured. For a multi-exponential decay the above transforms can be written as

$$
\begin{aligned}
\mathrm{S} . \mathrm{J} & =\sum_{i=1}^{n} \frac{\alpha_{i} \omega \tau_{i}^{2}}{1+\omega^{2} \tau_{i}^{2}} \\
\mathrm{G} . \mathrm{J} & =\sum_{i}^{n} \frac{\alpha_{i} \tau_{i}}{1+\omega^{2} \tau_{i}^{2}}
\end{aligned}
$$

where $\alpha_{i}$ represents the pre-exponential factors, $\tau_{i}$ represents individual lifetimes and $\mathbf{J}=$ $\sum_{i} \alpha_{i} \tau_{i}$. The phase delay and modulation ratios can be calculated using Equations 11 and 12

$$
\Phi=\tan ^{-1}(\mathrm{~S} / \mathrm{G})
$$




$$
M=\left(S^{2}+G^{2}\right)
$$

The resulting data can be fitted using non linear least square fitting procedure to obtain the lifetimes and the corresponding pre-exponential factors.

\subsubsection{Sample preparation}

Frequency domain fluorescence measurements were carried out using Chronos FD fluorometer (ISS, Champaign, Illinois). A $280 \mathrm{~nm}$ LED was used as an excitation source for Trp excitation. The light source was modulated in the frequency range of 20 to 250 $\mathrm{MHz}$ allowing for the resolution of lifetimes up to tens of picoseconds. The standards Pterphenyl and 2, 5 diphenyl oxazole were used for instrument calibration. The lifetime of P-terphenyl and 2, 5 diphenyl oxazole was determined previously to be 1.05 and $1.45 \mathrm{~ns}$ (Boens et al. 2007). The data were analyzed using Vinci software (ISS) which allows for data analysis by a single or multi-exponential decay as well as lifetime distribution models (Gaussian, Lorentzian, etc) to obtain appropriate fits. The quality of the fit was judged based on $\chi^{2}$ and the residual. Samples for the lifetime measurements were prepared in a similar way as described for samples for steady state measurements. The sample and the reference concentrations were adjusted in such a way that their integrated emission intensity at wavelength above $300 \mathrm{~nm}$ were identical

\subsection{CD-Spectroscopy}

$\mathrm{CD}$-spectra were measured on a JASCO-J15 CD-spectrophotometer. The CaM samples were prepared by dissolving CaM in $20 \mathrm{mM}$ HEPES buffer, $\mathrm{pH} 7.4,100 \mathrm{mM} \mathrm{KCl}, 1 \mathrm{mM}$ $\mathrm{CaCl}_{2}, 1 \mathrm{mM}$ EDTA or $1 \mathrm{mM}$ DM-nitrophen and the spectra were recorded from $200 \mathrm{~nm}$ 
to $300 \mathrm{~nm}$. DREAM samples were prepared by placing $50 \mu \mathrm{M}$ DREAM in $20 \mathrm{mM}$ Tris$\mathrm{HCl}$ buffer, pH 7.4, $10 \mathrm{mM} \mathrm{LDAO}, 1 \mathrm{mM}$ DTT, $1 \mathrm{mM} \mathrm{CaCl} 2$ or $1 \mathrm{mM}$ EDTA.

\subsection{Photothermal techniques}

\subsubsection{Theory}

Unlike traditional time-resolved spectroscopic studies, photothermal techniques such as photothermal beam deflection allow for the determination of time-resolved volume and enthalpy changes in biological and chemical systems. The physical principle behind these techniques is that a photo-excited molecule decays to the ground state by releasing its excess excitation energy in the form of heat (Larsen et al. 2007, Miksovska et al. 2003).

For solvents such as water, such heat release leads to a volume expansion $\left(\Delta \mathrm{V}_{\mathrm{th}}\right)$ that is associated with a density change as demonstrated in Scheme 4.

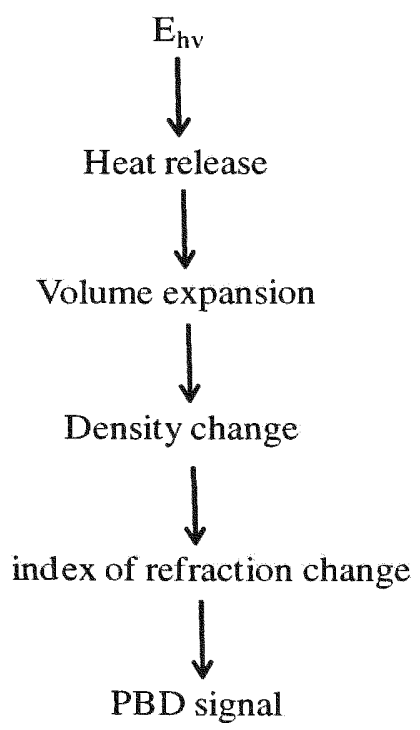

Scheme 4: 
If the photo-excitation of molecules of interest triggers additional photochemical processes, these processes are associated with a non-thermal volume change $\left(\Delta V_{\text {nonth }}\right)$ and contribute to the overall volume change detected in PBD. Such reactions include the formation/breakage of covalent bonds, change of surface charge distribution, or change in dimension of the molecule (van der Waals volume). When a pump laser with a Gaussian profile is used, the change in density leads to a refractive index gradient in the illuminated volume, which can be probed by monitoring the deflection of a probe beam that is passed through the illuminated volume. The magnitude of deflection of the probe beam is directly proportional to the change in the refractive index caused by both the thermal and non thermal volume changes $\left(\Delta \mathrm{V}_{\mathrm{th}}+\Delta \mathrm{V}_{\text {nonth }}\right)$.

The observed change in refractive index $(\Delta \mathrm{n})$ can be expressed as a sum of three contributions according to Equation 13.

$$
\Delta \mathrm{n}=\Delta \mathrm{n}_{\mathrm{th}}+\Delta \mathrm{n}_{\mathrm{pl}}+\Delta \mathrm{n}_{\mathrm{vo}}
$$

$\Delta \mathrm{n}_{\text {th }}$ is proportional to the heat release as shown in Equation 14

$$
\Delta \mathrm{n}_{\mathrm{th}} \sim(\mathrm{dn} / \mathrm{dt})\left(\mathrm{Q} / \rho \mathrm{C}_{\mathrm{p}}\right)
$$

where $\mathrm{dn} / \mathrm{dt}$ is the change in refractive index as a function of temperature, $\mathrm{Q}$ is the heat released into the solvent, $\rho$ is the density and $C_{p}$ is the specific heat capacity. $\Delta n_{p l}$ represents the contribution to the PBD signal by any species present in the sample (or any transient species formed upon photo excitation) that has their absorption maximum at the wavelength of the probe beam, to the change in refractive index as shown in Equation 15. 


$$
\Delta \mathrm{n}_{\mathrm{pl}}=\frac{\left(n_{0}^{2}+2\right)^{2} \alpha_{i}}{\left(18 n_{0} \epsilon_{0}\right) \Delta N}
$$

The term $\Delta \mathrm{N}$ is the number of excited molecules per unit volume, $\epsilon_{0}$ is the vaccum permittivity and $\alpha_{i}$ is the polarizability of the excited species. In general, the wavelength of the probe beam is selected in such a way that it is far away from the absorption band of reactants/products or any transiently populated intermediate which causes the $\Delta \mathrm{n}_{\mathrm{pl}}$ term zero to become negligible.

The term $\Delta \mathrm{n}_{\mathrm{vol}}$ represents the refractive index change that results from the the changes in molar volume of the photoexcited species and is represented by Equation 16 .

$$
\Delta \mathrm{n}_{\mathrm{vol}}=\frac{(\varepsilon-1)(\epsilon+2)}{6 n_{0}(\Delta V / V)}
$$

Where $n_{0}$ is the index of refraction of the undisturbed solvent, $\varepsilon$ is the permittivity of the solvent and $\triangle \mathrm{V}$ is the change in volume. The equations used for the analysis of PBD data are listed below

$$
\begin{aligned}
& \mathrm{S}=\mathrm{K} \mathrm{E}_{\mathrm{a}}\left[(\mathrm{dn} / \mathrm{dt})\left(1 / \rho \mathrm{C}_{\mathrm{p}}\right) \mathrm{Q}+\rho(\mathrm{dn} / \mathrm{d} \rho) \Delta \mathrm{V}_{\text {nonth }}+\Delta \mathrm{n}_{\mathrm{PL}}\right] \\
& \mathrm{R}=\mathrm{K} \mathrm{E}_{\mathrm{a}} \mathrm{E}_{\mathrm{hv}}\left[(\mathrm{dn} / \mathrm{dt})\left(1 / \rho \mathrm{C}_{\mathrm{p}}\right)\right] \\
& (\mathrm{S} / \mathrm{R}) \mathrm{E}_{\mathrm{hv}}=\mathrm{Q}+\left[\rho(\mathrm{dn} / \mathrm{d} \rho) \Delta \mathrm{V}_{\text {nonth }}+\Delta \mathrm{n}_{\mathrm{PL}}\right] /(\mathrm{dn} / \mathrm{dt})\left(1 / \rho \mathrm{C}_{\mathrm{p}}\right) \\
& \mathrm{F}=\alpha_{0}+\sum \alpha_{\mathrm{i}}\left[1-\exp \left(\mathrm{t} / \tau_{\mathrm{i}}\right)\right] \\
& \Delta \mathrm{V}=\Delta \mathrm{V}_{\text {nonth }} / \Phi \\
& \Delta \mathrm{H}_{\mathrm{f}}=\left(\mathrm{E}_{\mathrm{hv}}-\mathrm{Q}\right) / \Phi
\end{aligned}
$$


According to the Equation 17, the PBD signal for the sample (S) is directly proportional to the instrument response parameter $(\mathrm{K})$, the number of Einsteins absorbed $\left(\mathrm{E}_{\mathrm{a}}\right)$, and the temperature dependent factor $(\mathrm{dn} / \mathrm{dt})(1 / \mathrm{Cp} \rho) \mathrm{Q}$, where $\rho$ is the density, $\mathrm{Cp}$ is the specific heat capacity of the solvent. Q represents the heat released into the solvent. The second term in the Equation $17, \rho(\mathrm{dn} / \mathrm{d} \rho) \Delta \mathrm{V}_{\text {str }}$ reflects the change in the index of refraction due to non thermal volume change. The $\rho(\mathrm{dn} / \mathrm{d} \rho)$ has a constant value of 0.365 within the temperature range of our measurements, i.e. between $15-35^{\circ} \mathrm{C}$ (Eisenberg et al. 1965). $\Delta \mathrm{n}_{\mathrm{PL}}$ denotes the "population lens" which includes the contribution to the signal from any absorbing species at the wavelength of the probe beam (633 nm).

To eliminate the K term in Equation 17, the PBD signal of a reference compound was measured at the same temperature and instrument alignment as those used for sample measurements. The reference compound is a molecule that is non-fluorescent, does not undergo photochemistry, and that releases all its absorbed energy as a heat with a quantum yield of unity. According to Equation 18, the reference signal (R) is directly proportional to energy of the photon at the excitation wavelength $\left(E_{\mathrm{hv}}\right)$. Since the reference compound releases all the absorbed energy into the surrounding solvent the contribution to the observed reference PBD signal in the case of the reference is because of $\Delta \mathrm{V}_{\mathrm{th}}$. The ratio of the equation for the sample and reference PBD signal provides Equation 19. Using this equation, the non thermal volume change $\left(\Delta V_{\text {nonth }}\right)$ and the heat released $(\mathrm{Q})$ for a photo-triggered process can be obtained by plotting (S/R) $E_{\mathrm{hv}}$ versus $(\mathrm{dn} / \mathrm{dt})(1 / \mathrm{Cp} \rho) . \Delta \mathrm{V}_{\text {nonth }}$ and $\mathrm{Q}$ are then determined from the slope and intercept 
respectively, from the linear fit of the experimental data. For processes that occur between $\sim 10 \mu \mathrm{s}$ and $200 \mathrm{~ms}$, the rate constants can be obtained by fitting PBD traces to Equation 20. From the temperature dependence of the rate constant, the activation enthalpy is determined from Arrhenius plots. The observed volume and enthalpy changes correspond to the efficiency of the photo-initiated process. Hence, the observed volume and enthalpy changes are scaled to quantum yield for DM-nitrophen photodissociation by using Equations 21, 22, and 23. The change in enthalpy for the fast phase $\left(\Delta H_{f}\right)$ is determined by scaling the difference between the energy of the photon and the heat released into the solvent to the quantum yield. On the other hand, the change in enthalpy $\left(\Delta \mathrm{H}_{\mathrm{s}}\right)$ for the slowphase is obtained by scaling the heat released into the solution to the quantum yield as shown in Equation 23.

\subsubsection{Instrumentation}

The pump beam is provided by a $355 \mathrm{~nm}$ output ( $7 \mathrm{~ns}$ pulse, Nd: YAG laser Minilite 2, Continuum, CA) to photo-initiate the reaction. The energy of the excitation pulse was kept within the linear range of the PBD signal $(0-1 \mathrm{~mJ})$ to prevent multi photon absorption. The change in density was probed by using a $633 \mathrm{~nm}$ probe beam (cw laser didode, $3 \mathrm{~mW}$, LASIARIS ${ }^{\mathrm{TM}}$ ) as shown in Figure 4.2. The sample was placed in a temperature controlled cuvette holder (Quantum Northwest, FLASH 300). The probe beam and the pump beam were collinear and were propagated through the center of the sample. The diameter of the probe and pump beam were adjusted using pinholes and a mirror placed behind the sample holder directed the probe beam on the center of a homebuilt amplified bicell detector. The magnitude of the deflection of the probe beam was 
measured as a voltage difference between two cells of the detector. The signal was then digitized using a $500 \mathrm{MHz}$ digitizer (TDS 544A, Tektronix). The data obtained from the PBD measurements were analysed using Microcal Origin Pro software, version 8.0.

A Amplifier

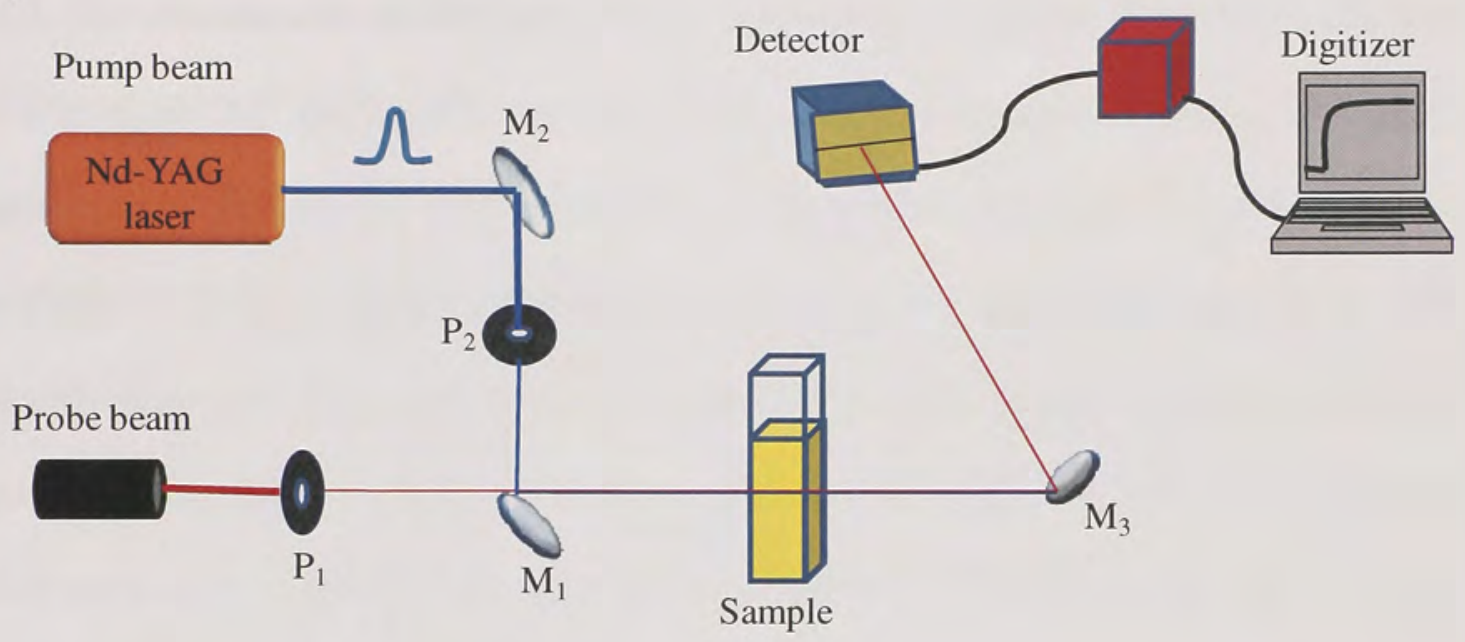

B

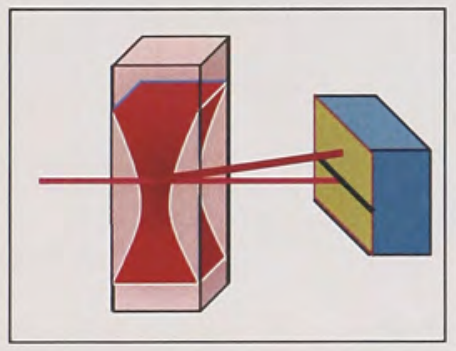

Figure 4.2. A) Schematic representation of the PBD setup. M and P denotes mirrors and pinholes, respectively. B) Cartoon picture of transient lens formed in the sample cuvette and its impact on the probe beam deflection.

\subsubsection{Preparation of the sample for the PBD measurement}

To minimize the $\mathrm{Ca}^{2+}$ contamination, buffers and solutions were stored in plastic containers that were previously boiled in distilled water and washed with chelex-100 
treated water. The glassware and the cuvettes were washed with $1 \mathrm{M} \mathrm{HCl}$ solution before each use. For all PBD experiments, potassium ferricyanate $\left(\mathrm{K}_{3}\left[\mathrm{Fe}(\mathrm{CN})_{6}\right]\right)$ was used as a reference compound. The sample used for DM-nitrophen photolysis measurements contained 1mM DM-nitrophen dissolved in $20 \mathrm{mM}$ HEPES buffer, $\mathrm{pH} 7.42,100 \mathrm{mM}$ $\mathrm{KCl}$. The concentration of DM-nitrophen was determined using an extinction coefficient of $4.33 \times 10^{-4} \mathrm{M}^{-1} \mathrm{~cm}^{-1}$ at $355 \mathrm{~nm}$ (Kaplan et al. 1988). The amount of $\mathrm{Ca}^{2+}$ and $\mathrm{Mg}^{2+}$ necessary to fully saturate DM-nitrophen was calculated based on the $K_{d}$ values (shown in Table 2). Apo-calmodulin was prepared by dialyzing the protein against $20 \mathrm{mM}$ HEPES buffer, $\mathrm{pH} 7.42,100 \mathrm{mM} \mathrm{KCl}, 1 \mathrm{mM}$ EDTA for 48 hours. The preparation of apo- CaM was verified using CD spectroscopy. The samples for the PBD measurements were prepared by dissolving $50 \mu \mathrm{M}$ protein in $20 \mathrm{mM}$ HEPES buffer, $\mathrm{pH} 7.42,100 \mathrm{mM}$ $\mathrm{KCl}, 450 \mu \mathrm{M}$ DM-nitrophen and $450 \mu \mathrm{M} \mathrm{CaCl}_{2}$. 


\subsection{Results}

\subsection{Electrophoresis}

Calmodulin was isolated as described in the Materials and Methods section and its purity was verified using $15 \%$ SDS-PAGE electrophoresis. The electrophoresis presented in Figure 5.1 shows a single band at $17 \mathrm{kDa}$ that corresponds to $\mathrm{CaM}$, indicating that the protein was isolated in a pure form.

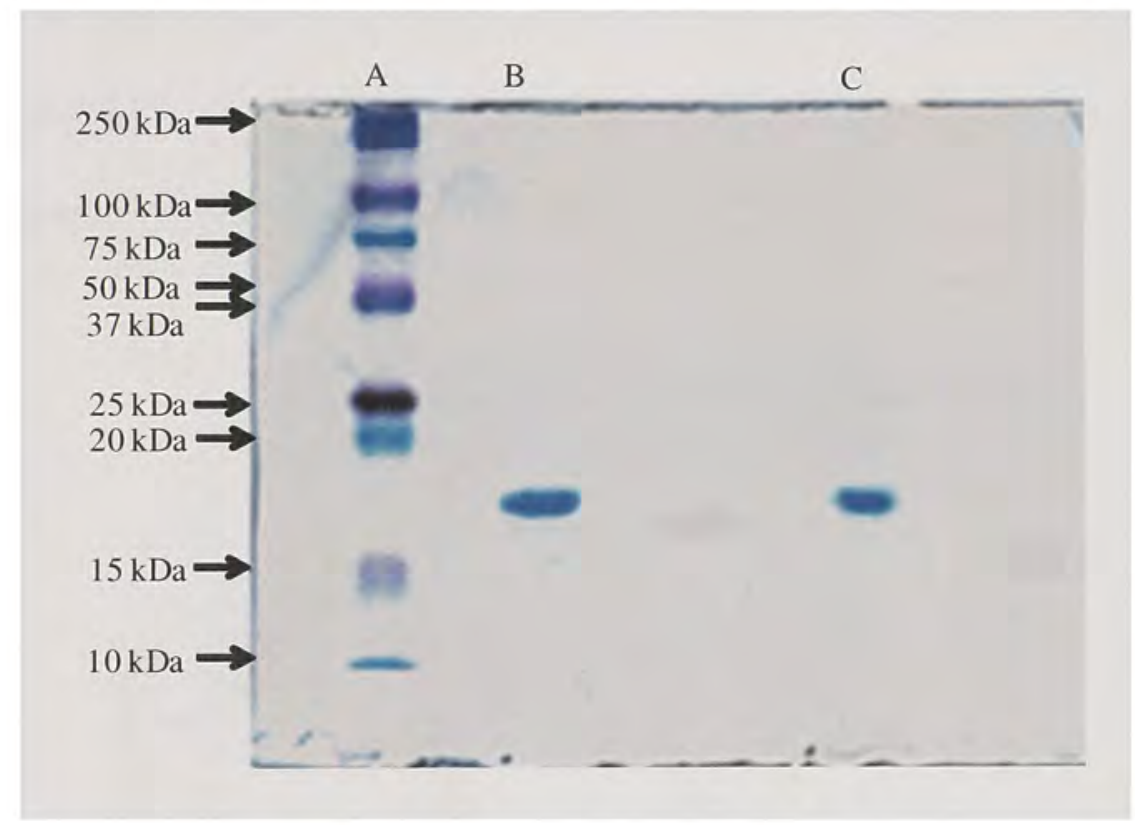

Figure 5.1. SDS-PAGE electrophoresis for CaM. A, B, and C represent molecular weight markers, apo-CaM, and $\mathrm{Ca}^{2+}$ bound $\mathrm{CaM}$, respectively.

\subsection{Steady state UV-visible spectroscopy}

The absorption spectra of unphotolysed and photolysed DM-nitrophen, $\mathrm{Ca}^{2+}-\mathrm{DM}$ nitrophen, $\mathrm{Mg}^{2+}$-DM-nitrophen were recorded. The spectra are shown in Figure 5.2. The absorbance spectra of unphotolysed DM-nitrophen, $\mathrm{Mg}^{2+}$-DM-nitrophen and $\mathrm{Ca}^{2+} \mathrm{DM}$ - 
nitrophen are similar and show a peak at $350 \mathrm{~nm}$ with a shoulder at $305 \mathrm{~nm}$. However, upon addition of the metal ions, the intensity of the absorption band at $350 \mathrm{~nm}$ decreases. Photolysis of DM-nitrophen is associated with a blue shift of the absorption maximum from $350 \mathrm{~nm}$ to $318 \mathrm{~nm}$ with a shoulder at $535 \mathrm{~nm}$. On the other hand, photolysis of $\mathrm{Mg}^{2+}$-DM-nitrophen shows an absorption maximum at $300 \mathrm{~nm}$ with a shoulder at 321 and $535 \mathrm{~nm}$. In the case of photolysed $\mathrm{Ca}^{2+}$-DM-nitrophen, the absorption spectra show a peak at $296 \mathrm{~nm}$ with a shoulder at 326 and $535 \mathrm{~nm}$. The peak at $535 \mathrm{~nm}$ corresponds to the formation of secondary photoproducts of photodissociation of 2-nitrosobenzaldehyde because of a long time exposure of DM-nitrophen to UV-light (Wieboldt et al. 2002).

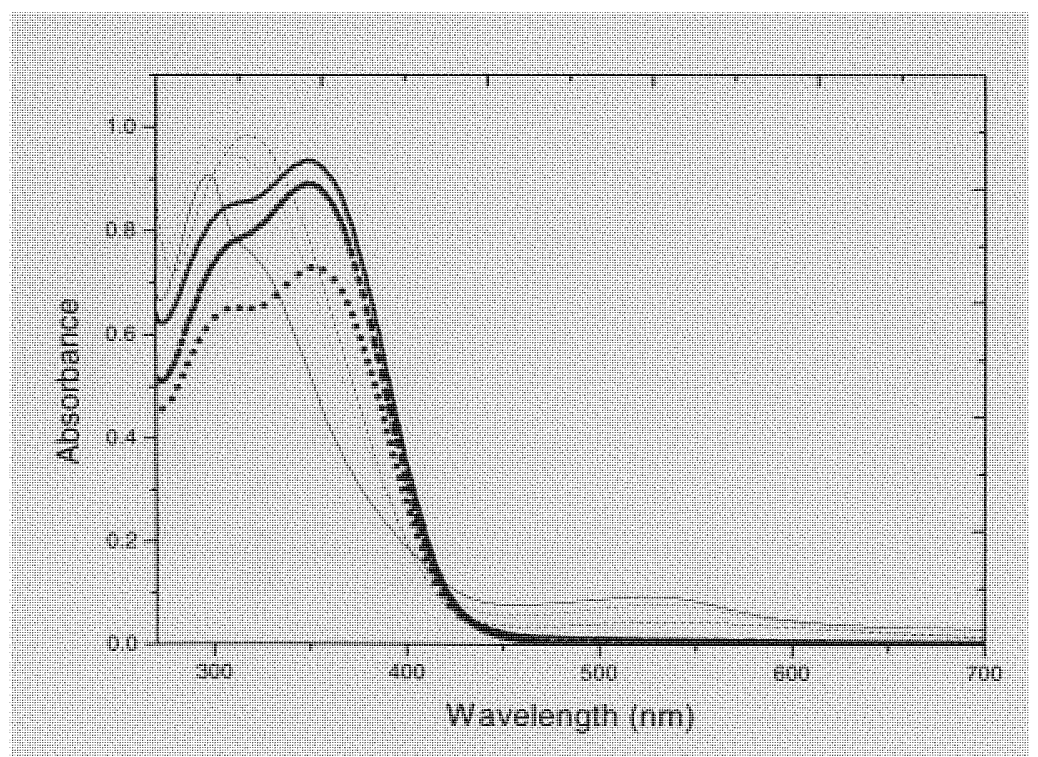

Figure 5.2. Absorption spectra of unphotolysed DM-nitrophen (thick line), $\mathrm{Mg}^{2+}-\mathrm{DM}$ nitrophen (thick dashed line), $\mathrm{Ca}^{2+}$-DM-nitrophen (thick dotted line) and photolysed DMnitrophen (dashed line), photolysed $\mathrm{Ca}^{2+}$-DM-nitrophen (thin line) and photolysed $\mathrm{Mg}^{2+}$ DM-nitrophen (dotted line). 


\subsection{PBD study of the photodissociation of DM-nitrophen}

The alignment of the PBD instrument was tested by measuring the reference and sample PBD signal for the as a function of the number of photons absorbed and as a function of the power of the pump beam. The data are shown in Figure 5.3 and 5.4. The linearity of the PBD signal as a function of laser power indicates that the sample or the reference do not undergo multiphoton absorption within the range of the laser power used. On the other hand the linearity of the reference PBD signal as a function of absorbance suggests the absence of the inner filter effect.

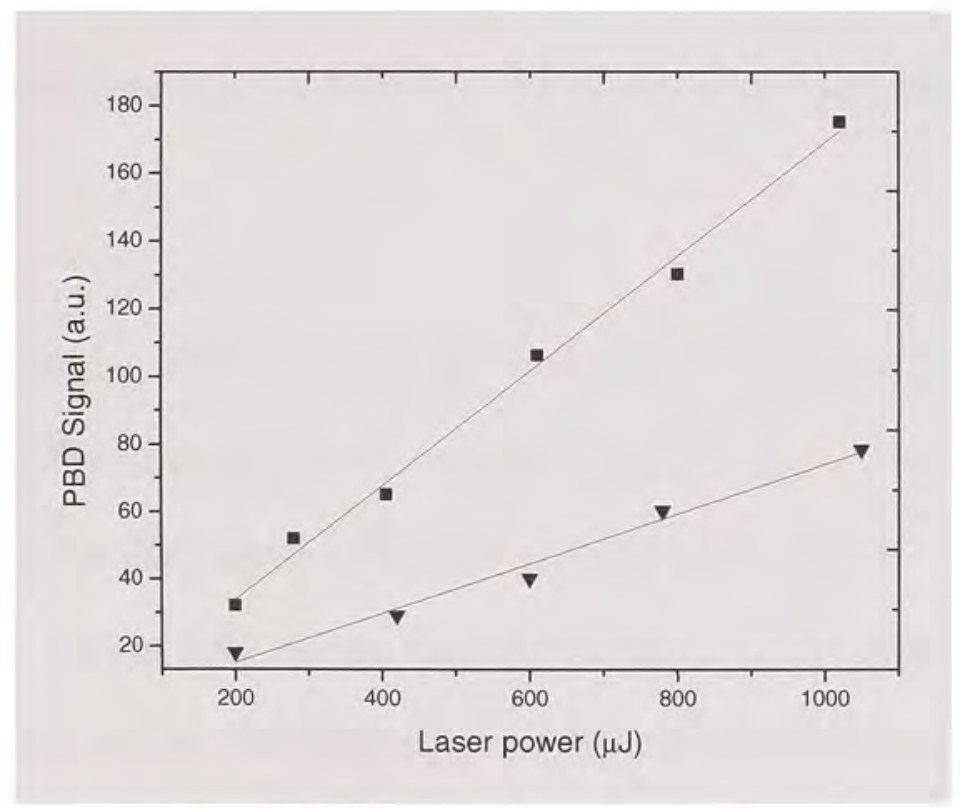

Figure 5.3. PBD signal as a function of the laser power for the sample (triangles) and the reference compound (squares). Conditions: Reference $\left(\mathrm{K}_{3}\left[\mathrm{Fe}(\mathrm{CN})_{6}\right]\right)$ and the sample $(1$ mM DM-nitrophen) were dissolved in 20 mM HEPES buffer, $\mathrm{pH} 7.42,100 \mathrm{mM} \mathrm{KCl}$. 


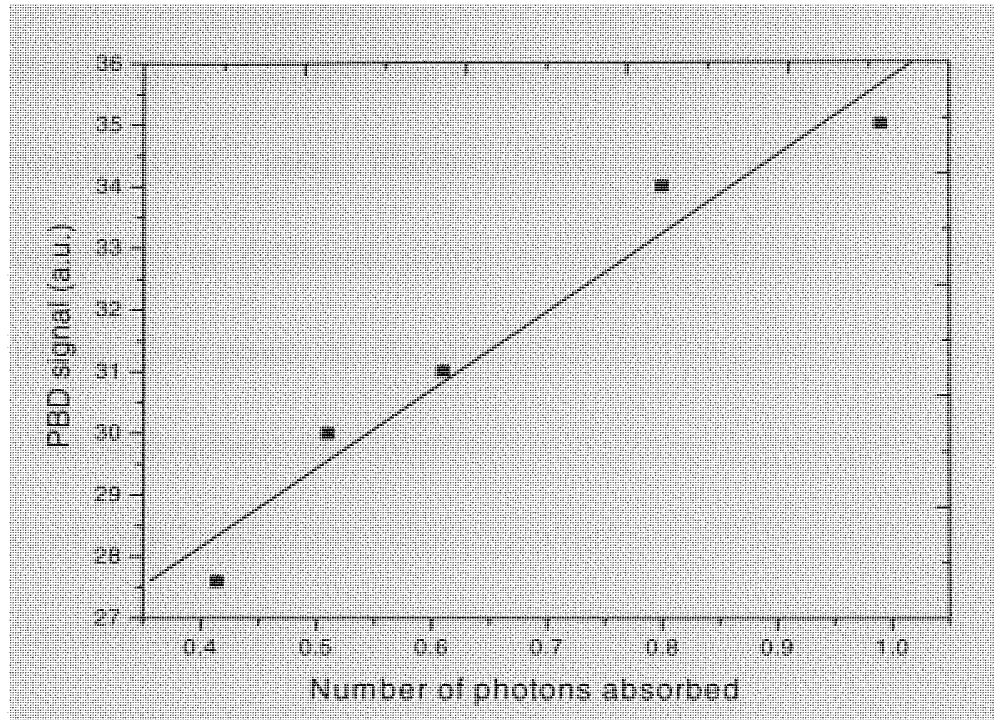

Figure 5.4. PBD signal as a function of the number of photons absorbed for the reference compound. Conditions: $\left.\mathrm{K}_{3}\left[\mathrm{Fe}(\mathrm{CN})_{6}\right]\right)$ dissolved in $20 \mathrm{mM}$ HEPES buffer, $\mathrm{pH} 7.42,100$ $\mathrm{mM} \mathrm{KCl}$.

Overlays of the PBD traces for the reference, DM-nitrophen, $\mathrm{Ca}^{2+}-\mathrm{DM}$-nitrophen and $\mathrm{Mg}^{2+}-\mathrm{DM}$-nitrophen are shown in Figure 5.5. In the case of the reference there is a fast increase in the PBD signal within $20 \mu$ s and the signal remains constant for about $200 \mathrm{~ms}$ and then decays back to the baseline because of the diffusion of the heat to the surrounding solvent. The PBD trace for DM-nitrophen has a similar time profile as the reference compound and does not exhibit any detectable kinetics on the $500 \mu$ s time scale. However, the amplitude of the PBD signal for DM-nitrophen photolysis is smaller than that of the reference, indicating the presence of thermodynamic events within $\tau<20$ $\mu$ s. On the other hand the PBD signal for $\mathrm{Ca}^{2+}-\mathrm{DM}$-nitrophen shows a fast increase within $20 \mu$ s that is followed by slow exponential kinetics with lifetime of $400 \mu$ s which 
remains constant up to $200 \mathrm{~ms}$. The presence of $400 \mu$ s kinetics is strongly dependent on the DM-nitrophen: $\mathrm{Ca}^{2+}$ ratio. Indeed, $\mathrm{PBD}$ traces for the photolysis of $\mathrm{Ca}^{2+}-\mathrm{DM}$ nitrophen measured at different ratios of DM-nitrophen: $\mathrm{Ca}^{2+}$ show a decrease in the amplitude of the slow phase as the ratio of DM-nitrophen to $\mathrm{Ca}^{2+}$ decreases as shown in Figure 5.6. No slow phase was detected for DM-nitrophen: $\mathrm{Ca}^{2+}$ ratio of $1: 2$ and higher. In the case of $\mathrm{Mg}^{2+}$ saturated DM-nitrophen, the PBD traces show a rapid increase similar to the DM-nitrophen signal, without any detectable kinetics between $20 \mu \mathrm{s}$ and $200 \mathrm{~ms}$ as shown in Figure 5.7.

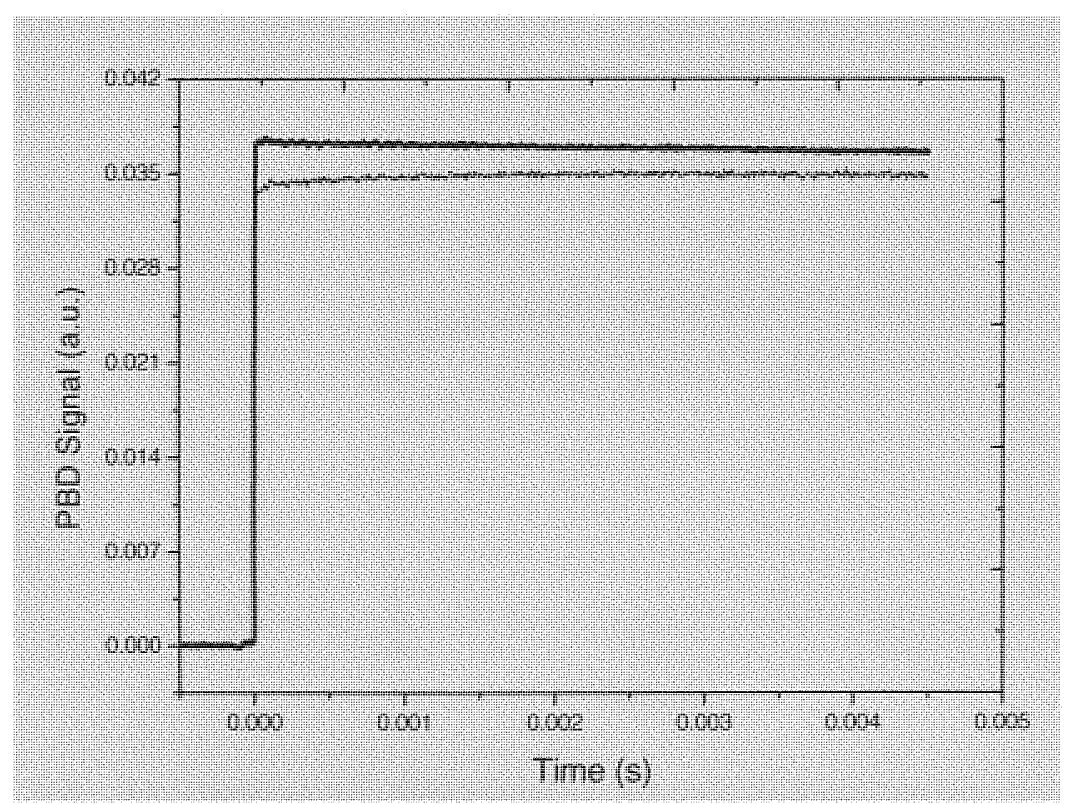

Figure 5.5. Overlay of PBD traces for photodissociation of DM-nitrophen (dotted line) and the reference compound (thick line) at $20^{\circ} \mathrm{C}$. Conditions: $1 \mathrm{mM}$ DM-nitrophen in 20 mM HEPES buffer, pH 7.42, $100 \mathrm{mM} \mathrm{KCl}$. 


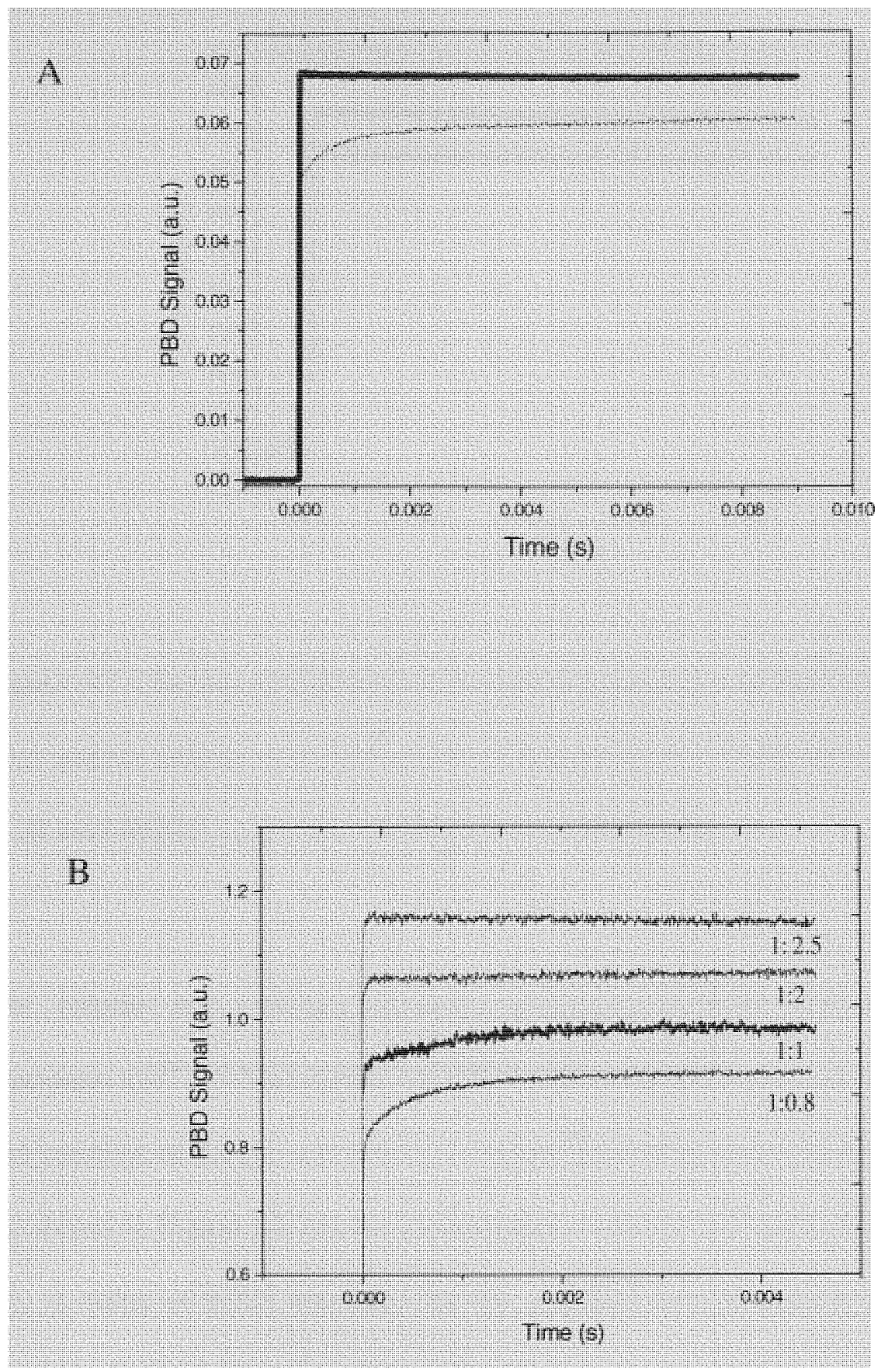

Figure 5.6. A) Overlay of PBD traces for photodissociation of $\mathrm{Ca}^{2+}$-DM-nitrophen (dotted line) and the reference compound (thick line) at $20^{\circ} \mathrm{C}$. Conditions: $1 \mathrm{mM} \mathrm{DM}$ nitrophen in $20 \mathrm{mM}$ HEPES buffer, $\mathrm{pH} 7.42,100 \mathrm{mM} \mathrm{KCl}, 800 \mu \mathrm{M} \mathrm{CaCl}_{2}$. B) Overlay PBD traces for different ratios of DM-nitrophen: $\mathrm{Ca}^{2+}$. 


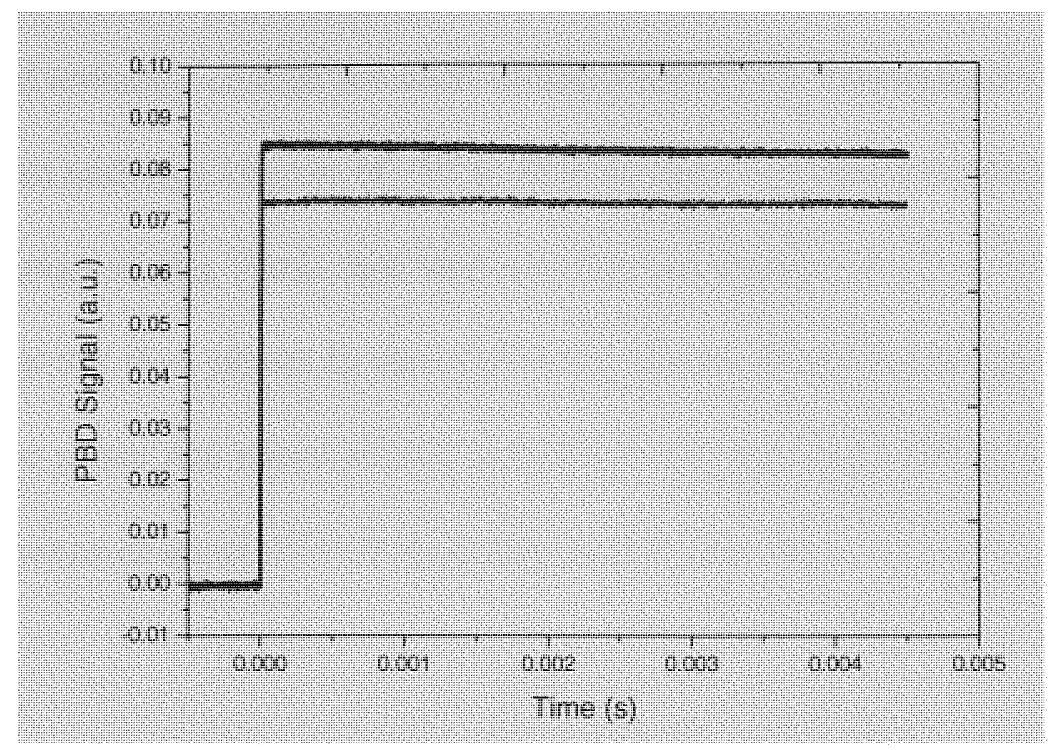

Figure 5.7. Overlay of PBD traces for photodissociation of $\mathrm{Mg}^{2+}-\mathrm{DM}$-nitrophen (dotted line) and the reference compound (thick line) at $20^{\circ} \mathrm{C}$. Conditions: $1 \mathrm{mM} \mathrm{DM}$-nitrophen in $20 \mathrm{mM}$ HEPES, pH 7.42, $100 \mathrm{mM} \mathrm{KCl,} 5 \mathrm{mM} \mathrm{MgCl}$.

The volume and enthalpy changes associated with the photodissociation of DMnitrophen, $\mathrm{Ca}^{2+}-\mathrm{DM}$-nitrophen and $\mathrm{Mg}^{2+}-\mathrm{DM}$-nitrophen were determined from the slope and intercept of the plot of $(S / R) E_{h v}$ versus $C_{p} \rho /(d n / d t)$ using Equation 19. The linear fits are shown in Figure 5.8 and the extrapolated values for $\Delta \mathrm{V}$ and $\Delta \mathrm{H}$ are listed in the Table 5.1. A value of 0.325 was used for the $\rho(\mathrm{dn} / \mathrm{d} \rho)$ term (Eisenberg et al. 1965) and the $\Delta \mathrm{V} / \Delta \mathrm{H}$ obtained from the slope and intercept were scaled to a quantum yield of 0.18 which was reported for the photodissociation of DM-nitrophen by Kaplan et al. (1988), according to Equations 21 and 22. The overall volume change of $12 \pm 1 \mathrm{~mL} \mathrm{~mol}^{-1}$ and an enthalpy change of $63 \pm 6 \mathrm{kcal} \mathrm{mol}^{-1}$ were observed for the photolysis of DM-nitrophen. On the other hand, photodissocitaion of $\mathrm{Ca}^{2+}$-DM-nitrophen shows two phases and the 
volume and enthalpy change for each of the phases were determined to be $-12 \pm 5 \mathrm{~mL}$ $\mathrm{mol}^{-1}$ and an enthalpy change of $-50 \pm 20 \mathrm{kcal} \mathrm{mole}^{-1}$ for the fast phase, and a positive volume change of $9 \pm 3 \mathrm{~mL} \mathrm{~mol}^{-1}$ and an enthalpy change of $-19 \pm 13 \mathrm{kcal} \mathrm{mol}^{-1}$ were observed for the slow phase. In the case of the photodissociation of $\mathrm{Mg}^{2+}-\mathrm{DM}$-nitrophen, only the fast phase was observed and an overall volume change of $7 \pm 2 \mathrm{~mL} \mathrm{~mol}^{-1}$ and an enthalpy change of about $-40 \pm 8 \mathrm{kcal} \mathrm{mol}^{-1}$ were determined.

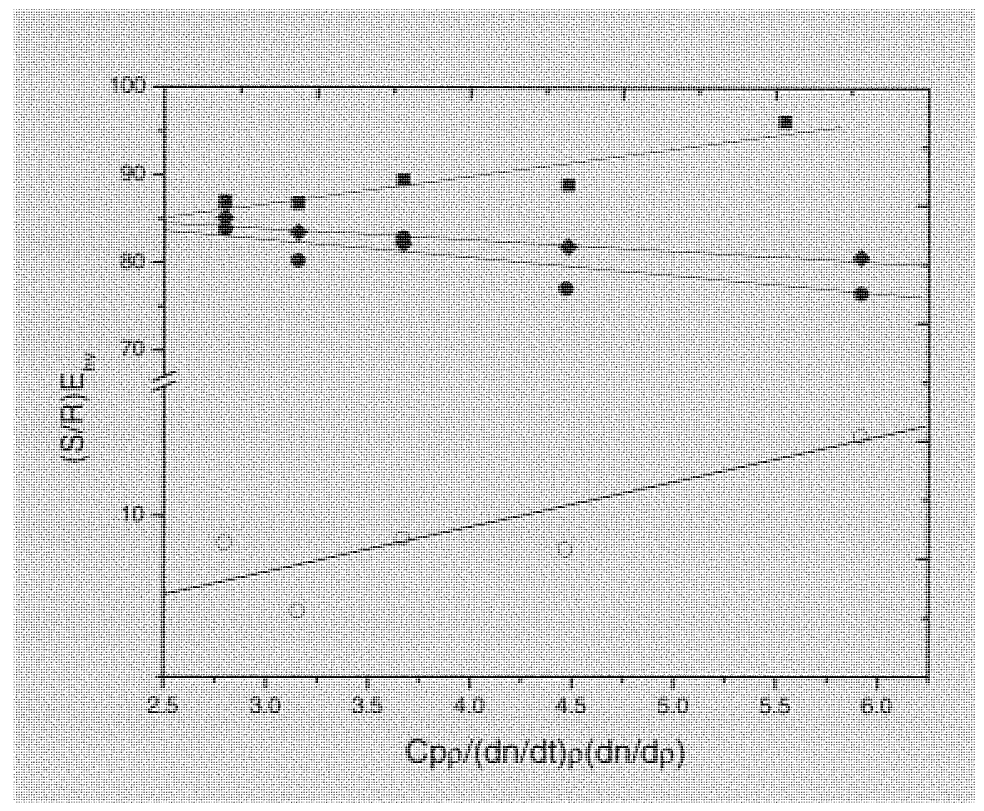

Figure 5.8. Plot of (S/R) $E_{h v}$ versus $C p \rho /(d n / d t) \rho(d n / d \rho)$ for photolysis of DM-nitrophen (squares), $\mathrm{Ca}^{2+} \mathrm{DM}$-nitrophen fast phase (solid circles) and slow phase (open circles), and $\mathrm{Mg}^{2+}-\mathrm{DM}$-nitrophen (diamonds). 
Table 5.1. Volume and enthalpy changes determined for photodissociation of DMnitrophen, $\mathrm{Ca}^{2+}-\mathrm{DM}$-nitrophen and $\mathrm{Mg}^{2+}-\mathrm{DM}$-nitrophen from the plot of (S/R) $\mathrm{E}_{\mathrm{hv}}$ versus $\mathrm{C} p \rho /(\mathrm{dn} / \mathrm{dt}) \rho(\mathrm{dn} / \mathrm{d} \rho)$ as shown Figure 5.8.

\begin{tabular}{|c|c|c|c|c|c|}
\hline & $\begin{array}{c}\Delta \mathrm{V}_{1} \\
\mathrm{~mL} \mathrm{~mol}^{-1}\end{array}$ & $\underset{\mathrm{kcal} \mathrm{mol}}{\Delta \mathrm{H}_{1}}$ & $\begin{array}{c}\Delta \mathrm{V}_{2} \\
\mathrm{~mL} \mathrm{~mol}^{-1}\end{array}$ & $\begin{array}{c}\Delta \mathrm{H}_{2} \\
\mathrm{kcal} \mathrm{mol}^{-1}\end{array}$ & $\begin{array}{c}\tau \\
\left(20^{\circ} \mathrm{C}\right)\end{array}$ \\
\hline DM-nitrophen & $12 \pm 1$ & $63 \pm 6$ & - & - & - \\
\hline $\mathrm{Ca}^{2+}-\mathrm{DM}$-nitrophen & $-12 \pm 5$ & $-50 \pm 20$ & $9 \pm 3$ & $-19 \pm 13$ & $400 \mu \mathrm{s}$ \\
\hline $\mathrm{Mg}^{2+}$-DM-nitrophen & $-7 \pm 2$ & $-40 \pm 8$ & - & - & - \\
\hline
\end{tabular}

\subsubsection{Thermodynamic parameters for calcium binding to CaM}

To determine the volume and enthalpy profile for $\mathrm{Ca}^{2+}$ binding to $\mathrm{CaM} \mathrm{I}$ have applied PBD in combination with $\mathrm{Ca}^{2+}$-DM-nitrophen photolysis. The sample preparation for these measurements is somewhat challenging since $\left[\mathrm{Ca}^{2+}\right]_{\text {total }}$ has to be such that DMnitrophen is $\mathrm{Ca}^{2+}$ saturated whereas $\mathrm{CaM}$ is predominantly in the apo form. The presence of apo $\mathrm{CaM}$ in the $\mathrm{Ca}^{2+}$-DM-nitrophen solution was verified using $\mathrm{CD}$-spectroscopy and the traces are shown in Figure 5.9. CD-data were recorded for CaM in the presence of unphotolysed $\mathrm{Ca}^{2+}$-DM-nitrophen, in the presence of $1 \mathrm{mM}$ EGTA, and after $\mathrm{Ca}^{2+}-\mathrm{DM}$ nitrophen photolysis using a $355 \mathrm{~nm}$ lamp. CD-signal for CaM in the presence of $1 \mathrm{mM}$ EGTA was measured as a control. The overlay of the $\mathrm{CD}$-signal of $\mathrm{CaM}$ in the presence of EGTA and in the presence of unphotolysed $\mathrm{Ca}^{2+}$-DM-nitrophen indicates that the protein remains in the apo form in the presence of $\mathrm{Ca}^{2+}-\mathrm{DM}$-nitrophen. Results show that the irradiation of the CaM- $\mathrm{Ca}^{2+}$-DM-nitrophen sample leads to a $10 \%$ decrease in the $\mathrm{CD}$ signal of CaM at 208 and $222 \mathrm{~nm}$ in agreement with the previous studies that shown that 
CaM CD signal decreases upon $\mathrm{Ca}^{2+}$ addition because of the increase in $\alpha$-helical content (Martin et al. 1986, Zhang et al. 1995) The traces are noisy below $210 \mathrm{~nm}$ because of the presence of DM-nitrophen and EGTA in the samples.

An overlay of the PBD trace obtained for the reference and CaM-Ca ${ }^{2+}-\mathrm{DM}$-nitrophen sample is shown in Figure 5.10. Comparison of the PBD traces for the photodissociation of $\mathrm{Ca}^{2+}$-DM-nitrophen and $\mathrm{Ca}^{2+}-\mathrm{DM}$-nitrophen in the presence of $\mathrm{CaM}$ are presented in Figure 5.11. The PBD trace in the presence of CaM shows a fast rise in PBD signal followed by an exponential increase of the signal occurring with a lifetime of about 600 $\mu \mathrm{s}$ and has a higher amplitude for the slow phase compared to the photodissociation of $\mathrm{Ca}^{2+}$-DM-nitrophen in the absence of CaM.

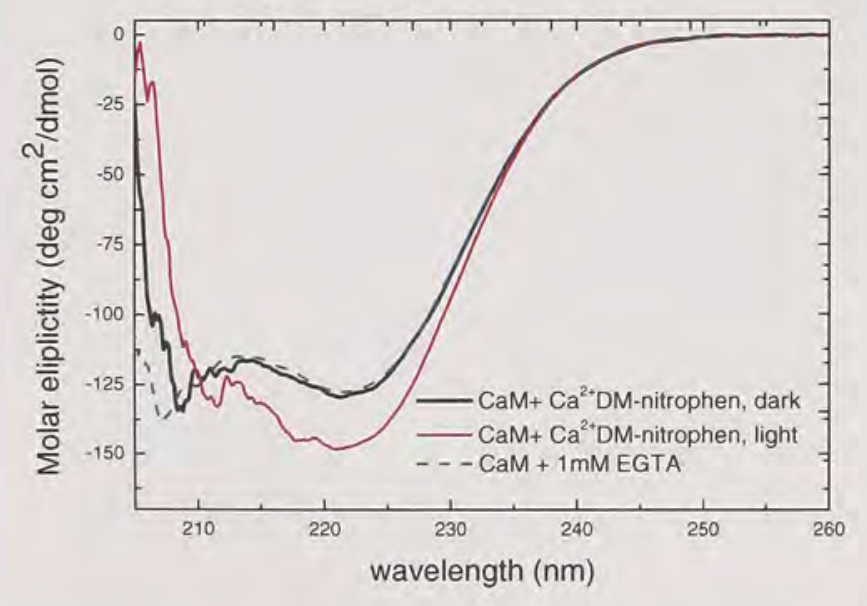

Figure 5.9. $\mathrm{CD}$ spectra of $\mathrm{CaM}$ in the presence of $\mathrm{Ca}^{2+}$ saturated DM-nitrophen before illumination (black trace), upon irradiation with $355 \mathrm{~nm}$ light for 5 minutes (red trace) and in the presence of EGTA (blue trace). Conditions: $50 \mu \mathrm{M}$ CaM in $20 \mathrm{mM}$ HEPES, pH 7.42, $100 \mathrm{mM} \mathrm{KCl}, 1 \mathrm{mM} \mathrm{CaCl} 2,1 \mathrm{mM}$ DM-nitrophen or 1mM EGTA. 


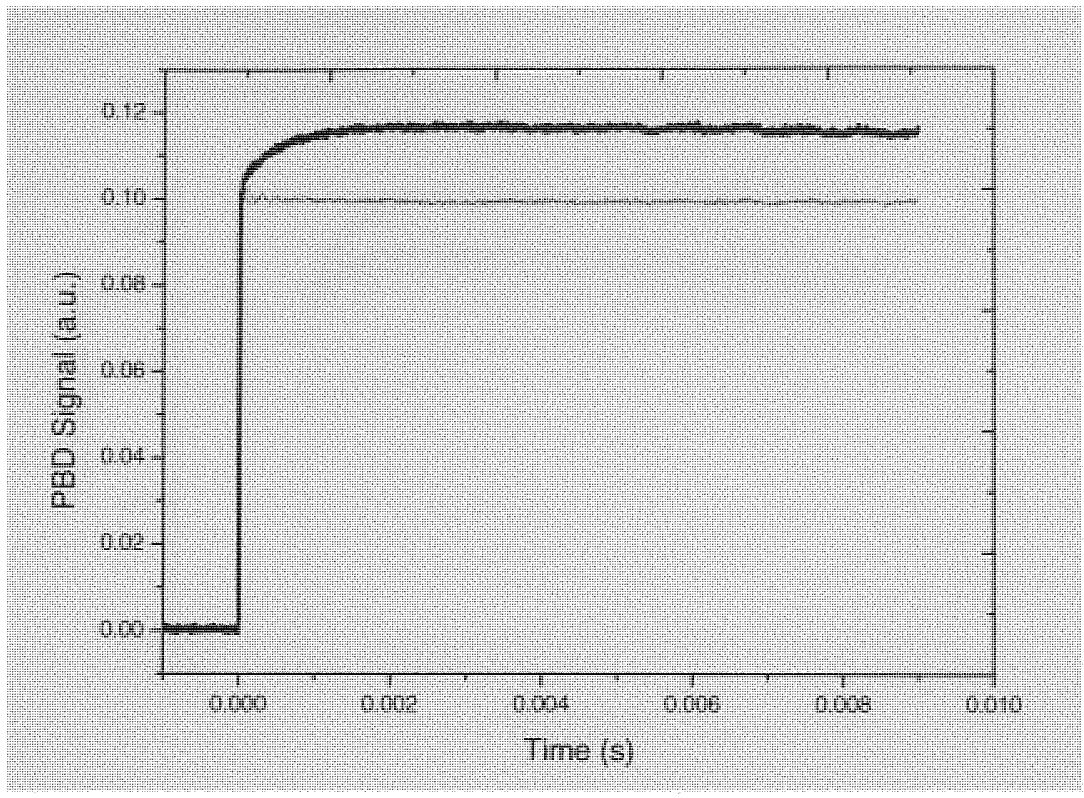

Figure 5.10. Overlay of PBD trace for the reference (thin line) and the photodissociation of $\mathrm{Ca}^{2+}-\mathrm{DM}$-nitrophen in the presence of $\mathrm{CaM}$ (thick line). Conditions: $50 \mu \mathrm{M} \mathrm{CaM}$ in 20 mM HEPES buffer, pH7.42, $100 \mathrm{mM} \mathrm{KCl}, 450 \mu \mathrm{M}$ DM-nitrophen, $450 \mu \mathrm{M} \mathrm{CaCl}_{2}$. 


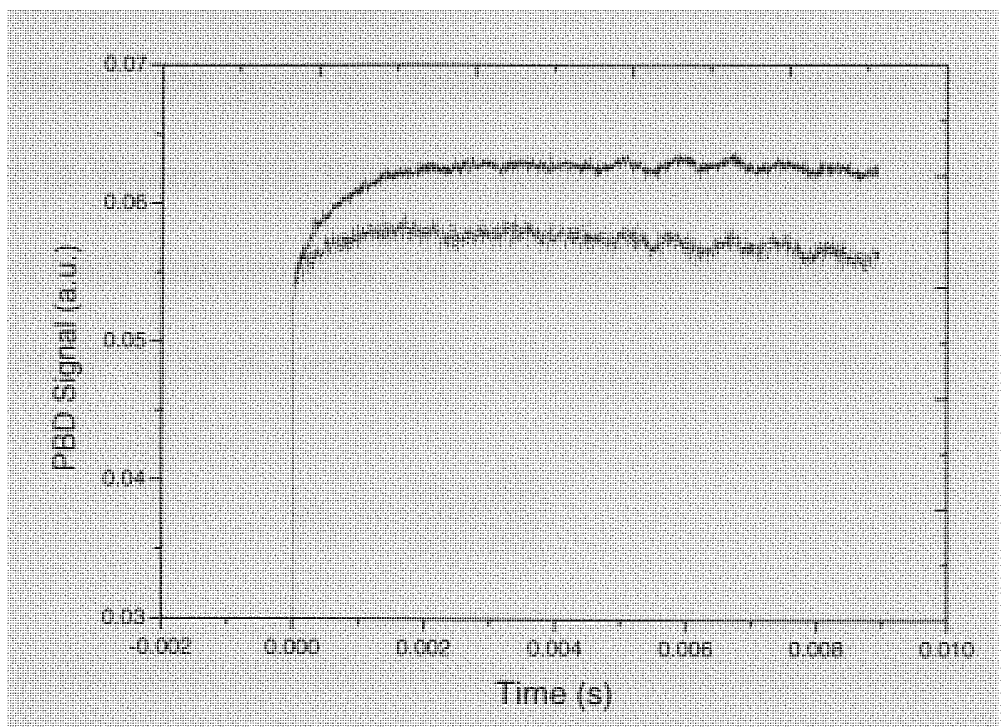

Figure 5.11. Overlay of PBD traces for $\mathrm{Ca}^{2+}$ saturated DM-nitrophen (dotted line), $\mathrm{Ca}^{2+}$ saturated DM-nitrophen in the presence of $\mathrm{CaM}$ (thin solid line). Conditions: $450 \mu \mathrm{M}$ DM-nitrophen in $20 \mathrm{mM}$ HEPES buffer, pH 7.42, $100 \mathrm{mM} \mathrm{KCl}, 450 \mu \mathrm{M} \mathrm{CaCl}_{2}$ and 50 $\mu \mathrm{M} \mathrm{CaM}$.

Volume and enthalpy changes associated with $\mathrm{Ca}^{2+}$ binding to $\mathrm{CaM}$ were obtained from the slope and intercept of the linear plot of $(\mathrm{S} / \mathrm{R}) \mathrm{E}_{\mathrm{hv}}$ versus $\mathrm{Cp} /(\mathrm{dn} / \mathrm{dt})$ as shown in Figure 5.2. The extrapolated values for $\Delta \mathrm{V}$ and $\Delta \mathrm{H}$ are listed in Table 5.2. Photodissociation of $\mathrm{Ca}^{2+}$-DM-nitrophen in the presence of $\mathrm{CaM}$ is associated with a volume change of $-13 \pm 3 \mathrm{~mL}^{-10 l e^{-1}}$ and an enthalpy change of $-61 \pm 32 \mathrm{kcal} \mathrm{mol}^{-1}$ for the fast phase and a volume change $21 \pm 2 \mathrm{~mL} \mathrm{~mol}^{-1}$ and an enthalpy change of $35 \pm 16$ $\mathrm{kcal} \mathrm{mol}^{-1}$ for the slow phase. The values of volume and enthalpy changes associated with the fast phase for $\mathrm{Ca}^{2+}$ binding to $\mathrm{CaM}$ are comparable to those obtained from the photo dissociation of $\mathrm{Ca}^{2+}$-DM-nitrophen. The kinetics of the slow phase is about $600 \mu \mathrm{s}$. 
The rates for the slow phase as a function of CaM concentration were also measured and are shown in Figure 5.13. From the analysis of the rate of slow phase kinetics as a function of CaM concentration, using the Michaelis-Menten approach (Equation 24), a value of $2 \times 10^{-5} \mathrm{M}$ for $\mathrm{K}_{\mathrm{M}}$ and $2764 \mathrm{~s}^{-1}$ for $\mathrm{v}_{\max }$ were obtained.

$$
v_{0}=\frac{v_{\max }[S]}{K_{M}+[S]}
$$

where $v_{0}$ is the initial reaction rate, $v_{\max }$ is the maximum reaction rate, $\mathrm{S}$ represents the substrate concentration and $K_{M}$ stands for the Michaelis-menten constant.

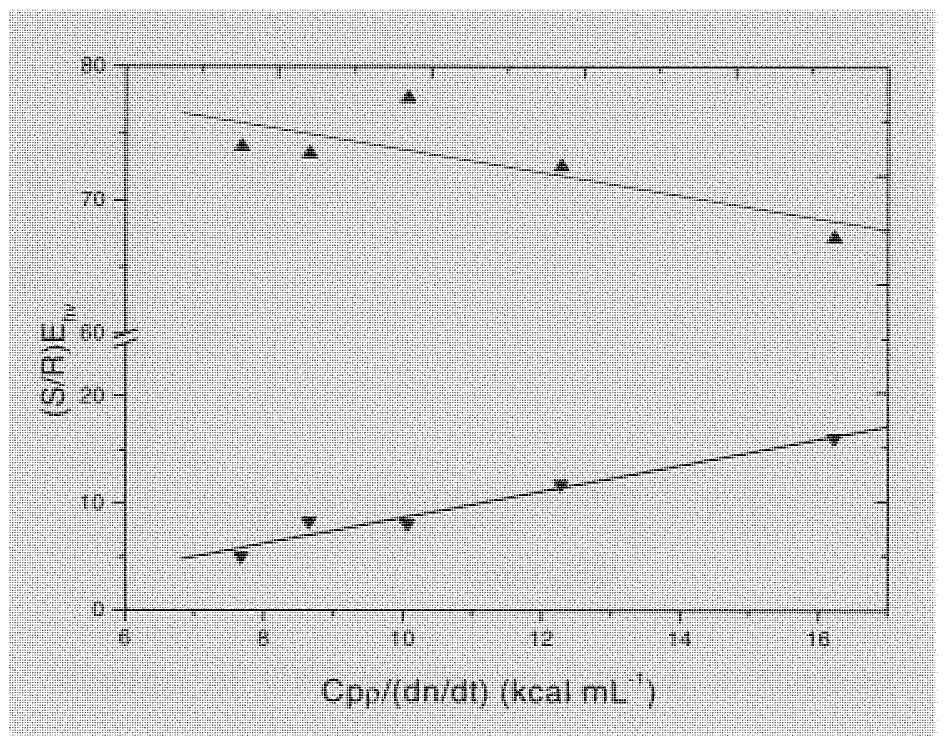

Figure 5.12. Plot of $(\mathrm{S} / \mathrm{R}) \mathrm{E}_{\mathrm{hv}}$ versus $\mathrm{Cp} \rho /(\mathrm{dn} / \mathrm{dt}) \rho$ for the photolysis of $\mathrm{Ca}^{2+} \mathrm{DM}$-nitrophen in the presence of CaM. 
Table 5.2.Volume and enthalpy changes associated with the photodissociation of $\mathrm{Ca}^{2+}$ DM-nitrophen in the presence of CaM.

\begin{tabular}{|l|l|l|l|c|c|}
\hline & $\begin{array}{c}\Delta \mathrm{V}_{1} \\
\mathrm{~mL} \mathrm{~mol}^{-1}\end{array}$ & $\begin{array}{c}\Delta \mathrm{H}_{1} \\
\mathrm{kcal} \mathrm{mol}^{-1}\end{array}$ & $\begin{array}{c}\Delta \mathrm{V}_{2} \\
\mathrm{~mL} \mathrm{~mol}^{-1}\end{array}$ & $\begin{array}{c}\Delta \mathrm{H}_{2} \\
\mathrm{kcal} \mathrm{mol}^{-1}\end{array}$ & $\begin{array}{c}\tau \\
\left(20^{\circ} \mathrm{C}\right)\end{array}$ \\
\hline $\mathrm{CaM}+\mathrm{Ca}^{2+}$-DM-nitrophen & $-13 \pm 3$ & $-61 \pm 32$ & $21 \pm 2$ & $35 \pm 16$ & $600 \mu \mathrm{s}$ \\
\hline
\end{tabular}

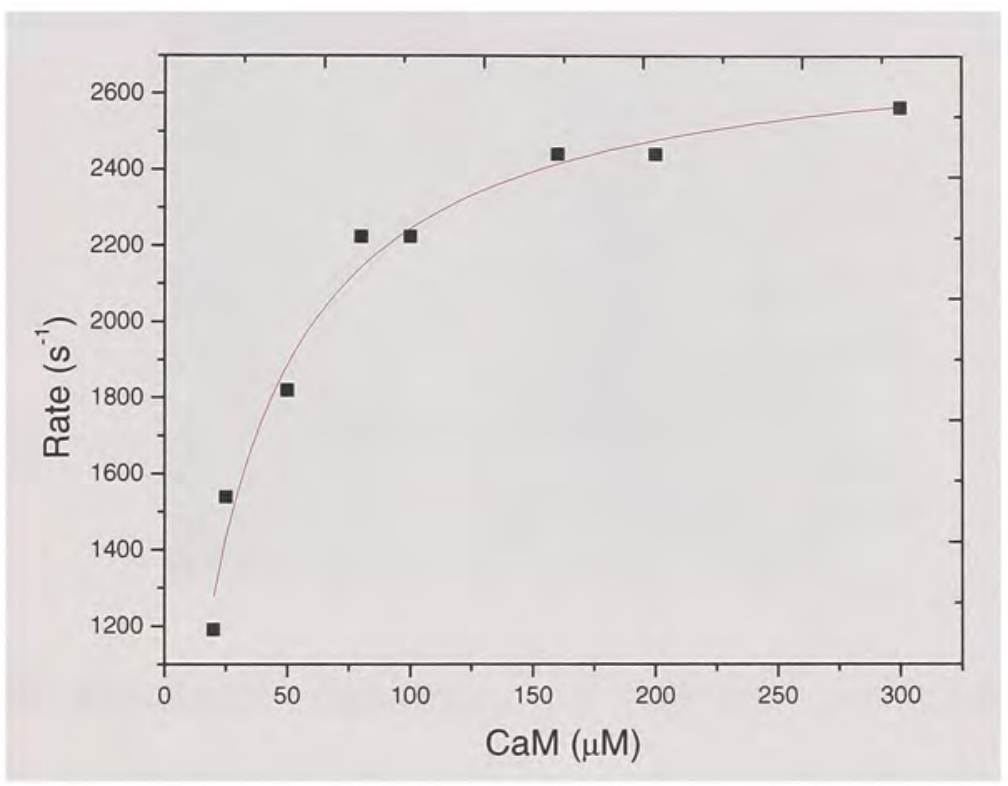

Figure 5.13. Kinetics of $\mathrm{Ca}^{2+}$ binding to $\mathrm{CaM}$ as a function of $\mathrm{CaM}$ concentration. Conditions: CaM in $20 \mathrm{mM}$ HEPES buffer, $\mathrm{pH} 7.42,100 \mathrm{mM} \mathrm{KCl}, 450 \mu \mathrm{M}$ DMnitrophen and $450 \mu \mathrm{M} \mathrm{CaCl}_{2}$. 


\subsection{Study on DREAM}

\subsection{Electrophoresis}

Down stream Regulatory Antagonist Modulator (DREAM) was isolated as described in Materials and Methods section and its purity wasverified using $15 \%$ SDS-PAGE electrophoresis. Electrophoresis is shown in Figure 5.14 and exihibits a single band at 22 $\mathrm{kDa}$ that corresponds to DREAM, indicating that the protein was isolated in pure form.

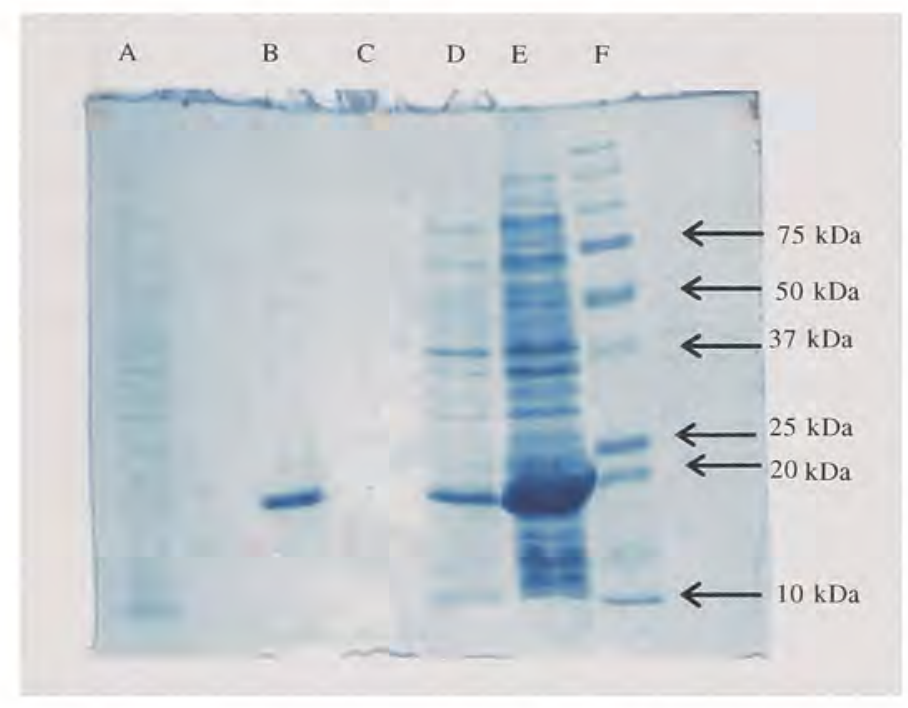

Figure 5.14. SDS-PAGE electrophoresis of DREAM. Lane A) eluate with buffer A containing $10 \mathrm{mM}$ imidazole; B) eluate with buffer A containing $300 \mathrm{mM}$ imidazole; C) eluate with buffer A containing; D) supernatant; E) cell lysate; F) molecular weight markers.

\subsubsection{CD -Spectroscopy}

The CD-spectra were measured for DREAM in the absence and presence of $\mathrm{Ca}^{2+}$ as shown in Figure 5.15. Addition of $\mathrm{Ca}^{2+}$ to the apo DREAM leads to the decrease of the $\mathrm{CD}$ signal at $222 \mathrm{~nm}$, indicating that $\mathrm{Ca}^{2+}$ binding to DREAM results in increase of 
the $\alpha$-helical content in the DREAM structure. Similar changes in DREAM spectra were reported previously by Craig et al. (2002). Indeed, an increase in the secondary structure upon $\mathrm{Ca}^{2+}$ binding seems to be characteristic of EF-hand proteins and it was reported for CaM (Martin et al. 1986, Zhang et al. 1995) and KChIP 2 (Chen et al. 2006).

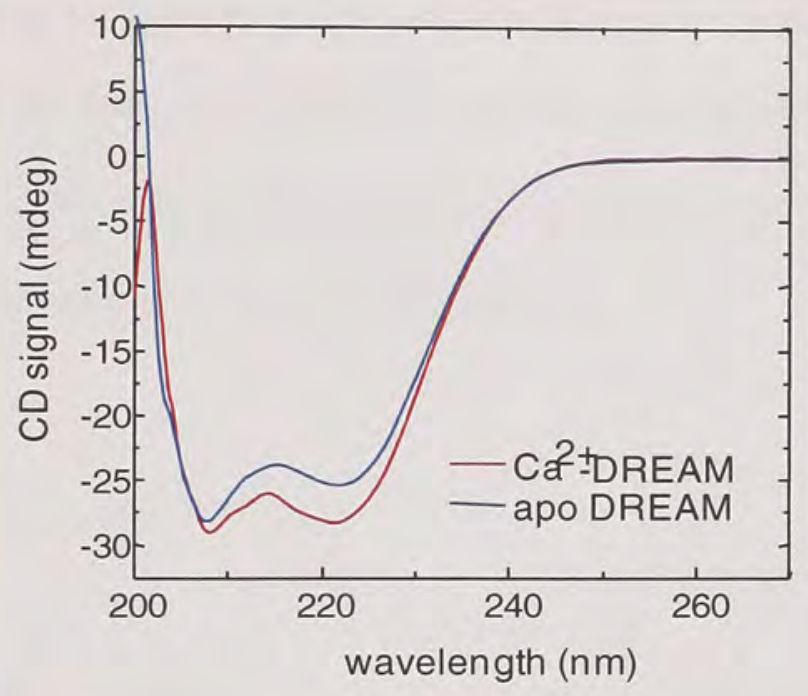

Figure 5.15. CD-spectra of DREAM in the apo and $\mathrm{Ca}^{2+}$ bound form. Conditions: $10 \mu \mathrm{M}$ DREAM in $20 \mathrm{mM}$ Tris buffer, $\mathrm{pH} 7.42,10 \mathrm{mM}$ LDAO, $1 \mathrm{mM}$ DTT, $1 \mathrm{mM}$ EDTA or 1 $\mathrm{mM} \mathrm{CaCl}_{2}$. 


\subsubsection{Steady state Emission spectra}

The steady state emission spectra of DREAM were recorded for apo, $\mathrm{Ca}^{2+}$ and $\mathrm{Mg}^{2+}$ bound forms of DREAM. In the apo form of DREAM, the emission spectrum shows a maximum at $345 \mathrm{~nm}$. The emission spectrum is blue shifted to $340 \mathrm{~nm}$ with a concomitant decrease in emission intensity upon the addition of $\mathrm{Ca}^{2+}$. A similar impact of $\mathrm{Ca}^{2+}$ binding on emission spectra was reported in previous studies by Osawa et al. (Osawa et al. 2005). The emission spectrum of $\mathrm{Mg}^{2+}$-DREAM is similar to the apo protein since any change in the emission maxima or emission intensity was not detected. The emission spectra are shown in Figure 5.16.

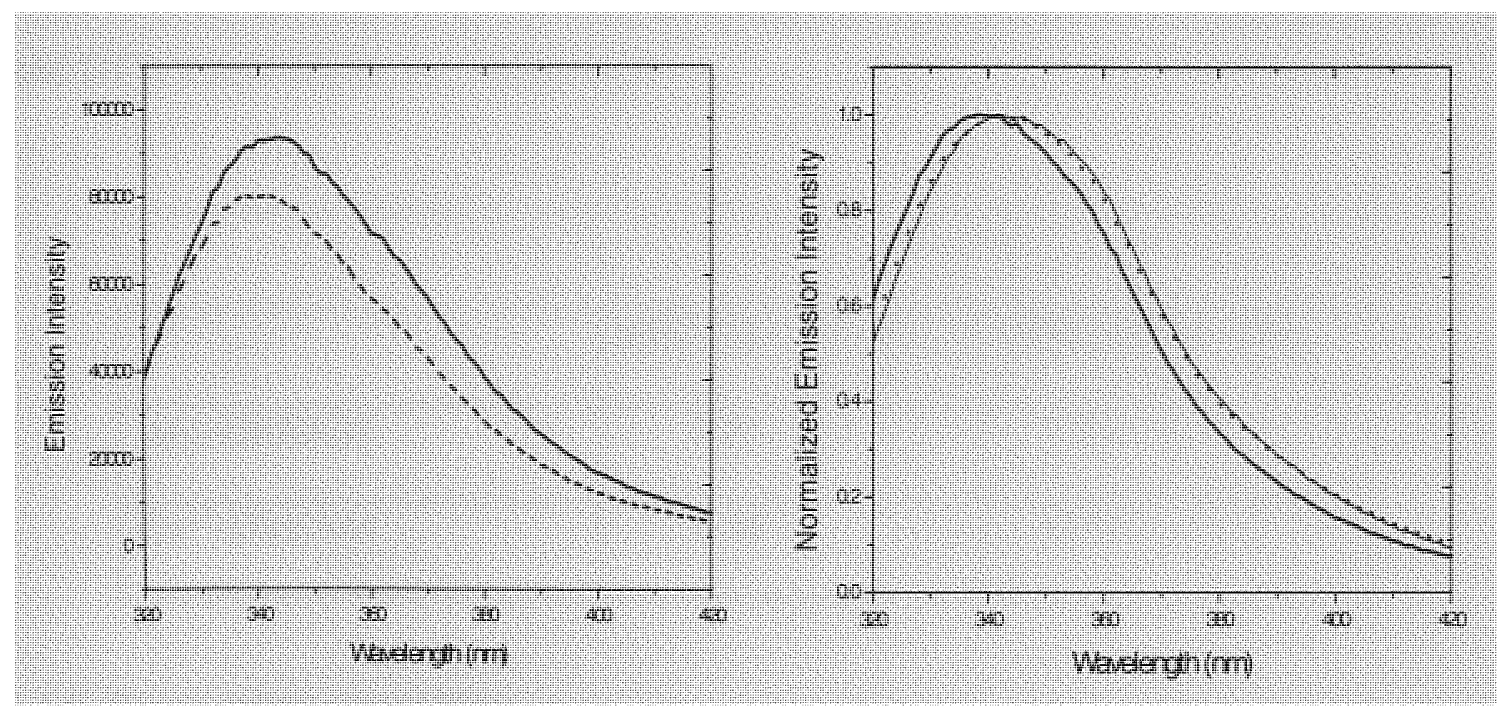

Figure 5.16. Emission spectra of DREAM. Left panel: Emission spectra of DREAM in the presence (dashed) and absence (solid) of $\mathrm{Ca}^{2+}$. Right panel: Overlay of normalized emission spectra in apo form (thin line), $\mathrm{Ca}^{2+}$ bound form (thick line) and $\mathrm{Mg}^{2+}$ bound form (dashed line). Conditions: $10 \mu \mathrm{M}$ DREAM in $20 \mathrm{mM}$ Tris buffer, pH7.42, $10 \mathrm{mM}$ LDAO, $1 \mathrm{mM}$ DTT, $1 \mathrm{mM}$ EGTA or $1 \mathrm{mM} \mathrm{CaCl} 2$ or $1 \mathrm{mM} \mathrm{MgCl} \mathrm{M}_{2}$. 


\subsubsection{Steady state polarization}

I used steady-state polarization to obtain information about changes in the DREAM oligomerization state upon $\mathrm{Ca}^{2+}$ addition. The data are shown Table 5.3. Interestingly my data did not show any significant differences in the apo and $\mathrm{Ca}^{2+}$ bound form of the protein. At $10 \mu \mathrm{M}$ DREAM, the polarization values are 0.37 and 0.38 in the apo and $\mathrm{Ca}^{2+}$ bound form of DREAM respectively. On the other hand, the polarization values are somewhat smaller for DREAM at $87 \mu \mathrm{M}$, which showed 0.33 for apo and 0.32 for $\mathrm{Ca}^{2+}$ bound form.

Table 5.3. Fluorescence polarization data for DREAM in the apo and $\mathrm{Ca}^{2+}$ bound forms. Conditions: $10 \mu \mathrm{M}$ or $87 \mu \mathrm{M}$ DREAM in $20 \mathrm{mM}$ Tris buffer, $\mathrm{pH}$ 7.42, $10 \mathrm{mM}$ LDAO, 1 mM DTT, $1 \mathrm{mM}$ EGTA or $1 \mathrm{mM} \mathrm{CaCl}$.

\begin{tabular}{|l|c|c|}
\hline & \multicolumn{2}{|c|}{ Polarization } \\
\hline & DREAM $(10 \mu \mathrm{M})$ & DREAM $(87 \mu \mathrm{M})$ \\
\hline apo-DREAM & 0.37 & 0.33 \\
\hline $\mathrm{Ca}^{2+}$-DREAM & 0.38 & 0.32 \\
\hline
\end{tabular}

\subsubsection{Tryptophan quenching}

Steady-state fluorescence quenching studies were carried out to probe the position and environment of Trp 169 in the apo and $\mathrm{Ca}^{2+}$ bound forms of DREAM. The analysis of quenching data was performed using the Stern-Volmer Equation 25 (Lakowicz et al. 2010) 


$$
F_{0} / F=1+K_{S V}[Q]
$$

Where $F_{0}$ is the emission intensity before the addition of quencher and $F$ is the emission intensity in the presence of quencher as shown in Figure 5.17. $K_{S V}$ is the Stern-Volmer constant and $\mathrm{Q}$ is the concentration of the quencher. $\mathrm{K}_{\mathrm{sv}}$ values were obtained from the slope of the plot of $\mathrm{F}_{0} / \mathrm{F}$ versus [Quencher], using acrylamide and $\mathrm{KI}$ as quenchers. Acrylamide and $\mathrm{KI}$ are expected to have more accessibility for Trp in the apo DREAM, as it is more solvent exposed (Osawa et al. 2005).
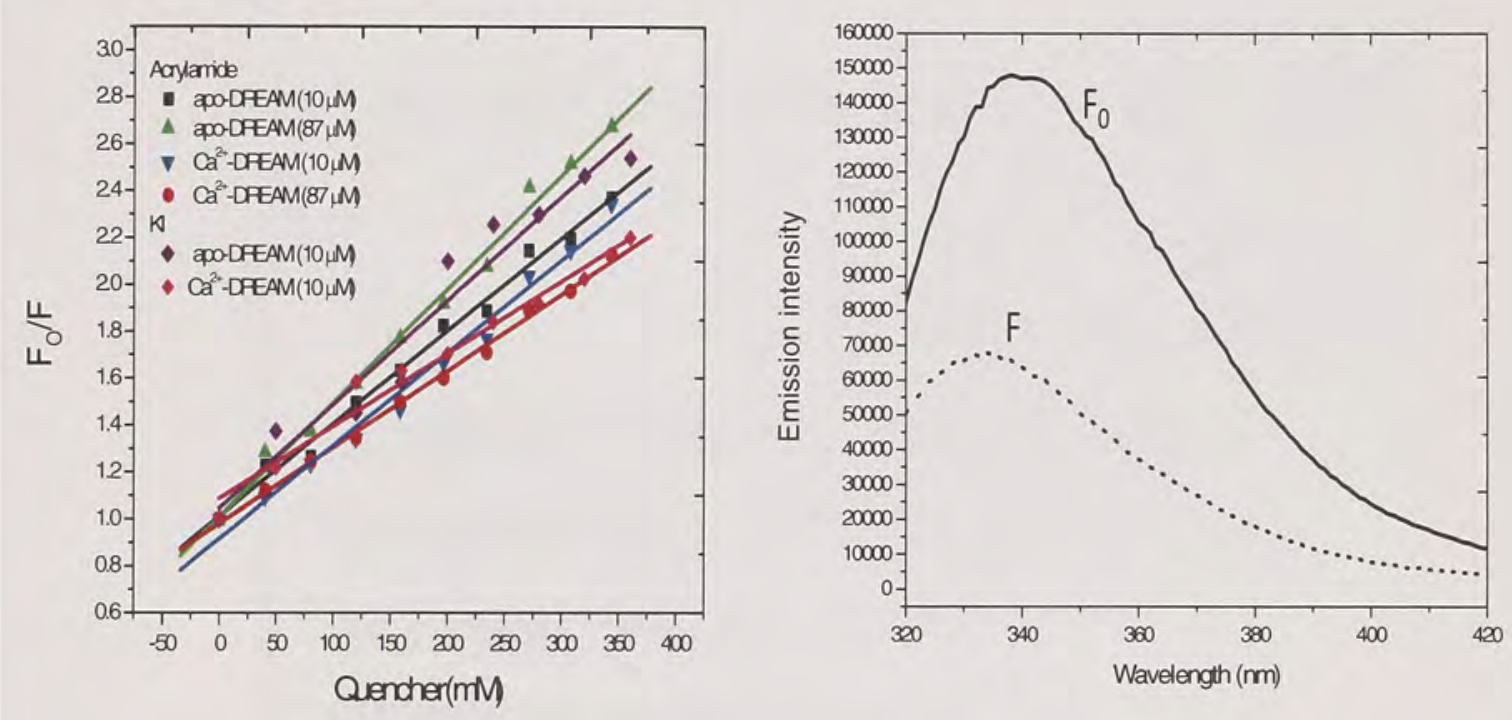

Figure 5.17. Right panel: Stern-Volmer plots for quenching of Trp fluorescence by acrylamide and KI. Left panel: Emission spectra of apo DREAM without quencher $\left(\mathrm{F}_{0}\right)$ and in the presence of $320 \mathrm{mM}$ acrylamide (F). Conditions: 10 and $87 \mu \mathrm{M}$ DREAM is dissolved in $20 \mathrm{mM}$ Tris buffer, $\mathrm{pH}$ 7.42, $10 \mathrm{mM}$ LDAO, $1 \mathrm{mM}$ DTT. 
As expected our data showed higher $\mathrm{K}_{\mathrm{sv}}$ values for the apo form, indicating that $\operatorname{Trp}$ emission is more quenched in the apo form than in $\mathrm{Ca}^{2+}$-DREAM. Quenching of $10 \mu \mathrm{M}$ DREAM with acrylamide provided $\mathrm{K}_{\mathrm{sv}}$ values of $3.97 \pm 0.01 \mathrm{M}^{-1}$ and $3.26 \pm 0.01 \mathrm{M}^{-1}$ for the apo and $\mathrm{Ca}^{2+}$ bound forms, respectively. On the other hand, for $87 \mu \mathrm{M}$ DREAM, the $\mathrm{K}_{\text {sv }}$ values were $4.8 \pm 0.1 \mathrm{M}^{-1}$ in apo and $3.9 \pm 0.1 \mathrm{M}^{-1}$ in $\mathrm{Ca}^{2+}$ bound form. In the case of $\mathrm{KI}$, the $\mathrm{K}_{\mathrm{sv}}$ values for quenching of at $10 \mu \mathrm{M}$ DREAM were $4.8 \pm 0.1 \mathrm{M}^{-1}$ and $3.3 \pm 0.1$ $\mathrm{M}^{-1}$ in apo and $\mathrm{Ca}^{2+}$ bound forms, respectively. The quenching was more effective with KI. Stern-Volmer plots are shown in Figure 5.17 and the $\mathrm{K}_{\mathrm{sv}}$ values are listed in Table 5.4 .

Table 5. 4. $\mathrm{K}_{\mathrm{sv}}$ values obtained for Trp quenching by acrylamide and $\mathrm{KI}$.

\begin{tabular}{|c|c|c|}
\hline \multirow{2}{*}{ Sample } & acrylamide & KI \\
\cline { 3 - 4 } & $\mathrm{K}_{\mathrm{sv}}\left(\mathrm{M}^{-1}\right)$ & $\mathrm{K}_{\mathrm{sv}}\left(\mathrm{M}^{-1}\right)$ \\
\hline apo-DREAM $(10 \mu \mathrm{M})$ & $3.97 \pm 0.01$ & $4.82 \pm 0.1$ \\
\hline $\mathrm{Ca}^{2+}$-DREAM $(10 \mu \mathrm{M})$ & $3.26 \pm 0.01$ & $3.31 \pm 0.1$ \\
\hline apo-DREAM $(87 \mu \mathrm{M})$ & $4.8 \pm 0.1$ & - \\
\hline $\mathrm{Ca}^{2+}$-DREAM $(87 \mu \mathrm{M})$ & $3.9 \pm 0.1$ & - \\
\hline
\end{tabular}

\subsubsection{Probing the hydrophobic surfaces using 1,8-ANS, 2,6-ANS and nile red.}

Hydrophobic surface probing agents 2,6-ANS, 1,8-ANS and nile red were used to obtain information about differences in the hydrophobic surface exposure in the apo and $\mathrm{Ca}^{2+}$ bound forms of DREAM. The structures of the probes are shown in Figure 5.18. These probes have been successfully used to monitor changes in hydrophobic surfaces of other 
proteins (Cocco et al. 1994, Itzhaki et al. 1994, Nishihira et al. 1993). They have a low fluorescence quantum yield in water but become highly fluorescent upon association to hydrophobic surfaces (Hawe et al. 2008). However, I could not use these agents in the presence of LDAO as the probes preferentially interact with the surfactant. Hence, samples were prepared in the absence of LDAO and steady state emission spectra were measured. At first I measured the emission spectra of DREAM in the absence of LDAO. Interestingly, in the absence of LDAO no difference was observed in the emission spectrum of $\operatorname{Trp}$ in apo and $\mathrm{Ca}^{2+}$ DREAM. Both the spectra showed the same emission maxima at $332 \mathrm{~nm}$ with identical intensity as shown in Figure 5.19. These results are in agreement with the previous studies that showed LDAO increases the DREAM solubility and promotes oligomerization of DREAM (Osawa et al. 2005).

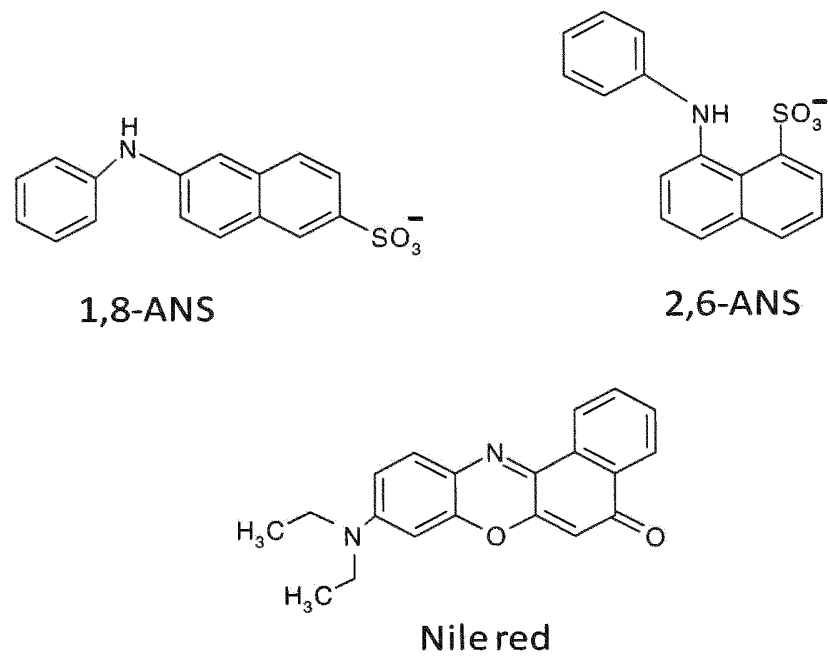

Figure 5.18. Structures of hydrophobic surface probing agents 


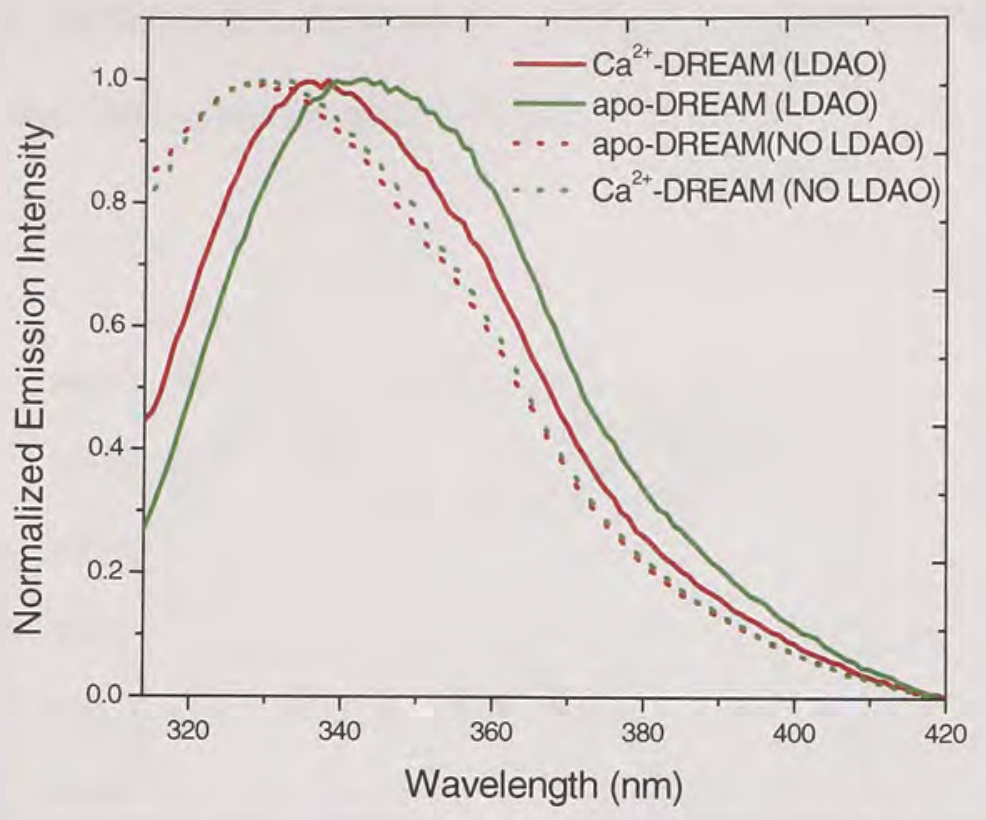

Figure 5.19. Emission spectra of DREAM in the presence and absence of LDAO. Conditions: $10 \mu \mathrm{M}$ DREAM in $20 \mathrm{mM}$ Tris buffer, $\mathrm{pH} 7.42,1 \mathrm{mM}$ DTT in the presence or absence of $10 \mathrm{mM}$ LDAO.

I measured the steady state emission spectra of 1,8-ANS, 2,6-ANS and nile red in apo and $\mathrm{Ca}^{2+}$ bound form of DREAM. The obtained spectra are shown in Figure 5.20. In the absence of $\mathrm{Ca}^{2+}$ the emission spectrum of 2,6-ANS showed an emission maxima at 460 nm. Upon $\mathrm{Ca}^{2+}$ addition, the emission spectrum is red shifted to $463 \mathrm{~nm}$. On the other hand, 2,6-ANS showed an emission maximum at $431 \mathrm{~nm}$ in the apo form and is blue shifted to $426 \mathrm{~nm}$ in the $\mathrm{Ca}^{2+}$ bound protein. In case of the nile red, the emission spectrum is very similar in the apo and $\mathrm{Ca}^{2+}$ bound forms of the protein with emission maximum at $622 \mathrm{~nm}$ but with a small increase in the emission intensity in the $\mathrm{Ca}^{2+}$ bound form. The obtained results show that all the three probes bind to different hydrophobic 
surfaces on the DREAM protein surface and there is larger hydrophobic surface exposed in $\mathrm{Ca}^{2+}$ bound form compared to apo protein.

A

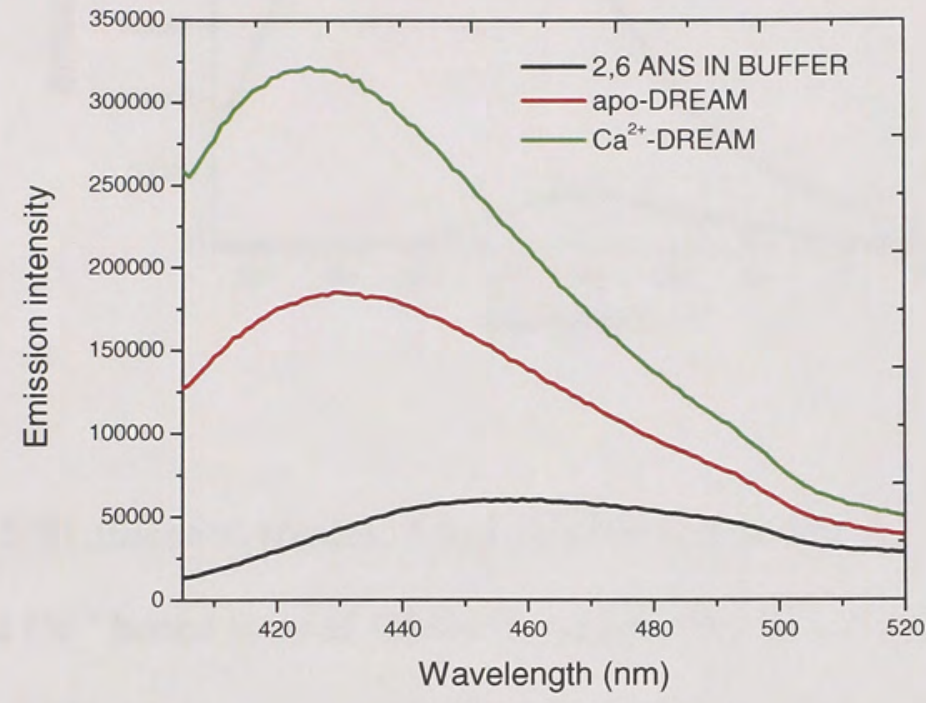

B

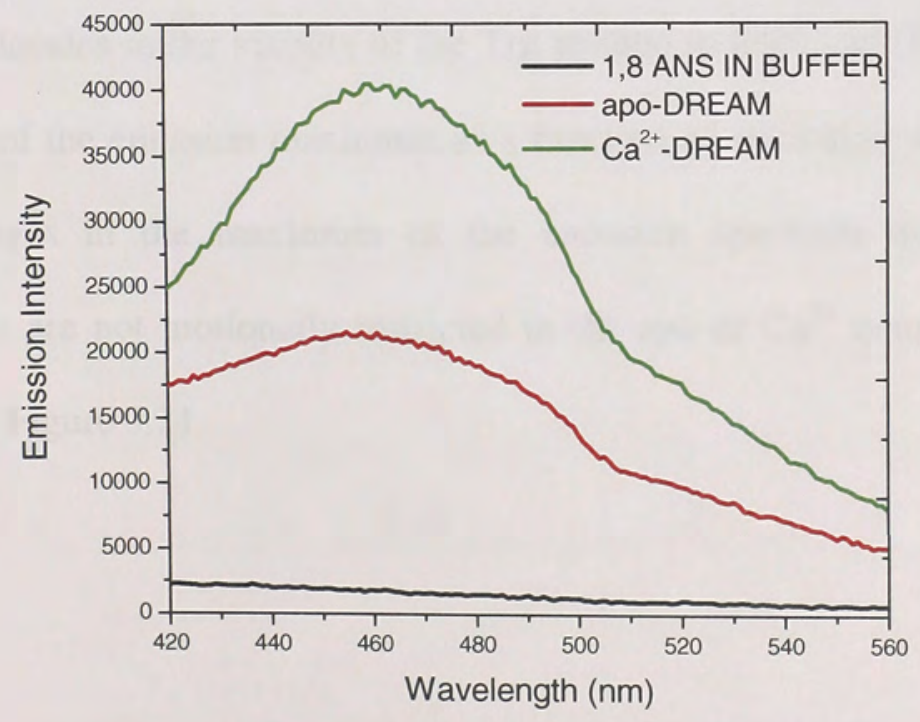




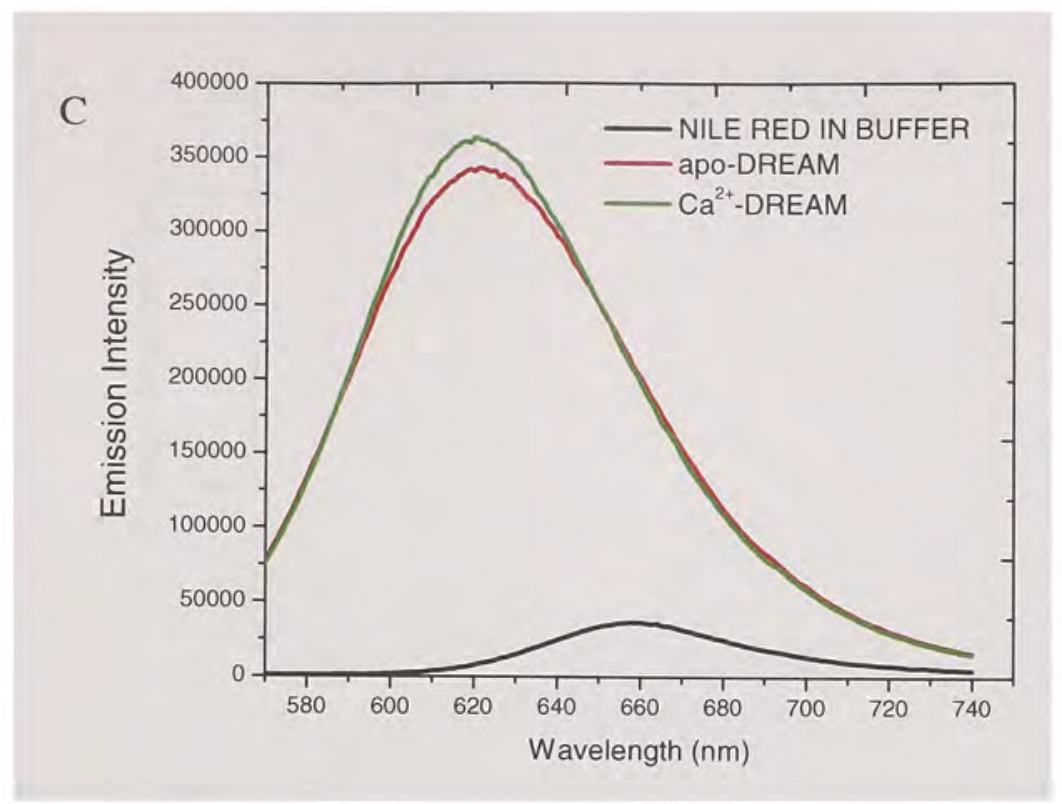

Figure 5.20. Emission spectra of hydrophobic surface probing agents in buffer and in the apo and $\mathrm{Ca}^{2+}$ bound form of DREAM. A) 2,6-ANS B) 1,8-ANS C) nile red. Conditions: $10 \mu \mathrm{M}$ DREAM dissolved in $20 \mathrm{mM}$ Tris, $\mathrm{pH} 7.42,1 \mathrm{mM}$ DTT, $1 \mathrm{mM} \mathrm{CaCl}_{2}$ or $1 \mathrm{mM}$ EGTA, $1 \mu \mathrm{M}$ 2,6-ANS or 1,8-ANS or nile red.

\subsubsection{REES Spectrum}

Red edge excitation shift (REES) measurements were made to probe the mobility of water molecules in the vicinity of the Trp residue in DREAM (Raghuraman et al. 2005). The plot of the emission maximum as a function of excitation wavelength did not show any changes in the maximum of the emission spectrum indicating that the water molecules are not motionally restricted in the apo or $\mathrm{Ca}^{2+}$ bound forms of DREAM as shown in Figure 5.21. 


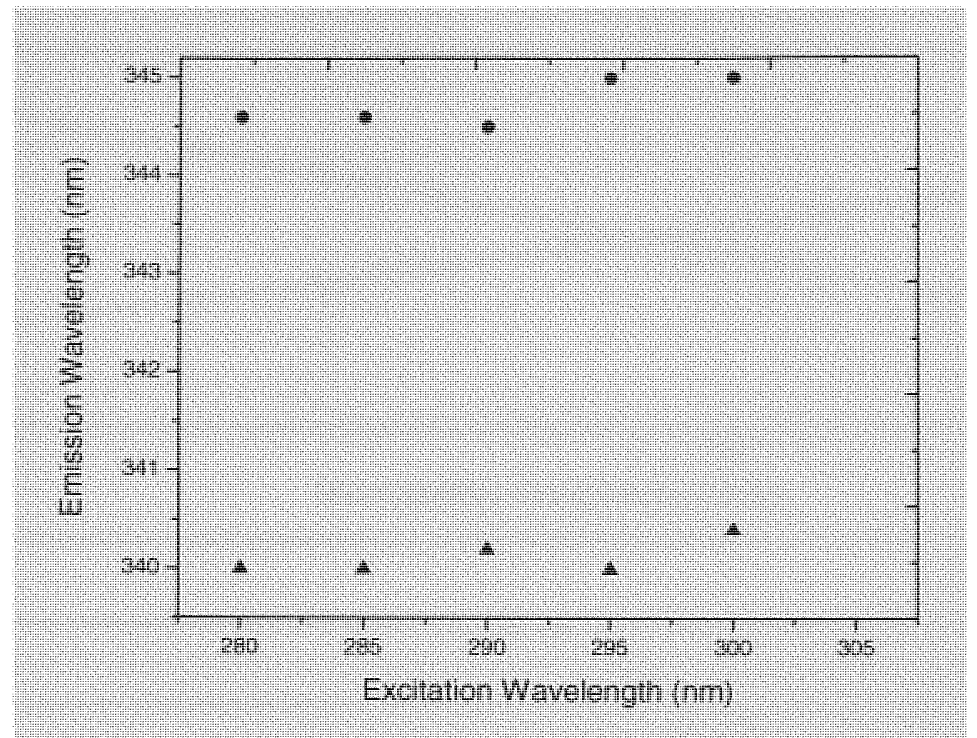

Figure 5.21. REES spectra for DREAM in the apo (circles) and $\mathrm{Ca}^{2+}$ bound form (triangles). Conditions: $10 \mu \mathrm{M}$ DREAM in $20 \mathrm{mM}$ Tris buffer, $\mathrm{pH}$ 7.42, $10 \mathrm{mM}$ LDAO, 1 mM DTT, $1 \mathrm{mM} \mathrm{EGTA} \mathrm{or} 1 \mathrm{mM} \mathrm{CaCl}{ }_{2}$.

\subsubsection{Fluorescence lifetime data}

Fluorescence lifetime of the $\operatorname{Trp} 169$, which is situated in the vicinity of the high affinity $\mathrm{Ca}^{2+}$ binding site, EF-hand 3, was measured using a frequency modulation approach to probe the dynamics of the protein. The data were best fitted to a sum of discrete exponential decay and Guassian distribution. The fit is shown in Figure 5.22 and the obtained fitting parameters are shown in Table 5.5. Phase delay (circles) and modulation ratio (squares) at each frequency in the range of 50 to $250 \mathrm{MHz}$ are shown and the solid lines represents the fit. The lifetimes obtained in the presence of $\mathrm{Mg}^{2+}$ are similar to that of the apo form, but upon $\mathrm{Ca}^{2+}$ binding the equilibrium shifted towards the fraction of the molecules having longer lifetime. In addition, the distribution of the $3.20 \mathrm{~ns}$ lifetime becomes broader in the $\mathrm{Ca}^{2+}$ bound form compared to apo form. 


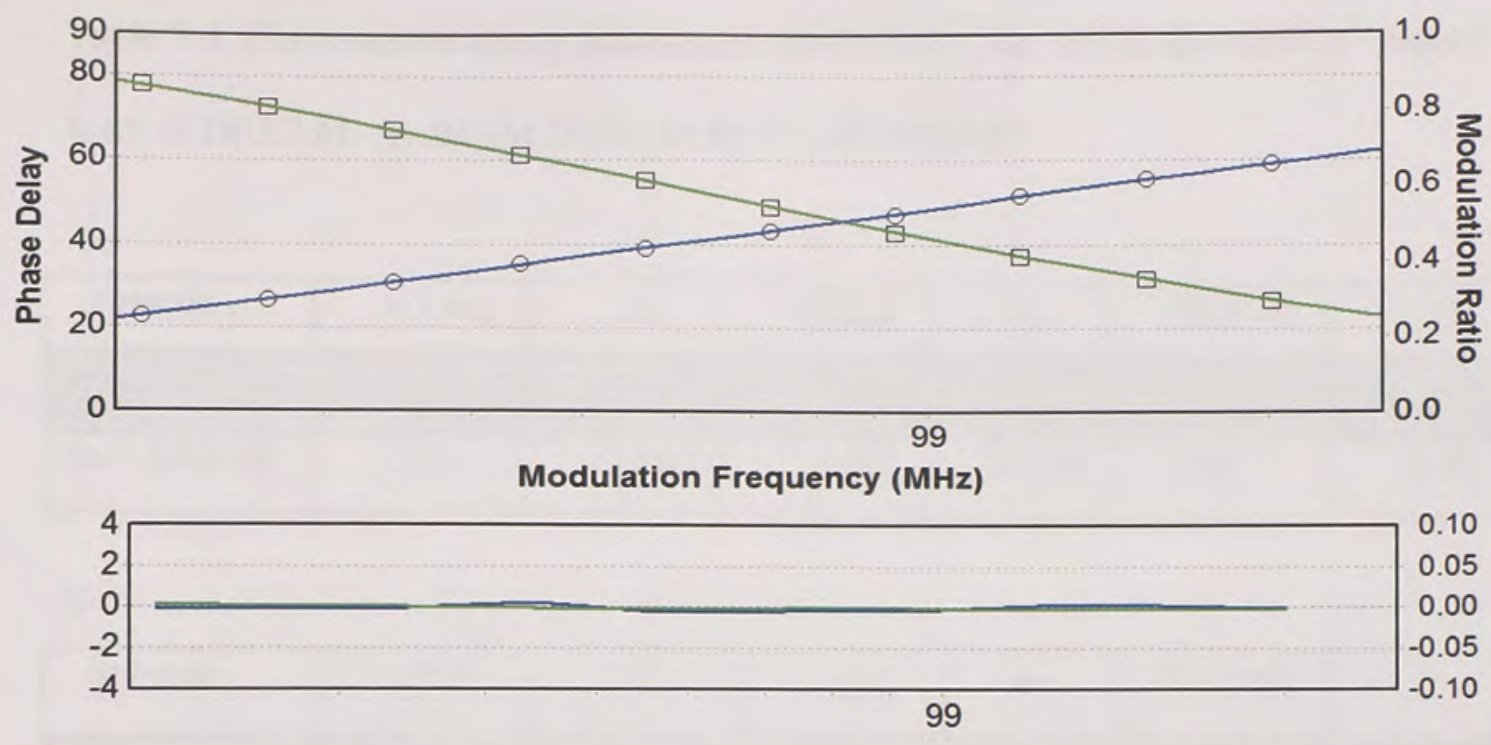

Figure 5.22. Top: Phase delay (squares) and modulation ratio (circles) in the frequency range of 50 to $250 \mathrm{MHz}$. Bottom: Residuals of the fit of phase delay (blue) and modulation ratio (green). Solid lines indicate the fit to sum of the discrete exponential decays and Guassian distribution. Conditions: $10 \mu \mathrm{M}$ or $87 \mu \mathrm{M}$ DREAM in $20 \mathrm{mM}$ Tris buffer, pH 7.42, 1 mM DTT, 10 mM LDAO, 1 mM EGTA or $1 \mathrm{mM} \mathrm{Ca}^{2+}$. 
Table 5.5. Fluorescence decay parameters obtained for $\operatorname{Trp} 169$ in apo and $\mathrm{Ca}^{2+}$ bound form of DREAM. A) $10 \mu \mathrm{M}$ DREAM B) $87 \mu \mathrm{M}$ DREAM

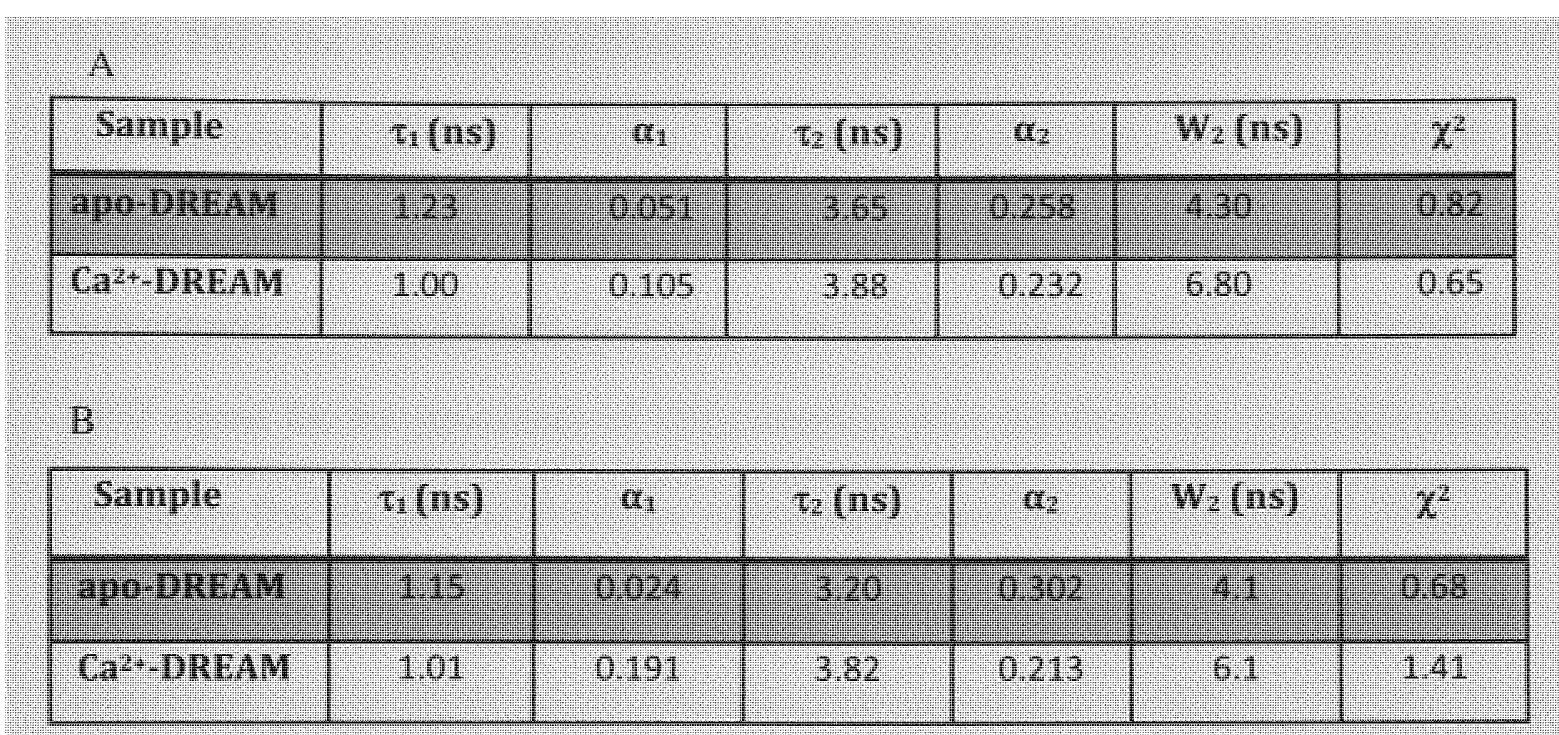




\subsection{Discussion}

\subsection{Photodissociation of DM-nitrophen}

Using PBD, the volume and enthalpy changes associated with the photodissociation of DM-nitrophen, $\mathrm{Ca}^{2+}-\mathrm{DM}$-nitrophen, and $\mathrm{Mg}^{2+}-\mathrm{DM}$-nitrophen were determined. In addition, using PBD in combination with the caged $\mathrm{Ca}^{2+}$ compound DM-nitrophen the volume and enthalpy changes associated with $\mathrm{Ca}^{2+}$ binding to $\mathrm{CaM}$ were determined. The PBD signal for the photolysis of DM-nitrophen does not show any detectable kinetics indicating that the photodissociation of this compound is completed within $20 \mu$ s. The observed volume change of $12 \pm 1 \mathrm{~mL} \mathrm{~mol}^{-1}$ and enthalpy change of $63 \pm 6 \mathrm{kcal} \mathrm{mol}^{-1}$ determined for the photolysis of DM-nitrophen are consistent with the cleavage of the single covalent bond, since the photodissociation of DM-nitrophen involves the cleavage of three covalent bonds ( $\mathrm{C}-\mathrm{N}, \mathrm{N}-\mathrm{O}, \mathrm{C}-\mathrm{H})$ and concomitant formation of two covalent bonds $(\mathrm{C}=\mathrm{O}, \mathrm{N}-\mathrm{H})$ as shown in Scheme 4 (Kaplan et al. 1988).

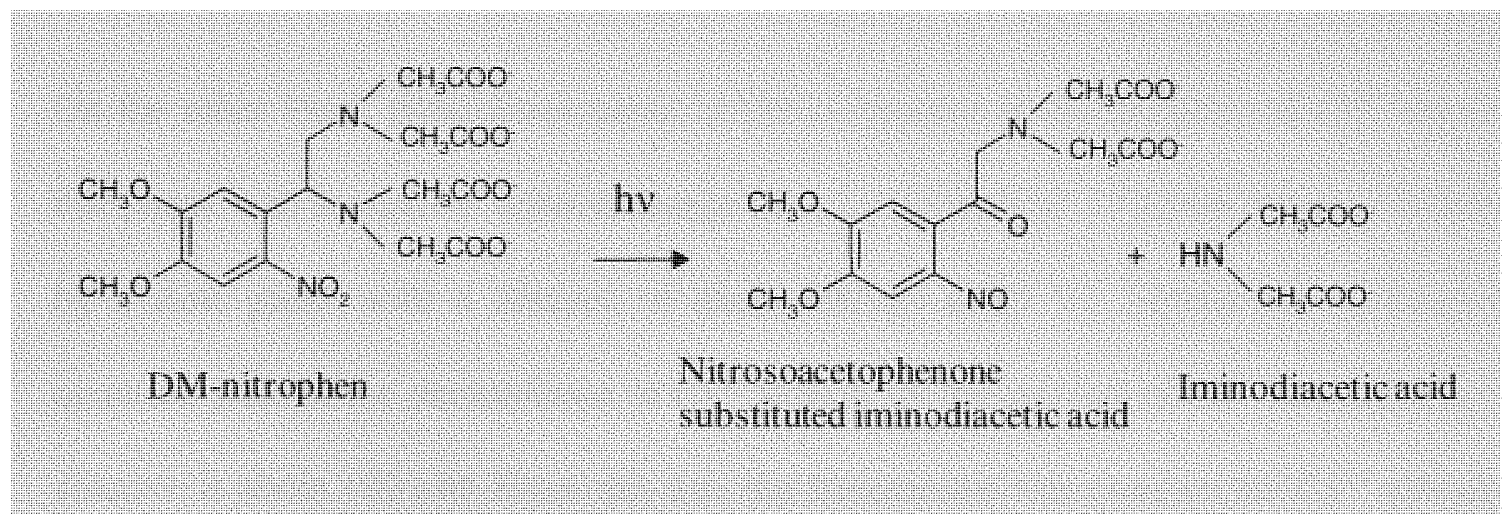

Scheme 4:

In addition previous studies have shown that the volume change associated with dissociation of a single covalent bond is about $5-10 \mathrm{~mL} \mathrm{~mol}^{-1}$ (Hunget et al. 1992., 
Herman et al. 1987). The reaction enthalpy change can be estimated on the basis of the bond enthalpies for the covalent bonds cleaved/formed during the photolysis of DMnitrophen, and are listed in Table 6.1. The calculated enthalpy value can be compared to the observed reaction enthalpy change of $63 \pm 6 \mathrm{kcal} \mathrm{mol}^{-1}$. The difference between the calculated and observed enthalpy change is because of the fact that the bond enthalpies strongly depend on the environment in which the bond exists.

Table 6.1. Bond enthalpies for the covalent bonds involved in the photodissociation of DM-nitrophen

\begin{tabular}{|c|c|c|c|}
\hline Bonds dissociated & $\Delta \mathrm{H}\left(\mathrm{kcal} \mathrm{mol}^{-1}\right)$ & Bonds formed & $\Delta \mathrm{H}\left(\mathrm{kcal} \mathrm{mol}^{-1}\right)$ \\
\hline C-N & 71 & $\mathrm{C}=\mathrm{O}$ & 167 \\
\hline $\mathrm{N}-\mathrm{O}$ & 120 & $\mathrm{~N}-\mathrm{H}$ & 91 \\
\hline $\mathrm{C}-\mathrm{H}$ & 98 & - & - \\
\hline
\end{tabular}

On the other hand, photodissociation of DM-nitrophen in the presence of $\mathrm{Ca}^{2+}$ shows a fast phase with a negative volume change of $-12 \pm 5 \mathrm{~mL} \mathrm{~mol}^{-1}$. The fast phase is followed by a slow phase with a lifetime of about $400 \mu$ s at $20^{\circ} \mathrm{C}$. Taking into account the quantum yield of the photorelease of $\mathrm{Ca}^{2+}$ to be 0.18 , the amount of $\mathrm{Ca}^{2+}$ released into the solution is about $180 \mu \mathrm{M}$. From this data the bimolecular rate constant for $\mathrm{Ca}^{2+}$ rebinding to DM-nitrophen is determined to be $13.8 \times 10^{6} \mathrm{M}^{-1} \mathrm{~s}^{-1}$. Similar rate constants were reported previously for $\mathrm{Ca}^{2+}$ binding to other $\mathrm{Ca}^{2+}$ chelators like EGTA and H-EDTA to be $2.7 \times 10^{6}$ and $4.5 \times 10^{6} \mathrm{M}^{-1} \mathrm{~s}^{-1}$ respectively (Naraghi et al. 1997). The slow phase 
exihibits a volume change of $9 \pm 3 \mathrm{~mL} \mathrm{~mol}^{-1}$ and an enthalpy change of $-19 \pm 13 \mathrm{kcal}$ $\mathrm{mol}^{-1}$. On the basis of those values, the slow phase can be associated with $\mathrm{Ca}^{2+}$ rebinding to the unphotolysed DM-nitrophen. The observed volume and enthalpy changes associated with the photodissociation of DM-nitrophen and concomitant $\mathrm{Ca}^{2+}$ release during the fast phase can be represented by Equation 25 and 26

$$
\begin{aligned}
& \Delta \mathrm{V}_{1}=\Delta \mathrm{V}_{\mathrm{DM} \text {-nitr }}+\mathrm{V}_{\mathrm{C} 2+}^{\circ} \\
& \Delta \mathrm{H}_{1}=\Delta \mathrm{H}_{\mathrm{DM} \text {-nitr }}+\Delta \mathrm{H}_{\mathrm{Ca} 2+}
\end{aligned}
$$

where $\Delta V_{D M-n i t r}$ represents the volume change that results from the photodissociation of DM-nitrophen, $\mathrm{V}^{\circ} \mathrm{Ca} 2+$ is the partial molar volume of $\mathrm{Ca}^{2+}, \Delta \mathrm{H}_{\mathrm{DM} \text {-nitr }}$ stands for the enthalpy change as a result of the photodissociation of DM-nitrophen, and $\Delta \mathrm{H}_{\mathrm{Ca} 2+}$ represents the enthalpy change because of the solvation of the $\mathrm{Ca}^{2+}$ ion. Substituting the value of $\Delta V_{D M n i t r}$ as $12 \pm 1 \mathrm{~mL} \mathrm{~mol}^{-1}$ in Equation 25 , the partial molar volume for $\mathrm{Ca}^{2+}$ was determined to be $-24 \mathrm{~mL} \mathrm{~mol}^{-1}$ which is in agreement with the previously determined value of $-23 \mathrm{~mL} \mathrm{~mol}^{-1}$ by Millero et al. (Millero et al. 1971). Similarly, using a value of $61 \pm 6 \mathrm{kcal} \mathrm{mol}^{-1}$ for the enthalpy associated with the photodissociation of DM-nitrophen in Equation 26, a negative enthalpy change of $-110 \pm 20 \mathrm{kcal} \mathrm{mol}^{-1}$ is obtained which can be attributed to the solvation of the $\mathrm{Ca}^{2+}$ ion in the solution (Gifford et al. 2007., Henzl et al. 2003).

On the other hand, the reaction volume change of $9 \pm 3 \mathrm{~mL} \mathrm{~mol}^{-1}$ observed for the slow phase can be associated with $\mathrm{Ca}^{2+}$ binding to unphotolysed DM-nitrophen. The volume change for the slow phase is comparable to the volume changes determined for $\mathrm{Ca}^{2+}$ 
binding to other $\mathrm{Ca}^{2+}$ chelators like EGTA and HEDTA which were determined to be 13 $\mathrm{mL} \mathrm{mol}^{-1}$ and $11.5 \mathrm{~mL} \mathrm{~mol}^{-1}$, respectively, by Kupke et al. (Kupke et al. 1989) using densimetric techniques. The small change in enthalpy of $-19 \pm 13 \mathrm{kcal} \mathrm{mol}^{-1}$ measured for the slow phase corresponds to $\mathrm{Ca}^{2+}$ rebinding to DM-nitrophen and matches well the previously observed enthalpy change of $12 \mathrm{kcal} \mathrm{mol}^{-1}$ for $\mathrm{Ca}^{2+}$ binding to other $\mathrm{Ca}^{2+}$ chelators like EDTA determined using isothermal calorimetry (Griko et al. 1999).

Photolysis of $\mathrm{Mg}^{2+}$-DM-nitrophen exihibits a volume change of $-7 \pm 2 \mathrm{~mL} \mathrm{~mol}^{-1}$ and an enthalpy change of $-40 \pm 8 \mathrm{kcal} \mathrm{mol}^{-1}$. I propose that these values correspond to the photodissociation of $\mathrm{Mg}^{2+}-\mathrm{DM}$-nitrophen with concomitant release of $\mathrm{Mg}^{2+}$. From the reaction volume change, the partial molar volume of $\mathrm{Mg}^{2+}$ is calculated to be $-20 \mathrm{~mL}$ mol $^{-1}$ by using Equation 27 , as described for the $\mathrm{Ca}^{2+}$ ion. The partial molar volume determined for $\mathrm{Mg}^{2+}$ is in agreement with the previously reported value of $-21 \mathrm{~mL} \mathrm{~mol}^{-1}$ by Millero et al. (Millero et al. 1971). In a similar way by using the value of $63 \pm 6 \mathrm{kcal}$ $\mathrm{mol}^{-1}$ for $\Delta \mathrm{H}_{\mathrm{DM} \text {-nitr }}$ in Equation 28 , a value of $-100 \pm 20 \mathrm{kcal} \mathrm{mol}^{-1}$ for $\Delta \mathrm{H}_{\mathrm{Mg} 2+}$ was obtained and can be attributed to the solvation of the $\mathrm{Mg}^{2+}$ cation.

$$
\begin{aligned}
& \Delta \mathrm{V}=\Delta \mathrm{V}_{\mathrm{DM} \text {-nitr }}+\mathrm{V}^{\circ}{ }_{\mathrm{Mg} 2+} \\
& \Delta \mathrm{H}=\Delta \mathrm{H}_{\mathrm{DM} \text {-nitr }}+\Delta \mathrm{H}_{\mathrm{Mg} 2+}
\end{aligned}
$$

where $\mathrm{V}_{\mathrm{Mg} 2+}^{\circ}$ represents the partial molar volume of $\mathrm{Mg}^{2+}$, and $\Delta \mathrm{H}_{\mathrm{Mg} 2+}$ is the enthalpy change for the solvation of $\mathrm{Mg}^{2+}$ cation.

The relationship between the photodissociation of DM-nitrophen and the rate of $\mathrm{Ca}^{2+}$ release is still unclear. Previous studies by Ellis-Davis et al. (Ellis-Davis et al. 1996) and 
McCray et al. (McCray et al. 1992) have used $\mathrm{Ca}^{2+}$ fluorescent indicators in combination with laser flash photolysis to monitor the rate of $\mathrm{Ca}^{2+}$ release. However, the kinetic data obtained from these measurements strongly depends on the response time of the $\mathrm{Ca}^{2+}$ indicator used. For example, the Ca-orange- $5 \mathrm{~N}$ fluorophore used by Ellis-Davis et al. (Ellis-Davis et al. 1996) has a response time slower than $60 \mu$ s and those cannot represent the $\mathrm{Ca}^{2+}$ release from the DM-nitrophen Photolysis. Thus, by using PBD the rate of release of $\mathrm{Ca}^{2+}$ from $\mathrm{Ca}^{2+}$-DM-nitrophen was shown to occur within $20 \mu$ s concomitantly with the dissociation of aci-nitro intermediates. Previous transient absorption studies have shown that the decay of aci-nitro intermediates occurs in two parallel pathways via cis and trans aci-nitro intermediates and exihibits a biphasic decay with the lifetime of 13 $\mu \mathrm{s}$ and $90 \mu \mathrm{s}$ at $\mathrm{pH} 7.2$ (Ellis-Davis et al. 1996). However, the relative contribution of the slower decay is only $30 \%$ and thus it is likely that the contribution of this phase to the PBD signal is too small to be detected.

Upon complete characterization of the photodissociation of DM-nitrophen and DMnitrophen in the presence of $\mathrm{Ca}^{2+}$ and $\mathrm{Mg}^{2+}$ ions, I determined the volume and enthalpy changes associated with $\mathrm{Ca}^{2+}$ binding to $\mathrm{CaM}$. Photodissociation of $\mathrm{Ca}^{2+}$-DM-nitrophen in the presence of CaM showed two phases. The volume and enthalpy changes observed for the fast phase were about $-13 \pm 3 \mathrm{~mL} \mathrm{~mol}^{-1}$ and $-61 \pm 32 \mathrm{kcal} \mathrm{mol}^{-1}$, respectively, and are similar to the $\mathrm{Ca}^{2+}-\mathrm{DM}$-nitrophen photolysis. This indicates that the fast phase involves the photodissociation of DM-nitrophen and concomitant release of $\mathrm{Ca}^{2+}$. On the other hand, the slow phase of $\mathrm{Ca}^{2+}$-DM-nitrophen in the presence of CaM shows a volume change of $21 \pm 2 \mathrm{~mL} \mathrm{~mol}^{-1}$ and an enthalpy change of $35 \pm 16 \mathrm{kcal} \mathrm{mol}^{-1}$. Two 
reactions occur upon photodissociation of $\mathrm{Ca}^{2+}-\mathrm{DM}$-nitrophen in the presence of $\mathrm{CaM}$. 1) The released $\mathrm{Ca}^{2+}$ binds to free unphotolysed DM-nitrophen 2) or $\mathrm{Ca}^{2+}$ binds to $\mathrm{CaM}$. Previous studies have shown that in the presence of two competing reactions the efficiency $(\eta)$ of the each reaction can be determined from their respective rate constants using Equations 29 and 30 (Abbruzzetti et al. 2000).

$$
\begin{aligned}
& \eta_{1}=\frac{k_{1}}{k_{1}+k_{2}} \\
& \eta_{2}=\frac{k_{2}}{k_{1}+k_{2}}
\end{aligned}
$$

where $k_{1}$ and $k_{2}$ are the rate constants for $\mathrm{Ca}^{2+}$ rebinding to unphotolysed DM-nitrophen and $\mathrm{Ca}^{2+}$ binding to CaM, respectively. Using the rate constants reported in Table 3 and 4 the efficiency for each reaction is calculated to be $\eta_{1}=0.6$ and $\eta_{2}=0.4$. From the efficiency of the reaction the volume change associated with $\mathrm{Ca}^{2+}$ rebinding to unphotolysed free DM-nitrophen is determined to be $5 \mathrm{~mL} \mathrm{~mol}{ }^{-1}$. Hence from the observed volume change of $21 \pm 2 \mathrm{~mL} \mathrm{~mol}^{-1}$ only $16 \pm 2 \mathrm{~mL} \mathrm{~mol}^{-1}$ corresponds to the volume change associated with $\mathrm{Ca}^{2+}$ binding to $\mathrm{CaM}$. By scaling the volume change of $16 \pm 2 \mathrm{~mL} \mathrm{~mol}^{-1}$ to the efficiency, $\eta_{2}$, a volume change of about $40 \mathrm{~mL} \mathrm{~mol}^{-1}$ was determined for $\mathrm{Ca}^{2+}$ binding to $\mathrm{CaM}$. The volume change, occurring on the $300-600 \mu \mathrm{s}$ timescale, is consistent with the conformational change in the C-terminal domain, since $490 \mu$ s kinetics were determined for the $\mathrm{Ca}^{2+}$ binding to $\mathrm{C}$-terminal domain by Park et al. using fluorescence spectroscopy (Park et al. 2007). Further evidence for associating the observed slow phase with $\mathrm{Ca}^{2+}$ binding to $\mathrm{CaM}$ was obtained from the increase in the slow phase kinetics as a function of CaM concentration as shown in Figure 5.13. At CaM 
concentration above $150 \mu \mathrm{M}$, the rate for $\mathrm{Ca}^{2+}$ binding is constant with the lifetime of 300 $\mu$ s suggesting that $\mathrm{Ca}^{2+}$ binding to $\mathrm{CaM}$ is gated by a conformational switch in the $\mathrm{C}$ terminal domain. The kinetics of $300 \mu \mathrm{s}$ are in agreement with previously reported data that showed that the rate of conformational switch in the C-terminal domain occurs within the lifetime of $390 \pm 100 \mu$ s (Malmendal et al. 1999).

\subsection{DREAM}

The conformational changes that are triggered by $\mathrm{Ca}^{2+} / \mathrm{Mg}^{2+}$ binding to DREAM and which ultimately lead to a change in the DREAM oligomerization state remains unclear. Here I used Trp 169 as a probe to monitor the conformational changes occurring in DREAM upon $\mathrm{Ca}^{2+}$ binding by using steady-state and time-resolved fluorescence spectroscopy. The emission spectra of DREAM shows emission maxima at $345 \mathrm{~nm}$ in apo form and it is blue shifted to $340 \mathrm{~nm}$ upon addition of $\mathrm{Ca}^{2+}$. The fluorescence emission data indicates that the Trp residue is more exposed to the solvent in the apo DREAM and upon $\mathrm{Ca}^{2+}$ binding the Trp moves into a more hydrophobic environment in agreement with the previous studies by Osawa et al. (Osawa et al. 2005). The emission spectrum of the apo DREAM is broader than the emission spectrum of $\mathrm{Ca}^{2+}$ bound form, suggesting that the structure of $\mathrm{Ca}^{2+}$-DREAM is more compact and less heterogenous compared to the apo form. This is also evident from the increase in $\alpha$-helical structure in $\mathrm{Ca}^{2+}$-DREAM. The emission spectrum measured in the presence of $\mathrm{Mg}^{2+}$ is similar to that of the apo form without any change in the emission maximum. One possible reason might be that the $\mathrm{Mg}^{2+}$ binding site (EF-hand 2) is relatively far away from Trp 169 and the $\mathrm{Mg}^{2+}$ induced conformational changes may not impact fluorescence properties of Trp. 
The data obtained from the Red edge excitation shift spectrum did not show any significant changes in the emission maximum of $\operatorname{Trp}$ as a function of excitation wavelength, suggesting the absence of motionally restricted water molecules in the vicinity of the Trp either in apo or $\mathrm{Ca}^{2+}$ bound form. Quenching studies were carried out using acrylamide, a neutral quencher, and iodide, an anionic quencher. The $\mathrm{K}_{\mathrm{sv}}$ values determined for quenching of $\mathrm{Ca}^{2+}$-DREAM by KI and acrylamide are similar and smaller than $\mathrm{K}_{\mathrm{sv}}$, for apo-DREAM. Interestingly $\mathrm{KI}$ is a stronger quencher of apo DREAM suggesting that the Trp 169 is surrounded by positively charged residues in the apo form. NMR structure of $\mathrm{Ca}^{2+}$ DREAM shows two positively charged residues in the vicinity of Trp 169 (Lusin et al. 2008). The conformational switch associated with $\mathrm{Ca}^{2+}$ binding may likely bring Trp residues closer to these lysine residues.

The emission spectra of hydrophobic surface probing agents 2,6-ANS, 1,8-ANS, and nile red show an increase in the emission intensity in the presence of DREAM indicating the probes binding to the proteins hydrophobic surface. The emission intensity for all three probes increases upon $\mathrm{Ca}^{2+}$ binding indicating a larger exposure of the hydrophobic surface in the $\mathrm{Ca}^{2+}$ bound form compared to the apo protein. The increase in the emission intensity upon $\mathrm{Ca}^{2+}$ binding indicates the exposure of a larger hydrophobic surface in the $\mathrm{Ca}^{2+}$ bound form which may be important for DREAM dissociation from DNA. These data suggests that in the apo form, the protein surface is more hydrophilic and it promotes DREAM interaction with DNA. As a result of $\mathrm{Ca}^{2+}$ induced conformational changes, the exposed hydrophobic patches cause the DREAM to dissociate from DNA and preferentially form dimers. 
Fluorescence lifetimes of Trp 169 were determined in the presence and absence of $\mathrm{Ca}^{2+}$ using frequency domain fluorescence measurements to obtain information about the protein dynamics on nanosecond time scale. The presence of bi-exponential decay indicates that the protein exists in two different conformations with different tryptophan environments. Calcium association shifts the equilibrium towards the conformation with tryptophan residue located inside the protein. In the apo form the fraction of the molecules having longer lifetime ( $3 \mathrm{~ns}$ ) are in higher proportion compared to the number of molecules having a shorter lifetime $(1 \mathrm{~ns})$. However, upon $\mathrm{Ca}^{2+}$ binding the equilibrium shifts towards the conformation with a 1 ns lifetime as a result of $\mathrm{Ca}^{2+}$ induced conformational changes.

I expected to see large differences in steady state polarization values since there is a change in the oligomerization state of DREAM from tetramer to dimmer upon $\mathrm{Ca}^{2+}$ binding. Interestingly, we did not see any significant differences between the apo and $\mathrm{Ca}^{2+}$ bound forms which may be attributed to the difference in the Trp lifetimes since, in addition to the change in the oligomerization state of DREAM, there is a concomitant change in the Trp lifetimes. Quenching studies, polarization and lifetime data were measured at lower $(10 \mu \mathrm{M})$ and higher $(87 \mu \mathrm{M})$ concentrations. The reason for choosing two different concentrations is that, DREAM at higher concentrations was used a control, since, previous studies showed that at $87 \mu \mathrm{M}$, DREAM exists as a tetramer in apo form and as a dimer in $\mathrm{Ca}^{2+}$ bound form (Osawa et al. 2001). We did not see any significant differences between the range of concentrations used indicating the strong affinity of DREAM monomers to form higher order aggregates. 


\subsection{Conclusion}

The mechanism associated with the ability of the CaBPs to undergo conformational changes and regulate various cellular processes in a $\mathrm{Ca}^{2+}$ dependent manner is still not clear. A detailed understanding of transduction of the $\mathrm{Ca}^{2+}$ signal into a biological response requires thorough knowledge of the dynamics and energetics associated with $\mathrm{Ca}^{2+}$ binding to $\mathrm{Ca}^{2+}$ transducers. By using $\mathrm{PBD}$ in combination with caged $\mathrm{Ca}^{2+}$ compound, DM-nitrophen, the kinetics of $\mathrm{Ca}^{2+}$ binding to the C-terminal domain of $\mathrm{CaM}$ was determined to be $600 \mu \mathrm{s}$. A positive volume change of $40 \mathrm{~mL} \mathrm{~mol}^{-1}$ associated with $\mathrm{Ca}^{2+}$ binding to the $\mathrm{C}$-terminal domain of $\mathrm{CaM}$ suggests the exposure of hydrophobic patches as a result of $\mathrm{Ca}^{2+}$ induced conformational changes and concomitant reorganization of the water molecules. As a part of this study, photodissociation of DMnitrophen, $\mathrm{Ca}^{2+}-\mathrm{DM}$-nitrophen and $\mathrm{Mg}^{2+}-\mathrm{DM}$-nitrophen has been characterized using PBD. In case of $\mathrm{Ca}^{2+}-\mathrm{DM}-$ nitrophen and $\mathrm{Mg}^{2+} \mathrm{DM}$-nitrophen, the PBD data showed that $\mathrm{Ca}^{2+}$ release occurs witin $20 \mu$ s after photolysis. Steady-state fluorescence spectroscopy was used to probe the conformational changes associated with $\mathrm{Ca}^{2+} / \mathrm{Mg}^{2+}$ binding to DREAM in the vicinity of the $\operatorname{Trp} 169$ and results show that $\operatorname{Trp}$ is more solvent accessible in the apo form, and upon $\mathrm{Ca}^{2+}$ binding $\operatorname{Trp}$ moves into more hydrophobic environment. Finally, time-resolved fluorescence spectroscopic study on DREAM suggest that DREAM exists in dynamic equilibrium between two conformations and $\mathrm{Ca}^{2+}$ binding promotes the conformation with Trp buried within the protein. 


\section{REFERENCES}

Abbruzzetti, S., Carcelli, M., Rogolino, D., Viappiani, C., 2003, Photochem. Photobiol. Sci., 2, 796-800

Abbruzzetti, S., Crema, E., Masino, L., Vecli, A., Viappiani, C., Small, J. R., Libertini, L. J., Small, E. W., 2000, Biophys. J., 78, 405-415

Adams, S. R., Tsien, R. Y., 1993, Annu. Rev. Physiol., 55, 755-784

Adams, S.R., Kao, J.P.Y., Grynkiewicz, G., Minta, A., Tsien, R.Y., 1988, J. Am. Chem. Soc., 110, 3212-3220

Ames, J. B., Dizhoor, A. M., Ikura, M., Palczewski, K., Stryler, L., 1999, J. Biol. Chem., 274, 19329-19337

Ames, J. B., Hendricks, K. B., Strahl, T., Huttner, I. G., Hamasaki, N., Thorner, J., 2000, Biochemistry, 39, 12149-12161

Ames, J.B., Ishima, R., Tanaka, T., Gordon, J.I., Stryer, L., Ikura, M., 1997, Nature, 389, 198-202

An, W.F., Bowlby, M.R., Bett, M., Cao, J., Ling, H.P., Mendoza, G., Hinson, J. W., Mattsson, K.I., Strassle, B.W., Trimmer, J.S., Rhodes, K.J., 2000, Nature, 403, 553-556

Andersson, M., Malmendal, A., Linse, S., Ivarsson, I., Forsen, S., Svensson, L. A., 1997, Protein Sci., 6, 1139-1147

Apei, E. D., Storm, D. R., 1992, Persp. Dev. Neurobiol, 1, 3-11

Ashley, C. C., Mulligan, I. P., Lea, T. J., 1991, Q. Rev. Biophys., 24, 1-73

Ayer, R. K., Zucker, R. S., 1999, Biophys. J., 77, 3384-3393

Babini, E., Bertini, I., Capozzi, F., Luchinat, C., Quattrone, A., Turano, M., 2005, J .Proteosome Res., 4, 1961-1971

Babu, Y. S., Bugg, C. E., Cook, W. J., 1988, J. Mol. Biol., 204, 191-204

Babu, Y.S, Sack, J.S., Greenhough, T.J., Bugg, C.E., Means, A.R., Cook, J.C., 1985, Nature, 37-40

Berezin, M. Y., Achlefu, S., 2010, Chem. Rev., 110, 2641-2684

Berridge, M. J., 1988, Neuron, 21, 13 
Berridge, M. J., 1997, J. Exp. Biol., 200, 315-319

Berridge, M. J., 1997, Nature, 386, 759-760

Berridge, M. J., Lipp, P., Bootman, M. D., 2000, Nat. Rev., 32, 11-21

Blanchard, H., Grochulski, P., Li, Y., Arthur, J. S., Davies, P. L., Elce, J. S., Cygler, M., 1997, Nat. Struct. Biol., 4, 532-538

Bley, F., Schaper, S., Gorner, H., 2008, Photochem. Photobiol., 84, 162-171

Blumenschein, T. M., Reinach, F. C., 2000, Biochemistry, 39, 3603-3610

Boens, N., Qin, W., Basaric, N., Hofkens, J., Ameloot, M., 2007, Anal. Chem., 79, 2137 2149

Boens, N., Qin, W., Basaric, N., Hofkens, J., Ameloot, M., Pouget, J., Lefevre, J. P., Valeur, B., Gratton, E., Vandeven, M., Silva, N. D., Engelborghs, Y., Willaert, K., Sillen, A., Rumbles, G., Phillips, D., Visser, A. J., Van hoek, A., Lakowicz, J. R., Malak, H., Gryczynski, I., Szabo, A.G., Krajcarski, D. T., Tamai, N., Miura, A., 2007, Anal Chem., 79, 2137-2149

Braunwell, K. H., Gundelfinger, E.D., 1999, Cell Tissue. Res., 295, 1-12

Brunet, S., Scheuer, T., Klevit, R., Catterall, W. A., 2005, J. Gen. Physiol., 126, 311-323

Burgoyne, R. D., 2007, Nat. Rev. Neurosci., 8, 182-193

Burgoyne, R. D., O'Callaghan, D. W., Hasdemir, B., Haynes, L. P., Alexei, V. T., 2004, Trends in Neurosci., 27, 204-209

Burgoyne, R.D., 2007, Nat.Rev.Neuroscie., 252, 8182-193

Burgoyne, R.D., Weiss, L.J., 2001, Biochem. J., 353, 1-12

Carrion, A. M., Link, W. A., Ledo, F., Mellstrom, B., Naranjo, J. R., 1999, Nature, 398, 80-84

Chen, B., Lowry, D.F., Mayer, L.M., Squier, T.C., 2008, Biochemistry, 47, 9220-9226

Chen, B., Mayer, U. M., Markille, L. M., Stenoien, D. L., Squier, C. T., 2005, Biochemistry, 44, 905-914

Chen, C. P., Lee, L., Chang, L. S., 2006, Prot Sci., 25, 345-351 
Cheng, Q., Steinmetz, M. J., Jayaraman V., 2002, J. Am. Chem. Soc., 124, 7676-7677

Chin, D., Means, A.R., 2000, Trends Cell Boil., 10, 322-328

Clapham, D. E., 1995, Cell, 80, 259-268

Clapham, D. E., 2007, Cell, 131, 1047-1058

Cocco, M. J., Lecomte, J. T., 1994, Prot Sci., 3, 267-281

Cook, W. J., Jeffrey, L. C., Cox, J. A., Vijay-Kumar, S., 1993, J. Mol. Biol., 229, 461471

Corrie, E. T., Barth,V. R., Munasinghe, V. R. N., Hutter, D. R., 2003, J. Am. Chem. Soc., 125, 8546-8554

Corrie, J. E. T., Barth, A., Munasinghe, V. R. N., Trentham, D. R., Hutter, M., 2003, J. Am. Chem. Soc., 125, 8546-8554

Coughlan, C.M., Breen, K.C., 2000, Pharmacol. Ther., 86, 111-145

Cox, D. E., Edstrom, R. D., 1982, J. Biol. Chem., 257, 12728-12733

Craig, T.A., Benson, L.M., Venyaminov, S.Y., Klimtchuk, E.S., Bajzer, Z., Prendergast, F.G., Naylor, S., Kumar, R., 2002, J. Biochem., 277, 10955-10966

Craig, T.A., Capell, A., Steiner, H., Romig, H., Keck, S., Baader, M., Grim, M.G., Baumeister, R., Haass, C., 2000, Cell Biol., 2, 205-211

Dantzig, J. A.; Higuchi, H.; Goldman, Y. E., 1998, Methods Enzymol., 72

Drake, S. K., Falke, J. J., 1996, Biochemistry, 35, 1753-1760

Eaton, W. A., Munoz, V., Thompson, P. A., Henry, E. R., Hofrichter, J., 1998, Acc. Chem. Res., 31, 745-753

Eaton, W. A., Munoz, V., Thompson, P. A., Henry, E. R., Hofrichter, J., 2000

Eisenberg, J., 1965, J. Chem. Phys., 43, 3887-3892

Ellis-Davis, G. C. R., 2008, Chem. Rev., 108, 1603-1613

Ellis-Davis, G.C.R., 2007, Nat. Methods, 4, 619-628 
Essen, L. O., Perisic, O., Katan, M., Williams, R. L., 1996, Nature, 380, 595-602

Faga, L.A, Sorensen, B. R., Vanscyoc, W. S., Shea, M. A., 2003, Proteins, 50, 381-391

Gagne, S.M., Tsuda, S., Li, M.X., Smillie, L.B., Skyes, B.D., 1995, Nat. Struct. Biol., 784-789

Ganong, W.F., 2005, Review of Medical Physiology, $22^{\text {nd }}$ Edition

Gaplovsky, M., Ill'ichev, Y. V., Kamdzhilov, Y., Kombarova, S. V., Mac, M. A.

Gensch, T., Viappiani, C., 2003, Photochem. Photobiol. Sci. 2, 699-721

George, M. V., Scanio, J. C., 1980, J. Phys. Chem., 84, 492-495

Gereke, V., Moss, S. E., 2002, Physiol. Rev., 82, 331-371

Gifford, J.L., Walsh, P.M., Vogel, H.J., 2007, Biochem. J., 405, 191-221

Giovannardi, S., Lando, L., Peres, A., 1998, News Physiol. Sci. 13, 25-255

Giovannardi, S., Lando, L., Peres, A., 1998, News Physiol. Sci. 13, 25-255

Givens, R. S., Conrad, P. G., Yousef, A. L., Lee, J-I., 2003, CRC Handbook of photochemistry and photobiology, $2^{\text {nd }}$ edition

Griko, Y. V., 1999, Biophys. Chem., 79, 117-127

Guo, W., Malin, S. A., Johns, D. C., Jeromin, A., Nerbonne, J. M., 2002, J. Biol. Chem., 277, 26436-26443

Gurney, A.M., Lester, H.A., 1987, Physiol. Rev., 67, 583-617

Haiech, J., Moulhaye, S. B., Kilhoffer, M. C., 2004, Biochim. Biophys. Acta, 1742, 179183

Hansen, K. C., Rock, R. S., Larsen, R.W., Chan, S. I., 2000, J. Am. Chem. Soc., 122, 11567-11568

Harootunian, A. T., Kao, J. P. Y., Tsien, R. Y., 1988, Harb. Symp. Quant. Biol. 53, 935943

Hassoni, A. A., Gray, P.T., 1994, J. Physiol., 478, 461-467 
Hawe, A., Scutter, M., Jiskoot, W., 2008, Pharm. Res., 25, 1487-1499

Hayashi, N., Matsubara, M., Takasaki, A., Titani, K., Taniguchi, H., 1998, J. Phys. Chem., 93, 2101-2106

Heery, D.M., Kalkhoven, E., Hoare, S., Parker, M. J., 1997, Nature, 387, 733-736

Henzl, M. T., Larson, J. D., Agah, S., 2003, Anal. Biochem., 319, 216-233

Herzberg, O., James, M.N.G., 1988, J. Mol. Biol., 203,761-779

Hohenester, E., Maurer, P., Hohenadl, C., Timpl, R., Jansonius, J. N., Engel, J., 1996, Nat. Struct. Biol., 3, 67-73

Houdusse, A., Cohen, C., 1996, Structure, 4, 21-32

Iino, Masamitsu, 2008, Biochem. Biophys. Res. Commun., 369, 220-224

Ikura, M., Clore, G.M., Gronenborn, A.M., Zhu, G., Klee, C.B., Bax, A., 1992, Science, 256, 632-638

Ikura, M., et al., 1986, 258, 632-638., Meador, W.E., Means, A.R., Quiocho, F.A., 262, Science, $1718-1721$

Ilari, A., Johnson, K. A., Nastopoulos, V., Verzili, D., Zamparelli, C., Colotti, G., Tsernoglou, D., Chiancone, E., 2002, J. Mol. Biol, 317, 447-458

Ill'ichev, Y. V., Schworer, M. A., Wirz, J., 2004, J. Am. Chem. Soc., 126, 4581-4595

Itzaki, L. S., Evans, P. A., Dobson, C. M., Radford, S. E., 1994, Biochemistry, 33, 52125220

Jasuja, R. J., Keyoung, G. P., Reid, D. R., Trentham, S. Khan, 1999, Biophys. J. 76, $1706-1719$

Jasuja, R., Keyoung, J., Reid, G. P., Trentham, D. R., Khan, S., 1999, Biophys. J., 76, 1706-1719

Jia, J., Han, Q., Borregaard, N., Lollike, K., Cygler, M., 2000, J. Mol. Biol., 300, 1271 1281

Jia, J., Tarabykina, S., Hansen, C., Berchtold, M., Cygler, M., 2001, Structure, 9, 267275 
Johnson, J. D., Snyder, C., Walsh, M., Flynn, M., 1996, J. Biol. Chem., 259, 761-767

Kaplan, J. H., 1993, Annu. Rev. Physiol., 55, 755-784

Kaplan, J. H., Ellis-Davies, G. C. R., 1988, Proc. Natl. Acad. Sci., 85, 6571-6575

Kojetin, D. J., Venters, R. A., Kordys, D. R., Thomson, R. J., Kumar, R., Cavanagh, J., 2006, Nat. Struct. Mol. Biol., 13, 641-647

Krestinger, R., Rudnick, S. E., Wiesman, L. J., 1986, J. Inorg. Biochem., 28, 289-302

Kubinova, H., Tjandra, N., Grzeisk, S., Ren, H., Klee, C.B., Bax, A., 1985, Nat. Struct. Biol., 2, 768-776

Kupke, D. W., Shank, B. S., 1989, J. Phys. Chem., 93, 2101-2106

Laemmli, A., 1970, Nature, 227

Lakowicz, J. R., Laczko, G., Cherek, H., Gratton, E., Limkeman, M., 1984, Biophys. J., 25, 463-477

Lakowicz, J. R., Principles of Fluorescence Spectroscopy, Springer, 2010, Third Edition,

Larsen, R. W., Miksovska, J., 2007, Coord. Chem. Rev., 251, 1101-1127

Lautermilch, N. J., Few, A. P., Scheuer, T., Catterall, W. A., 2005, J. Neurosci. 25, 70627070

Ledo, F., Carrion, A. M., Link, W. A., Mellstrom, B., Naranjo, J. R., 2000, Mol. Cell. Biol., 20, 9120--9126

Ledo, F., Kremer, L., Mellstropm, B., Naranjo, J. R., 2002, EMBO. J., 21, 4583-4592

Lee, Y. H., Tanner, J. J., Larson, J. D., Henzl, M. T., 2004, Biochemistry, 43, 1000810017

Li, W-H., Llops, J., Whitney, M., Zlokarnik, G., Tsien, R. Y., 1998, Nature, 392, 936940

Likic, V. A., Strehler, E. E., Gooley, P.R., 2003, Protein Sci., 12, 2215-2229

Lilliehook, C., Chan, S., Choi, E. K., Zaidi, N .F., Wasco, W., Mattson, M.P., Buxbaum, J. D., 2002, Mol. Cell Neuro. sci, 19, 552-559

Linse, S., Helmersson, A., Forsen, S., 1991, J. Biol. Chem., 266, 8050-3054 
Lusin, J.D., Vanarotti, M., Li, C., Valiveti, A., Ames, J.B., 2008, Biochemistry, 47, 22522264

Makino, C. L., 123, 2004, J. Gen. Physiol. 123, 729-741

Martin, S. R., Bayley, P. M., 1986, Biochemistry, 238, 485-490

Mayer, G., Heckel, A., 2006, Angew. Chem. Int. Ed., 45, 4900-4921

McCray, J. A., Trentham, D. R., 1989, Annu. Rev. Biophys.Biophys. Chem., 18, 239-270

Meador, W.E., Means, A. R., Quiocho, F.A., 1992, Science, 257, 1251-1255

Meador, W.E., Means, A. R., Quiocho, F.A., 1993, Science, 262, 1718-1721

Mellstrom, B., Naranjo, J. R., 2001, Cell Dev. Biol., 12, 59-63

Mellstrom, B., Naranjo, J.R., 2001, Curr. Opin. Neurobiol., 11, 312-319

Millero, F. J., 1971, Chem. Rev., 71, 147-176

Misovska, J, Larsen, R.W., 2003, Methods in Enzymology: Biophotonics, Marriott, G. and Parker, I., 360, part A, 302-329

Monroe, W. T., McQuain, M. M., Chang, M. S., Alexander, J. S., Haselton, F. R., 1999, J. Biol. Chem., 274, 20895-20900

Morrison, H., Migdalof, B. H., 1965, J. Org. Chem., 30, 3996

Nagae, M., Nozawa, A., Koizumi, N., Sano, H., Hashimoto, H., Sato, M., Shimizu, T., 2003, J. Molec. Biol., 278, 42240-42246

Nagerl, U. V., Novo, D., Mody, I., Vergara, J., 2000, Biophys. J., 79, 3009-3018

Nakamura, T. Y., 2001, Proc. Natl. Acad. Sci., 98, 12808-12813

Nalfeski, E. A., Falke, J. J., 1996, Protein Sci., 5, 2375-2390

Naraghi, M., 1997, Cell Calcium, 22, 255-268

Nef, P., 1996., Guide book to the calcium-binding proteins. Oxford University Press, Newyork, 94-98

Nerbonne, J.M., 1986, Optical Met. Cell. Physiol., 73, 417-445 
Nerbonne, J.M., 1996, Curr. Opin. Neurobiol., 6, 379-386

Newton, A.C., 1995, Curr. Biol., 5, 973-976

Nishira, J., Isshbasshi, T., Sakai, M., Tsuda, S., Hirichi, K., 1993, Arch. Biochem. Biophys., 302, 128-133

Nolte, R. T., Wisley, G.B., Westin, S., Cobb, J. E., Lambert, M. H., Kurokawa, R., Rosenfeld, M.G., Willson, T.M., Glass, C. K., Milburn, M.V., 1998, Nature, 395, 137 143

O’ Callaghan, D. W. et al. 2003, J. Cell Sci., 116, 4833-4845

O’ Niel, K.T., Degrado, W.F., Trends biochem. Sci., 15, 59-64

Olwin, B. B., Eldelman, A. M., Krebs, M., Storm, D. R., 1984, J. Biol. Chem., 259, 10949-10955

Olwin, B. B., Storm, D. R., 1985, Biochemistry, 24, 8081-8086

Osawa, M., Dace, A., Tong, K.I., Valiveti, A., Ikura, M., Ames, J.B., J. Biol. Chem., 280, 18008-18014

Osawa, M., Tong, K.I., Lilliehook, C., Wasco, W., Buxbaum, J.D., Mary Cheng, H.Y., 2001, J. Biochem., 276, 41005-41013

Park, H. Y., Kim, S.A., Korlach, J., Rhoades, E., Kwok, L. W., Zipfel, W. R., Waxham, M. N., Webb, W. W., Pollack, L., 2007, Proc. Natl. Acad. Sci., 105, 542-547

Pelliccioli, A. P., 2002., Callamaras, N., Parker, I., 1998, Methods Enzymol., 291, 380403

Pelliccioli, A. P., Wirz, J., 2002, Photochem. Photobiol. Sci., 1, 441-458

Pennesi, M. E., Howes, K. A., Baehr, W., Wu, S. M., 2003, Proc. Natl. Acad Sci., 100, 6783-6788

Persechini, A., White, H. D., Gansz, K. J., 1996, J. Biol. Chem., 271, 62-67

Pioletti, M., Findeisen, F, Hura, G.L., Minor, D.L., 2006, Nat. Struct. Mol. Biol., 13, 987995

Potter, J. D., Gergely, J., 1975, J. Biol. Chem., 257, 7678-7683 
Raid, R.E., Gariepy, J., Saund, A.K., Hodges, R.S., 1981, J. Biol. Chem., 256, 2742-2751

Reid, R. E., 1990, J. Biol. Chem., 265, 5971-5976

Reid, R. E., Hodges, R. S., 1980, J. Theor. Biol., 84, 401-444

Rescher, U., Gerke, V., 2004, J. Cell Sci., 117, 2631-2639

Ross, J. A., Jameson, D.M., 2008, Photochem. Photobiol. Sci., 7, 1301-1312

Sampath, A. et al., 2005, Neuron, 46, 413-420

Sanada, K., Shimizu, F., Kameyama, K., Haga, K., Haga, T., Fukada, Y., 1996, FEBS Lett., 384, 227-230

Sanz, C., Mellstron, B., Link, W. A., Naranjo, J. R., Fernandez-luna, J. L., 2001, EMBO J., 20, 2286-2292

Schaad, N. C., De Castro, E., Nef, S., Hegi, S., Hinrichsen, R., Martone, M.E., Ellisman, M.H., Sikkink, R., Sygush, J., Nef, P., 1996, Proc. Natl. Acad. Sci., 93, 9253-9258

Schlichting, I., 2000, Acc. Chem. Res. 33, 532-538

Schworer, Wirz, J., 2005, Photochem. Photobiol. Sci., 4, 33-42

Schworer, M., Wirtz, J., 2001, Helv. Chim. Acta, 84, 1441-1457

Schworer, M., Wirtz, J., 2001, Helv. Chim. Acta, 84, 1441-1457

Scott, D. L., White, S. P., Otwinowski, Z., Yuan, W., Gelb, M. H., Sigler, P. B., 1990, Science, 250, 1541-1546

Scsucova, S., Palacios, D., Savignac, M., Mellstrom, B., Naranjo, J. R., 2005, Nucleic Acids Res., 33, 2269-2279

Shaw, G. S., Findlay, W. A., Semchuk, P. D., Hodges, R. S., Skyes, B. D., 1992, J. Am. Chem. Soc., 114, 6258-6259

Shaw, G. S., Hodges, R. S., Skyes, B. D., 1990, Science, 249, 280-283

Shaw, G.S., Golden, L.F., Hodges, R.S., Sykes, B.D., 1991, J. Am. Chem. Soc., 113, 5557-5563

Shea, M. A., Verhoeven, A. S., Pedigo, S., 1996, Biochemistry, 35, 2943-2957 
Shiau, A. K., Barstad, D., Loria, P. M., Cheng, L., Kushner, P. J., Agard, D. A., Greene, G.L., 1998, Cell, 95, 927-937

Slippy, T. M., Cruz-Martin, A, Jeromin, A., Schweizer, F. E., 2003, Nat. Neurosci, 6, $1031-1038$

Sorensen, B. R., Faga, L.A., Hultman, R., Shea, M. A., 2002, Biochemistry, 41, 15-20

Specht, A., Ursby, T., Weik, M., Peng, L., Kroon, J., Bourgeois, D., Goeldner, M., 2001, Chem. Biol., 11, 845-848

Srajer, V., Teng, T-Y., Ursby, T., Pradervand, C., Ren, Z., Adachi, S-I., Schildkamp, W., Bourgeois, D., Wulff, M., Moffat, K., 1996, Science, 274, 1726-1729

Tatsu, Y., Shigeri, Y., Sogabe, S., Yumoto, N., Yoshikawa, S., Biochem. Biophys. Res. Commun., 227, 688-693

Tjandra, N., Kuboniwa, H., Ren, H., Bax, A., 1995, Eur. J. Biochem., 230, 1014-1024

Urbauer, J.L., Short, J.H., Dow, L.K., Wand, A.J., 1995, Biochemistry, 34, 8099-8109 Valeur, B., 2002, Wiley-VCH Publishers

Van-Koeveringe, G, A., Van-Mastright, R., 1994, Cell Calcium, 32, 423-430

Vijay-Kumar, S., Cook, W. J., J. Molec. Biol, 224, 413-426

Walker, J. W., Gilbert, S. H., Drummond, R. M., Yamada, M., Sreekumar, R., Carraway, R. E., Ikebe, M., Fay, F. S., 1998, Proc. Natl. Acad. Sci., 95, 1568-1573

Weng, X., Luecke, H., Song, I. S., Kang, D. S., Kim, S. H., Huber, R., Protein Sci., 1993, 2, 448-458

Wieboldt, R., Ramesh, D., Jabri, E., Karplus, P. A., Carpenter, B. K., Hess, G. P., 2002, J. Org. Chem., 67, 8827-8831

Yazawa, M., Vorherr, T., James, P., Carafoli, E., Yagi, K., 1992, Biochemistry, 31, 31713176

Zhang, M., Tanaka, T., Ikura, M., 1995, Nat. Struct. Biol., 2, 758-767

Zucker, R. S., Biochem. Soc. Trans., 1993, 21, 395 